\title{
Field Determination of Vertical Permeability to Air in the Unsaturated Zone
}

\begin{tabular}{l|lll}
\hline GEOLOGICAL SURVEY PROFESIONAL PAPER & 1051
\end{tabular}


Field Determination of

Vertical Permeability to

Air in the Unsaturated Zone

By EDWIN P. WEEKS

\begin{tabular}{lllll}
\hline GEOLOGICAL & SURVEY & PROFESSIONAL & PAPER & 1051
\end{tabular}

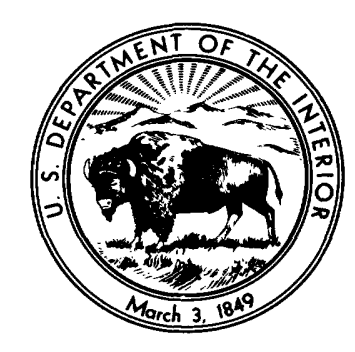

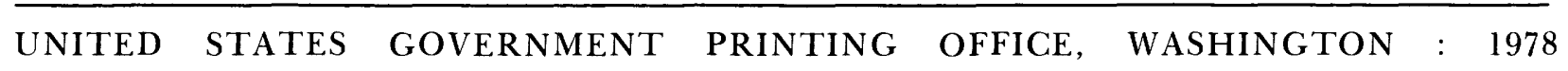




\title{
UNITED STATES DEPARTMENT OF THE INTERIOR
}

\author{
CECIL D. ANDRUS, Secretary
}

\section{GEOLOGICAL SURVEY}

H. William Menard, Director

\footnotetext{
Library of Congress Cataloging in Publication Data

Weeks, Edwin P., 1936-

Field determination of vertical permeability to air in the unsaturated zone.

(Geological Survey Professional Paper 1051)

Bibliography: p. 41

1. Sediments (Geology)-Permeability. 2. Sediment (Geology)-United States.

I. Title. II. Series: United States Geological Survey Professional Paper 1051.

$\begin{array}{lll}\text { QE471.2.W43 624'.1513 } & 77-10571\end{array}$
}

For sale by the Superintendent of Documents, U.S. Government Printing Office

Washington, D.C. 20402

Stock Number 024-001-03092-6 


\section{CONTENTS}

Page

Abstract

Introduction

Previous work

Terminology....

Notation ..

Conversion of English to metric units of measurement.

Theory

Sources of error in converting air permeability to hydraulic conductivity

Effects of moisture content

Klinkenberg effect.

Absorption effects

The method.

Site inspection

Instrumentation.

Data obtained.

Results .

Data analysis

Birch Creek Playa, Idaho.

Lubbock, Texas, airport site.

Comparison of results for different sites and dates
1

2

2

3

4

4
5

5

6

6

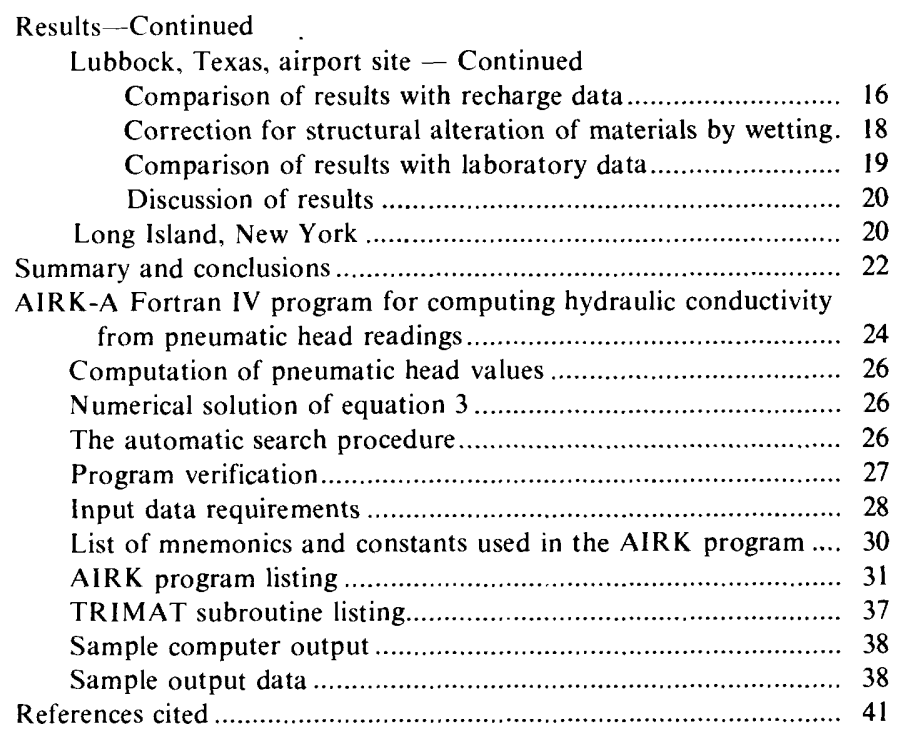

\section{ILLUSTRATIONS}

Figure 1. Piezometer nest used to determine pneumatic head differences in the unsaturated zone...

2. Photograph showing piezometers, manifold, and manometer used to determine pneumatic head........................................... 7

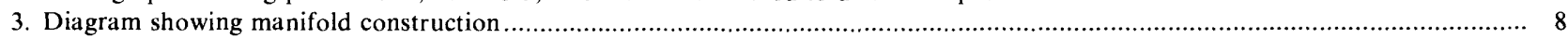

4. Comparison of pneumatic heads measured at four depths at Lubbock, Tex., airport site A to best-fitting analog simulation........... 9

5. Sample logs and construction diagrams of wells tested at Idaho National Engineering Laboratory, Idaho.................................... 11

6. Comparison of pneumatic heads measured at the Birch Creek Playa, Idaho, site to the best-fitting numerical simulation............... 13

7. Locations of instrumentation used in air-permeability determinations and recharge experiments near the Lubbock, Tex., Regional Airport.

8. Sample $\log$ of test well at Lubbock, Tex., airport spreading site

9. Comparison of pneumatic heads measured at five depths at Lubbock, Tex., airport site B to best-fitting numerical simulation ....... 16

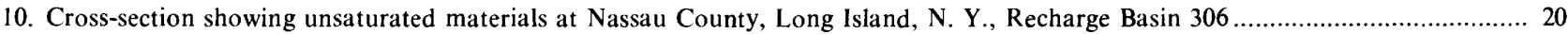

11. Comparison of pneumatic heads measured at two depths at an installation inside Recharge Basin 306, Nassau County, Long Island, N. Y., to the best-fitting numerical simulation

12. Sketch showing the relationship between an air-permeability installation and the nodal configurations used to solve for air permeability .. 25 


\section{TABLES}

TABLE 1. Summary of vertical air permeability values computed from pneumatic head data obtained from installations at the Birch Creek

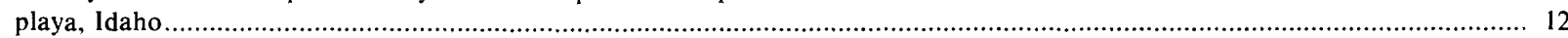

2. Depths of piezometers in three installations used to determine vertical air permeability at the Lubbock, Tex., airport spreading site... 14

3. Summary of hydraulic conductivity values computed using pneumatic head data obtained from installations at the Lubbock, Tex.,

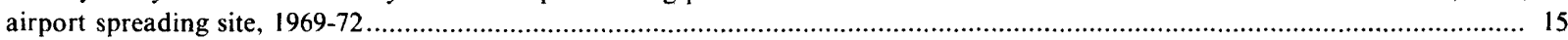

4. Comparison of hydraulic conductivity values estimated from recharge data, from the air-permeability determinations, and from

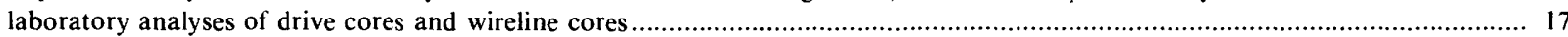

5. Laboratory data for 30 cores from the Ogallala Formation in the Southern High Plains of Texas, showing comparisons of measured hydraulic conductivity to those computed from air permeability ...................................................................... 19

6. Summary of analyses of pneumatic head data obtained from installations at the Nassau County, Long Island Recharge Basin 306.21 


\title{
FIELD DETERMINATION OF VERTICAL PERMEABILITY TO AIR IN THE UNSATURATED ZONE
}

\author{
By EDWIN P. WEEKS
}

\begin{abstract}
The vertical permeability to air of layered materials in the unsaturated zone may be determined from air pressure data obtained at depth during a period when air pressure is changing at land surface. Such data may be obtained by monitoring barometric pressure with a microbarograph or surveying altimeter and simultaneously measuring down-hole pneumatic head differences in specially constructed piezometers. These data, coupled with air-filled porosity data from other sources, may be compared with the results of electric-analog or numerical solution of the one-dimensional diffusion equation to make a trial-and-error determination of the air permeability for each layer. The permeabilities to air may in turn be converted to equivalent hydraulic conductivity values if the materials are well drained, are permeable enough that the Klinkenberg effect is small, and are structurally unaffected by wetting.
\end{abstract}

The method was tried at several field sites. Results from three of these sites are compared with laboratory data and air-injection or infiltration data. Permeabilities to air determined for playa sediments from a test in Idaho are about two times higher than laboratory data, and about 50 percent lower than the permeability to air determined from air injection tests. Equivalent hydraulic conductivities determined from permeability values to air for the bottom four of six layers of unsaturated materials at a site in the semiarid Southern High Plains of Texas are in good agreement with hydraulic conductivity values determined by analysis of infiltration data, indicating that the method is useful for determining the hydraulic conductivity of layers at depth under certain conditions. However, hydraulic conductivity computed from the permeability to air for the surface layer at this site is a few times higher than the infiltration-determined value. The same general results were obtained for the surface layer from several other tests, suggesting that the method may not be suitable for determining hydraulic conductivity near the surface. Comparison of results for determinations of permeability to air with infiltration data for two installations near a spreading basin on Long Island, N.Y., were contradictory. Hence, applicability of the method to determine the hydraulic conductivity of unsaturated materials in which residual moisture content is relatively high needs further testing.

Permeabilities to air determined by this method are representative of relatively large volumes of materials, and the hazard of disturbing the materials during measurement is small. Moreover, the method measures vertical permeability, rather than horizontal permeability or some composite of horizontal and vertical permeability. Hence, the method offers potential advantages over present methods to evaluate sites for artificial recharge by spreading; to evaluate ground-water pollution hazards from feedlots, sanitary landfills, and land irrigated with sewage effluent; and to evaluate sites for temporary storage of gas in the unsaturated zone.

\section{INTRODUCTION}

This report describes application of a method proposed by Stallman (1967) to determine, in situ, the vertical permeability to air of materials in the unsaturated zone. The method is based upon the observation that, when the atmospheric pressure changes at land surface, air moves to or from the unsaturated zone to maintain a pressure balance between air in the soil and the atmosphere. The rate of this air movement and the resultant rate of pressure change at depth are affected by both the permeability and the air-filled porosity of the materials in the unsaturated zone. Consequently, the media properties may be determined by analysis of the time lag of pressure changes at depth relative to those at the surface.

For this study, the method proposed by Stallman was used to determine the vertical permeability to air of each layer of a sequence of layered unsaturated materials at several sites, based on data from relatively simple and easily instrumented installations. Also, applicability of the air-permeability data to compute hydraulic conductivity of layers at depth was tested at two sites by comparison with hydraulic conductivities estimated from the behavior of artificially created perched ground-water mounds.

Stallman's method differs from most previous field methods for determining either the permeability to air or the hydraulic conductivity of unsaturated material in that it provides measurements in the vertical direction both at the surface and at depth. Such knowledge of the vertical permeability of materials in the unsaturated zone is potentially useful for planning water-spreading operations; for assessing the ground-water pollution hazard of sanitary landfills, feedlots, or sites of spray irrigation of sewage effluent; and for determining the feasibility of temporarily storing gas in the unsaturated zone.

\section{PREVIOUS WORK}

Movement of air to and from the unsaturated zone in response to barometric pressure changes was first described 
and analyzed by Buckingham (1904). In addition to describing the phenomenon, Buckingham presented an equation for the attenuation of the amplitude and the phase lag of a periodic atmospheric pressure wave at any depth in a homogeneous layer bounded below by an impermeable boundary. However, use of observed air pressure or pneumatic head at depth to determine the permeability of materials in the unsaturated zone was first proposed by R.W. Stallman (written commun., 1962). Stallman (1967) and Stallman and Weeks (1969) later described application of the method at Badger Wash, near Cuba, N. Mex. Data obtained at this site were analyzed based on the assumption that the unsaturated materials comprised a single homogeneous layer bounded below by an impermeable boundary. Because of instrument problems during data acquisition, the results of analysis of data from this site were inconclusive.

The method apparently was discovered independently by G.A. Morris and D.F. Snoeberger (1971). They (in collaboration with R.B. Rozsa, J. Baker, and C.J. Morris) have applied the method to determine the permeability to air of the material comprising several nuclear chimneys at the Nevada Test Site (Rozsa, Snoeberger, and Baker, 1975, and references contained therein). An elaborate data acquisition system was used (Snoeberger, Morris, and Baker, 1972), consisting of pressure transducers connected to pipes open at different depths in the chimney, and equipped to transmit data at 15-minute intervals by telephone to the Lawrence Livermore Laboratory at Livermore, Calif. For data analysis, the nuclear chimney rubble was assumed to consist of a homogeneous unit extending to infinity below land surface, and pressure changes at depth were analyzed using an analytical equation and the principal of superposition (Rozsa, Snoeberger, and Baker, 1975, p. 7). Although the assumption that air movement can occur to infinite depth in the chimney rubble poorly represents actual boundary conditions, measured and computed pressures at depth matched closely. Also, computed permeabilities to air compared favorably with those determined by numerical analysis of air injection data. The authors concluded that their application of the method gave results correct within an order of magnitude.

Other field methods for determining permeability to air have relied upon injecting air at land surface into the soil at the center of a circular surface area sealed by paraffin (Evans and Kirkham, 1949), into a tube inserted into the soil (Kirkham, 1946; Grover, 1955; Tanner and Wengel, 1957), into an auger hole (King, 1968), or into a packed-off section of drill hole (Boardman and Skrove, 1966). In general, these methods measure a permeability that is some composite of the vertical and horizontal permeability, and the measurements are representative of only a relatively small sample of material. Thus, these methods are not strictly comparable to the method proposed by Stallman.

\section{TERMINÖLOGY}

Terminology involving discussion of the flow of both air and water through porous media is made more complicated by differences in conventional usage that has developed with regard to the different fluids. The permeability of a porous medium to air generally is described in terms of intrinsic permeability, and the term "air permeability" refers to the intrinsic permeability of the air-dry medium as measured with air or another gas. On the other hand, the permeability of a porous medium to water generally is reported as the "hydraulic conductivity," a term that is dependent on the kinematic viscosity of water at the prevailing temperature as well as the properties of the medium. Thus, the dissimilar terms air permeability and hydraulic conductivity are used in this report to reflect conventional usage.

Other complications arise from use of the term "intrinsic permeability," which is often defined as being a property of the medium alone (Hubbert, 1940, p. 818-819; Lohman and others, 1972, p. 9). As pointed out by Childs (1969, p. 166-167), this concept may be misleading when applied to natural earth materials because of physical changes in the medium that occur upon exposure to different fluids, including waters of different chemical quality. Hence, intrinsic permeability is independent of the viscosity of the fluid used, but often is dependent upon the nature of the fluid. Because of the need to specify the fluid used to determine the intrinsic permeability, the term "permeability" is sometimes used in this report to designate intrinsic permeability to the specified fluid.

\section{NOTATION}

$A=$ area of perched mound at the top of a zone being analyzed, $\mathrm{m}^{2}$;

$b=$ initial saturated thickness of water-table aquifer, $\mathrm{m}$;

$C=$ capacitance of a single capacitor used in the resistor-capacitor grid for simulating gas flow in the unsaturated zone, farads;

$C M C=$ quantity of expanding lattice clay minerals of the montmorillonite (smectite) group, expressed as a decimal fraction of the total mineral content;

= acceleration due to gravity, approximately equal to $9.81 \mathrm{~m} / \mathrm{sec}^{2}$;

$=$ pneumatic head at start of test, $\mathrm{m}$;

$=$ pneumatic head at time $t$ during test, m;

= pneumatic head at end of test, $\mathrm{m}$;

$=$ hydraulic gradient, $\mathrm{m} / \mathrm{m}$;

$=$ intrinsic permeability, $\mu^{2}$;

$=$ relative permeability to air, defined as the ratio of the air permeability at a given moisture content to that for the air-dry medium, dimensionless;

= hydraulic conductivity, $\mathrm{m} /$ day;

= hydraulic conductivity based on field-determined air permeability and corrected for effects of wetting upon the structure of the medium, $\mathrm{m} /$ day; 
$K_{e} \quad=$ hydraulic conductivity computed from field-determined air permeability, $\mathrm{m} /$ day;

$L=$ thickness of unsaturated zone above capillary fringe, $\mathrm{m}$;

$n \quad=$ porosity, dimensionless;

$n_{d}=$ air-filled porosity at prevailing moisture content, dimensionless;

$p \quad=$ pressure at a point, $\left(\mathrm{N} / \mathrm{m}^{2}\right) ;$

$\bar{P} \quad=$ mean atmospheric pressure during a test period, $\mathrm{N} / \mathrm{m}^{2}$

$P D \quad=$ pneumatic diffusivity for an air-dry medium, $\mathrm{m}^{2} /$ day;

$P D_{e}=$ effective pneumatic diffusivity, determined at the prevailing moisture content of the medium, $\mathrm{m}^{2} /$ day;

$Q \quad=$ average inflow rate to spreading basin, $\mathrm{m}^{3} /$ day;

$R \quad=$ resistance of a single resistor used in the resistor-capacitor grid for simulating gas flow in the unsaturated zone, ohms;

$R K=$ ratio of hydraulic conductivity measured with water to that computed from air permeability measured on the sample at its prevailing moisture content, dimensionless;

$s \quad=$ drawdown in water-table aquifer, $\mathrm{m}$;

$t \quad=$ time in air-permeability test, seconds;

$z \quad=$ vertical dimension in unsaturated zone, or height above an arbitrary datum, $\mathrm{m}$;

$\mu a=$ absolute viscosity of air at the prevailing soil temperature, $\mathrm{kg} / \mathrm{m} \cdot \mathrm{sec}$

$v_{w}=$ kinematic viscosity of water at a given temperature, $\mathrm{m}^{2} / \mathrm{sec}$;

$\rho_{a} \quad=$ density of air, $\mathrm{kg} / \mathrm{m}^{3}$;

$\phi^{a}=$ pneumatic head or potential, height of constant-density air column above reference plane at the prevailing atmospheric pressure, m.

\section{CONVERSION OF ENGLISH TO METRIC UNITS OF MEASUREMENT}

In this report, measurements are generally given in metric units, although those measurements relating to equipment

\begin{tabular}{|c|c|c|c|}
\hline English units & & Conversion fact & Metric units \\
\hline $\begin{array}{l}\text { Length in inches (in) } \\
\text { in feet (ft) }\end{array}$ & $\begin{array}{l}\mathrm{x} \\
\mathrm{x}\end{array}$ & $\begin{array}{l}25.40 \\
.3048\end{array}$ & $\begin{array}{l}=\text { millimeters }(\mathrm{mm}) \\
=\text { meters }(\mathrm{m})\end{array}$ \\
\hline Area in square & & & \\
\hline feet $\left(\mathrm{ft}^{2}\right)$ & $\mathbf{x}$ & .0929 & $=$ square meters $\left(\mathrm{m}^{2}\right)$ \\
\hline inches (in $\left.{ }^{2}\right)$ & $\mathbf{x}$ & 645.2 & $=$ square millimeters $\left(\mathrm{mm}^{2}\right)$ \\
\hline Area in acres & $\mathrm{x}$ & .4047 & $=$ hectares (ha) \\
\hline Volume in cubic feet $\left(\mathrm{ft}^{3}\right)$ & $\mathbf{x}$ & .02832 & $=$ cubic meters $\left(\mathrm{m}^{3}\right)$ \\
\hline Weight in pounds (lb) & $\mathbf{x}$ & .4536 & $=$ kilograms $(\mathrm{kg})$ \\
\hline $\begin{array}{l}\text { Pressure in } \\
\text { inches of mercury }\end{array}$ & $\mathbf{x}$ & 03386 & $\begin{array}{c}=\text { bars }\left(10^{5} \text { Newtons } /\right. \\
\text { square meter })\end{array}$ \\
\hline $\begin{array}{l}\text { in atmospheres } \\
\text { Hydraulic conductivity }\end{array}$ & $\mathbf{x}$ & 1.013 & $=$ bars \\
\hline $\begin{array}{l}\text { in feet per day (ft } / d) \\
\text { Permeability }\end{array}$ & $\mathbf{x}$ & .3048 & $=$ meters $/$ day \\
\hline in darcies & $\mathbf{x}$ & .987 & $=$ square microns \\
\hline
\end{tabular}

are given in both metric and English units. However, the AIRK program was written using English units, and English units are used in the description of that program to avoid confusion.

\section{THEORY}

The properties of a dry porous medium that affect the rate of pressure change at depth may be quantified by the term (Katz and others, 1959, p. 408):

$$
P D=\frac{k \bar{P}}{\mu a^{n}} ;
$$

where $k=$ intrinsic permeability, $L^{2}$;

$\bar{P}=$ mean pressure during pressure change, $M / L T^{2}$

$\mu_{a}=$ absolute viscosity of air at the prevailing temperature, $M / L T$;

$n$ = porosity, dimensionless.

The quantity $P D$ is here termed "pneumatic diffusivity" in analogy with the comparable term from ground-water hydraulics, "hydraulic diffusivity" (Lohman and others, 1972 , p. 8). However, the unsaturated zone generally contains water absorbed to the grains and held by capillarity at grain contacts, which reduces the permeability of the medium to air and the volume of pore space available for air storage. Thus, under field conditions, the medium property that affects air pressure changes may be termed "effective pneumatic diffusivity," or

$$
P D_{e}=\frac{K_{r a} k \bar{P}}{\mu a^{n} d}
$$

where $K_{r a}$ is the ratio of the air permeability at the prevailing moisture content to that for the dry medium; and $n_{d}$ is interconnected air-filled porosity at the prevailing moisture content.

If it is assumed that gas flow due to a change in atmospheric pressure occurs only in the vertical direction, that absolute pressure is small enough that the ideal gas laws apply, that change in pressure with depth has a negligible effect on gas density, and that air permeability of the medium is large enough that the Klinkenberg1 (1941) effect may be ignored, the equation governing the isothermal flow of air in the unsaturated zone may be written (Katz and others, 1959 , p. 408 , eq. $10-17$ ):

$$
\frac{\partial^{2} \phi^{2}}{\partial z^{2}}=\frac{\mu a^{n} d}{K_{r a} k \bar{P}} \frac{\partial \phi^{2}}{\partial t}
$$

'The Klinkenberg effect occurs during gas flow through a capillary or porous medium when the mean free path of the gas molecules approaches in size the diameter of the capillary tube or pore. Under these conditions, the Hagan-Poiseuille velocity distribution no longer holds, as some gas molecules tend to slip along the capillary wall. Thus, for very fine grained materials, the intrinsic permeability as measured by gas flow exceeds that measured by liquid flow. 
where $\phi=$ pneumatic head, equal to $P / \rho_{a} g+z$;

$p=$ pressure at a point, $\mathrm{N} / \mathrm{m}^{2}$;

$P_{a}=$ density of air, $\mathrm{kg} / \mathrm{m}^{3}$;

$g=$ acceleration due to gravity, $9.81 \mathrm{~m} / \mathrm{sec}^{2}$;

and $z=$ the height above a reference plane, $\mathrm{m}$ (positive upward).

This partial differential equation is linear with respect to $\phi^{2}$ rather than $\phi$. However, for problems in which the pneumatic head varies only slightly from its mean value, the equation may be written:

$$
\frac{\partial^{2} \phi}{\partial z^{2}}=\frac{\mu a^{n} d}{K_{r a} k \vec{P}} \frac{\partial \phi}{\partial t}
$$

Strictly speaking, use of this equation requires that head terms in the solution be replaced by their squares. For example, if initial head for a problem is designated $h_{i}$ and final head $h_{f}$, and head at an intermediate time $h_{t}$, the dimensionless head, $\frac{h_{t}-h_{f}}{h_{i}-h_{f}}$, would be replaced by the term $\frac{h_{t}^{2}-h_{f}^{2}}{h_{i}^{2}-h_{f}^{2}}$ (Katz and others, 1959, p. 413-414). However, for the applications described below, the total pneumatic head change was never more than $.01 \vec{P}$. Under these conditions, the value $\frac{h_{t}^{2}-h_{i}^{2}}{h_{f}^{2}-h_{i}^{2}}$ would not vary from that for $\frac{h_{t}-h_{i}}{h_{f}-h_{i}}$ by more than .5 percent. Thus, the use of equation 3 simplifies the computation without significantly changing the solution. The approach is analogous to that of using Dupuit-Forchheimer assumptions to analyze problems involving drawdowns in water-table aquifers. Thus, Jacob's (1963, p. 248) correction term, $s-s^{2} / 2 b$, where $s=$ drawdown and $b$-aquifer thickness, could be used to compute a corrected $\left(h_{t}-h_{i}\right)$ term if $\left(h_{t}-h_{i}\right)$ were used for s, and $\bar{P} / \rho_{a} g$ for $b$. Based on this analogy, such corrections, or the use of the $h^{2}$ terms, would be necessary only if $\left(h f-h_{i}\right)$ were greater than $.1 \bar{P}$.

Assuming that $z=0$ at the land surface and $-L$ at the top of the capillary fringe above the water table, the flow system in the field is subject to the boundary conditions:

$$
\begin{aligned}
& \phi=f(t) \text { at } z=0 ; \\
& \frac{\partial \phi}{\partial z}=0 \text { at } z=-L .
\end{aligned}
$$

The first of these boundary-condition equations specifies that the total pneumatic potential at land surface varies as an arbitrary function of time. The second equation specifies that no gas flow occurs across the boundary $z=-L$ (presumably the top of the capillary fringe).

The field situation is complicated by the fact that the materials in the unsaturated zone generally are layered, with the materials in each layer having a different intrinsic permeability and air-filled porosity. Under these circumstances, additional boundary conditions are imposed at each contact between layers. For example, at the junction of layers $n$ and $n-1$, the boundary conditions:

$$
\frac{K_{r a} k_{n}}{\mu_{a}}\left(\frac{\partial \phi_{n}}{\partial z}\right)=\frac{K_{r a} k_{n-1}}{\mu_{a}}\left(\frac{\partial \phi_{n-1}}{\partial z}\right)
$$

and

$$
\phi_{n}=\phi_{n-1}
$$

are imposed. These two equations specify that the flux from one layer equals that into the adjoining layer, and that pneumatic head is the same in the two layers at their common boundary.

Analytical solutions for flow in layered systems are complicated and difficult to evaluate (Carslaw and Jaeger, 1959, p. 326). However, electric-analog or numerical simulation provides a feasible approach to the problem, because the internal boundary conditions will be met implicitly in the simulation model when the air permeabilities and air-filled porosities are correctly simulated.

To analyze data obtained from a layered sequence of materials, it is a good strategy to add one layer at a time to the simulation model, starting with the bottom layer. By following this procedure, and assuming that air-filled porosity is known for each layer from other data, the permeability to air at the prevailing moisture content of the uppermost layer will be the only unknown to be solved for during any given simulation. Successive estimates of this uppermost layer permeability can be substituted into the model until a satisfactory match between simulated and observed heads at the bottom of or within the layer is obtained, based on measured head variations at the top of the layer. Once this permeability has been determined, it may be assigned to that layer, and a new layer, with as yet unknown permeability, added to the model. The process is repeated until all the layers are included in the model, as described.in detail in the section on the AIRK (air permeability) program.

\section{SOURCES OF ERROR IN CONVERTING AIR PERMEABILITY TO HYDRAULIC CONDUCTIVITY}

The vertical hydraulic conductivity of materials in the unsaturated zone, rather than their air permeability, is generally the parameter of interest to hydrologists, and may be estimated from the air-permeability data based on the well-known viscosity conversion (Muskat, 1946, p. 72). However, care must be exercised in using these estimates, as they may differ from the true hydraulic conductivity because of three factors discussed in detail below.

1. The air-permeability measurements are made at the prevailing moisture content, and thus the computed product of relative air permeability times intrinsic 
permeability $\left(K_{r a}{ }^{k}\right)$ is lower than the true intrinsic permeability.

2. For tight materials, gas permeabilities are greater than liquid permeabilities because of the Klinkenberg (1941) effect.

3. Water will often react with the medium by absorbing either directly to the clay particles or to the cations absorbed on the clay surfaces. Such reactions may result in structural changes in the medium that drastically alter its intrinsic permeability (Johnston and Beeson, 1945).

\section{EFFECTS OF MOISTURE CONTENT}

The effect of prevailing soil-moisture content on air permeability does not appear to be significant in the semiarid regions where the method has been tested. A reasonable assumption under these conditions is that moisture content is at or below field capacity throughout the unsaturated zone down to the capillary fringe. Field capacity is generally described as the moisture content at which gravity drainage is incipient, and may be related to investigations of simultaneous flow of water and air by assuming that field capacity is the highest moisture content at which the effective hydraulic conductivity is zero. For this moisture content, the permeability to air has been found by several investigators (Botset, 1940; Osoba and others, 1951; Leverett and Lewis, 1941) to range from 0.6 to 0.8 that of the air-dry medium. Thus, errors in estimating intrinsic permeability from air permeability at the prevailing moisture content would be relatively small under these conditions.

Errors resulting from the effects of moisture content on the permeability of the medium to air may be much greater where residual moisture content is greater than field capacity, as would commonly be the case in humid regions. Consequently, care should be taken to obtain air-pressure readings only after long dry periods, during which the sediments have had a chance to drain to near field moisture capacity.

\section{THE KLINKENBERG EFFECT}

This effect, as described by Klinkenberg (1941), occurs at low gas pressures in fine-grained materials, and results in gas permeabilities measured at low ambient pressures being larger than the corresponding liquid permeabilities. Katz and others $(1959$, p. 46) presented a chart for converting gas permeability to liquid permeability when the Klinkenberg effect is significant. However, because the Klinkenberg effect is significant only for materials having an intrinsic permeability of less than about 10 millidarcies, it generally could be ignored for the conditions encountered during this study.

\section{ABSORPTION EFFECTS}

Upon wetting, the granular materials comprising the unsaturated zone will absorb water, causing, in some cases, structural and intrinsic permeability changes in the porous medium. Such changes generally result from the presence of clay minerals in the medium, and their magnitude is dependent on the initial moisture content of the material, on the mineralogy and absorbed cation chemistry of the contained clays, and on the chemical quality of the percolating water. The water-quality effects occur because of absorption of water in greater or lesser amounts by the exchangeable cations associated with the clay minerals. For example, exchangeable sodium on clays in the presence of water of very low dissolved-solid concentrations will absorb relatively large amounts of water. Such absorption will cause swelling of montmorillonite and mixed-layer clays, resulting in great reductions in permeability (Quirk and Schofield, 1955; McNeal and Coleman, 1966; McNeal and others, 1968). Even when only non-swelling clay minerals are present, however, the absorption of water by the exchangeable cations results in disaggregation of clay particles and the migration into and blockage of pores by clay platelets (Johnston and Beescn, 1945, p. 45). This pore blockage may result in greatly reduced permeability of the medium.

Most comparisons of permeability to air and to water have been based on laboratory studies, and indicate that the differences in permeability to the two fluids can be extreme. For example, Johnston and Beeson (1945, p. 47) report reductions in permeability of as much as a few thousandfold upon changing the permeant fluid from air to brine, and of as much as several thousandfold upon changing from air to distilled water. Reeve (1953) also reports differences of as much as several thousandfold between permeability to air and to distilled water. These differences are undoubtedly much greater than those that would occur if the air permeability were measured at field moisture capacity rather than air dryness. Nonetheless, results of laboratory tests on 30 cores from the Ogallala Formation in the Southern High Plains in Texas, described under "Results," show variations of as much as 500 to 1 between hydraulic conductivity measured directly and that computed from air permeability at the prevailing moisture content.

Differences between the hydraulic conductivities computed from air permeability test data and the hydraulic conductivities determined from recharge experiments are much smaller than those determined in the laboratory, as described under "Results." Sufficient data have been collected to indicate that the air permeability test gives a value for intrinsic permeability of the surface layer that is generally a few times higher than that determined from recharge experiments, probably as a result of structural changes in the medium due to wetting. On the other hand, determinations by the two procedures of intrinsic permeability of layers at depth were approximately equal for one extenșive test, also described under "Results," despite the presence of swelling clays in some of the layers. These 
results suggest that the permeability of materials at depth may not be greatly affected by structural changes due to wetting, and that the air-permeability method might be useful for estimating their hydraulic conductivity. However, any investigator planning to use or test the method should be aware of the potential error in hydraulic conductivity estimates that might arise because of the effects of wetting on the structure of the medium.

\section{THE METHOD}

The first requirement for application of the described method to determine vertical air permeability at a selected site is an investigation to ensure that geologic and hydrologic conditions at the site meet, at least approximately, the theoretical assumptions on which the method is based. Once the investigator is satisfied that the site conditions are suitable, the site is instrumented. Wide latitude exists in selecting suitable instrumentation and installation procedures. The selections described here are relatively simple and inexpensive, and have proven successful in several field applications. Data collection can generally be completed during an afternoon barometric decline if normal weather prevails. Data analysis should be relatively straight forward for anyone with access to a large digital computer, using the FORTRAN IV computer program listed and described in the section on the AIRK program.

\section{SITE INSPECTION}

Geologic and hydrologic conditions will always be more complex than those assumed for the theory of this method. Hence, it is important that the conditions be investigated to ensure that they are satisfactorily approximated by the theoretical assumptions. To apply the method, it is assumed that the unsaturated zone consists of a sequence of horizontal layers, each being of large areal extent and uniform thickness. Each layer is also assumed to have areally and vertically uniform permeability and air-filled porosity. It is further assumed that both land surface and the water table are horizontal, and that the barometric changes are areally uniform. Finally, it is assumed either that no open boreholes, cracks, crevices, animal burrows, or other openings exist that would provide preferred flow paths for air movement, or else that the openings are so widely and uniformly distributed that the unsaturated zone still behaves as a porous medium. The validity of these assumptions as related to actual conditions at any field site should be carefully considered before applying the method at the site, and in selecting screen depths when the site is instrumented.

Subsurface geologic data, including sample and geophysical logs, are needed from at least one test hole in the site area. These data are used to determine the depth to water, to select the layers into which the unsaturated zone is to be divided, and to estimate the air-filled porosity for each chosen layer. If data are available for additional test holes, the continuity and dip of the beds can also be determined.
Selection of layers within the unsaturated zone will be clearcut if the unsaturated zone is strongly stratified into only a few units. However, if lithologic changes in the unsaturated zone are gradational, or the zone comprises thinly interbedded materials, the selection criteria must be more subjective, as the number of layers must be kept within practical limits. For this study, six was the maximum number of layers instrumented, but more could be instrumented if called for by the site geology.

As part of the site investigation, it should be ascertained that all wells and test holes in the vicinity of the site are grouted or backfilled through the unsaturated zone to ensure against air circulation in open well bores.

\section{INSTRUMENTATION}

Instrumentation for this method must be emplaced in a hole augered or drilled to the desired depth in the unsaturated zone. Drilling procedure is important, as the hole must be drilled without adding water or mud that could plug the wall of the hole and stop or restrict air movement into or out of the adjacent unsaturated material. In addition, drilling should be halted above the water table, as saturated auger or drill cuttings from below the water table tend to plaster the well bore above the water table with low-permeability material. Generally, augering is the best method for installing the hole, although for deep or consolidated sequences of unsaturated materials, the hole could be installed by air-rotary methods. All the holes used in this study were augered except those at the NRTS (National Reactor Testing Station, now Idaho National Engineering Laboratory), which were drilled by air-rotary methods.

Considerable latitude exists for variation in the construction of the air piezometers, which are installed above the capillary fringe in the lowermost layer and at each layer boundary, as selected during the site inspection. The screens should be relatively short to avoid air circulation within the screened section, and the pipes leading to the surface should be of small diameter to minimize storage effects within the pipe. During this study, the sites usually were instrumented using standard $32 \mathrm{~mm} \times 610 \mathrm{~mm}$ (1 1/4-inch by 24 -inch) well screens connected to the surface by $6.4 \mathrm{~mm}$ (1/4-inch) steel pipe. At some sites, however, where the chosen layers were thin, $150 \mathrm{~mm}$ (6-inch) sections of $32 \mathrm{~mm}$ (1 1/4-inch) well screen or $25 \mathrm{~mm}$ (1-inch) diameter, $100 \mathrm{~mm}$ (4-inch) long brass foot valves were used to screen the piezometers.

The screens are emplaced in the auger hole to form a piezometer nest, as shown schematically in figure 1 . The bottom screen is emplaced above and as near the top of the capillary fringe as feasible. Gravel or coarse sand is poured into the annulus around the screen and pipe to about 0.1 meter above the top of the screen. A layer of dry dirt approximately 0.1-0.2 meter thick is dropped on the gravel to seal it from the grouting material. Expanding cement (Peck, 1964) is poured through a drop pipe or tremie (to 
avoid plugging the side of the hole with cement) to the level at which the next screen is to be installed. The process is repeated until the uppermost screen is installed, and the hole is cemented to land surface, thus completing the piezometer nest.

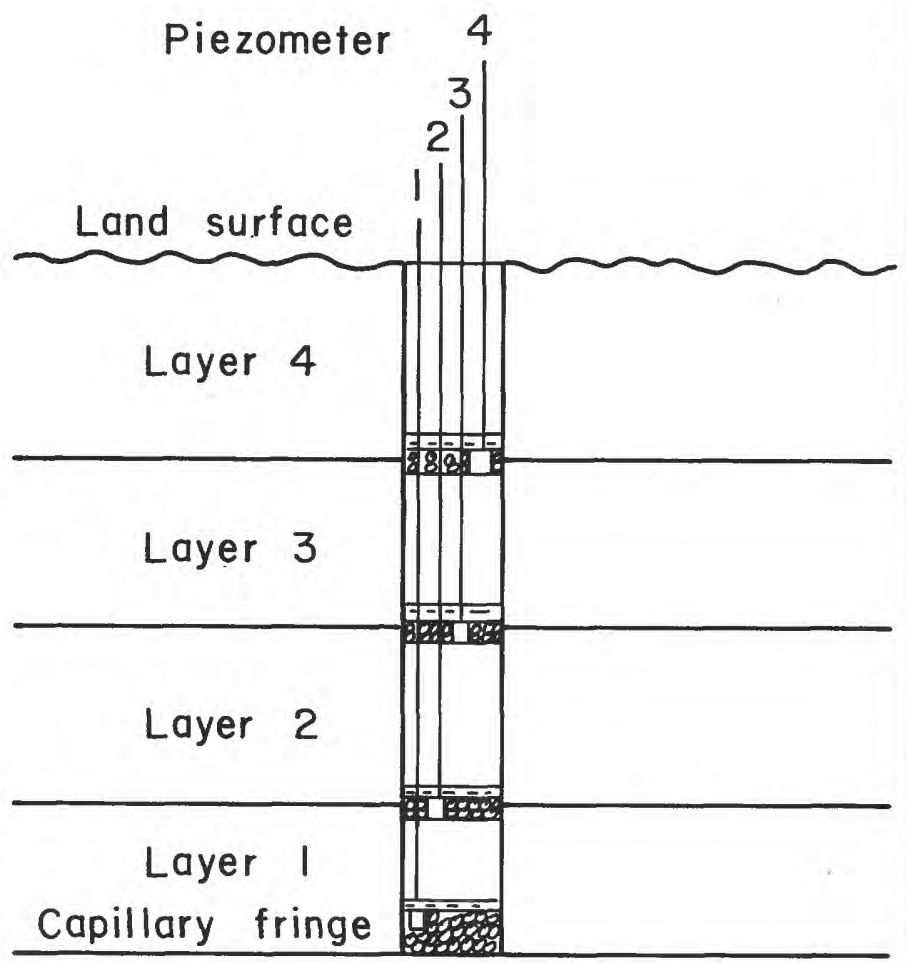

FIGURE 1. - Sketch showing typical piezometer nest used to determine pneumatic heads at selected depths in the unsaturated zone.

Pressure readings, in terms of liquid head, are obtained by connecting the piezometers through a manifold to an inclined manometer, as shown photographically in figure 2 and schematically in figure 3 . Differences in pneumatic head between each piezometer and the atmosphere are made by opening the manifold valve connecting that piezometer to the manometer, all the other manifold valves being closed. Zero manometer readings are obtained by opening the manifold to atmosphere. The change in atmospheric pressure during the test is measured with a microbarograph and (or) a surveying altimeter.

Under field conditions, a manometer inclined at a 10:1 slope and filled with fluid of specific gravity 1.20 (commercial manometer fluid for outdoor use) has been found to give readings accurate to about $0.25 \mathrm{~mm}(0.01$ inch), which is equivalent to about $30 \mathrm{~mm}$ ( 0.1 foot) of pneumatic head. A $760 \mathrm{~mm}$ (30-inch) manometer, having a range of $76 \mathrm{~mm} \mathrm{(3}$ inches) is adequate to measure pneumatic head differences under most conditions. Because downhole pneumatic head will sometimes be less than that at land surface, it is desirable to establish, by slightly overfilling the manometer-fluid reservoir, a reading of about $13 \mathrm{~mm}(0.5$ inch) at zero pressure difference. Thus, for a $760 \mathrm{~mm}$ (30-inch) manometer, a net range of about $64 \mathrm{~mm}$ ( 2.5 inches) is available for measuring the major head differences occurring during the test. Such a range generally is adequate even when unusually large atmospheric pressure changes occur.

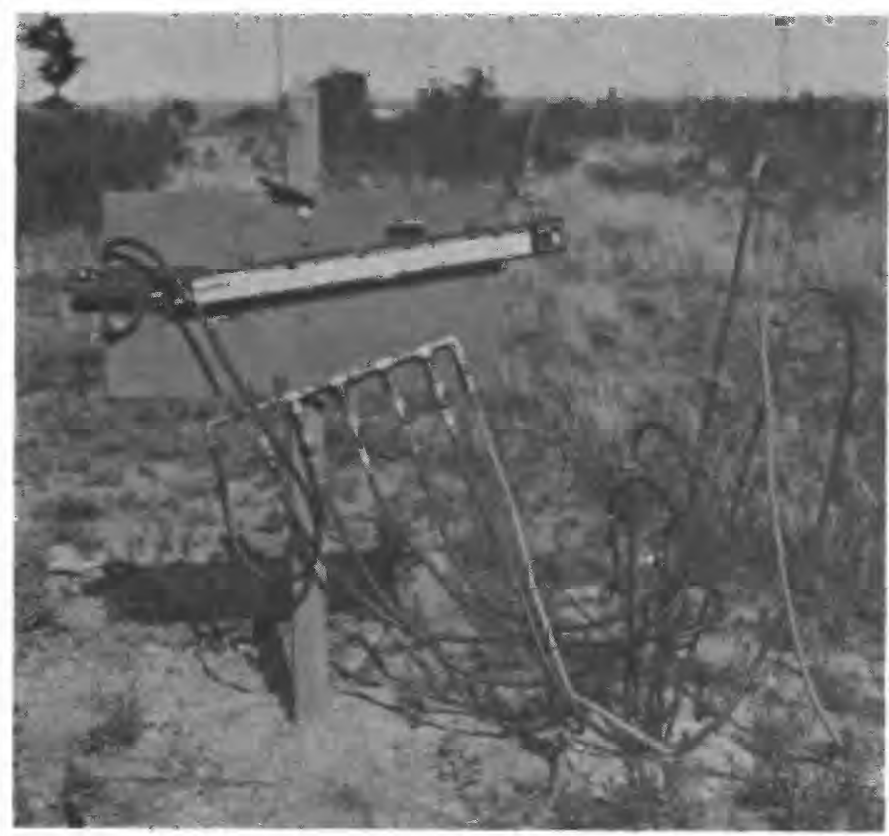

FIGURE 2. - Photograph showing piezometers, manifold, and manometer used to determine pneumatic head versus depth and time. Photograph by Richmond F. Brown.

\section{DATA OBTAINED}

Data required for the method include curves or tables of pneumatic head versus time at each depth during a period when atmospheric pressure is changing. During the investigation, it was found to be most convenient to obtain these data during a normal afternoon barometric decline. In most of the areas where tests were run, such a pressure decline usually is equivalent to 3 to 4 millibars or about 30 to $36 \mathrm{~m}$ of pneumatic head in 4 to 5 hours. Generally, when determining the downhole response to diurnal barometric changes, differences in pneumatic head between each depth and land surface are measured in terms of liquid head at about 15-minute intervals. Readings generally are started at about 10 or 11 a.m., when the barometer is normally quite stable, as such readings provide good initial conditions for the analysis. The readings generally are continued through the afternoon decline until 6 or 7 p.m., when a diurnal barometric rise normally occurs.

For electric-analog analysis, the measured pneumatic head differences are added algebraically to the absolute pneumatic head, as determined from a microbarograph or an altimeter. The resultant pneumatic head values can be plotted versus time to produce a family of curves (fig. 4), one curve for each piezometer and one for atmospheric pressure, 


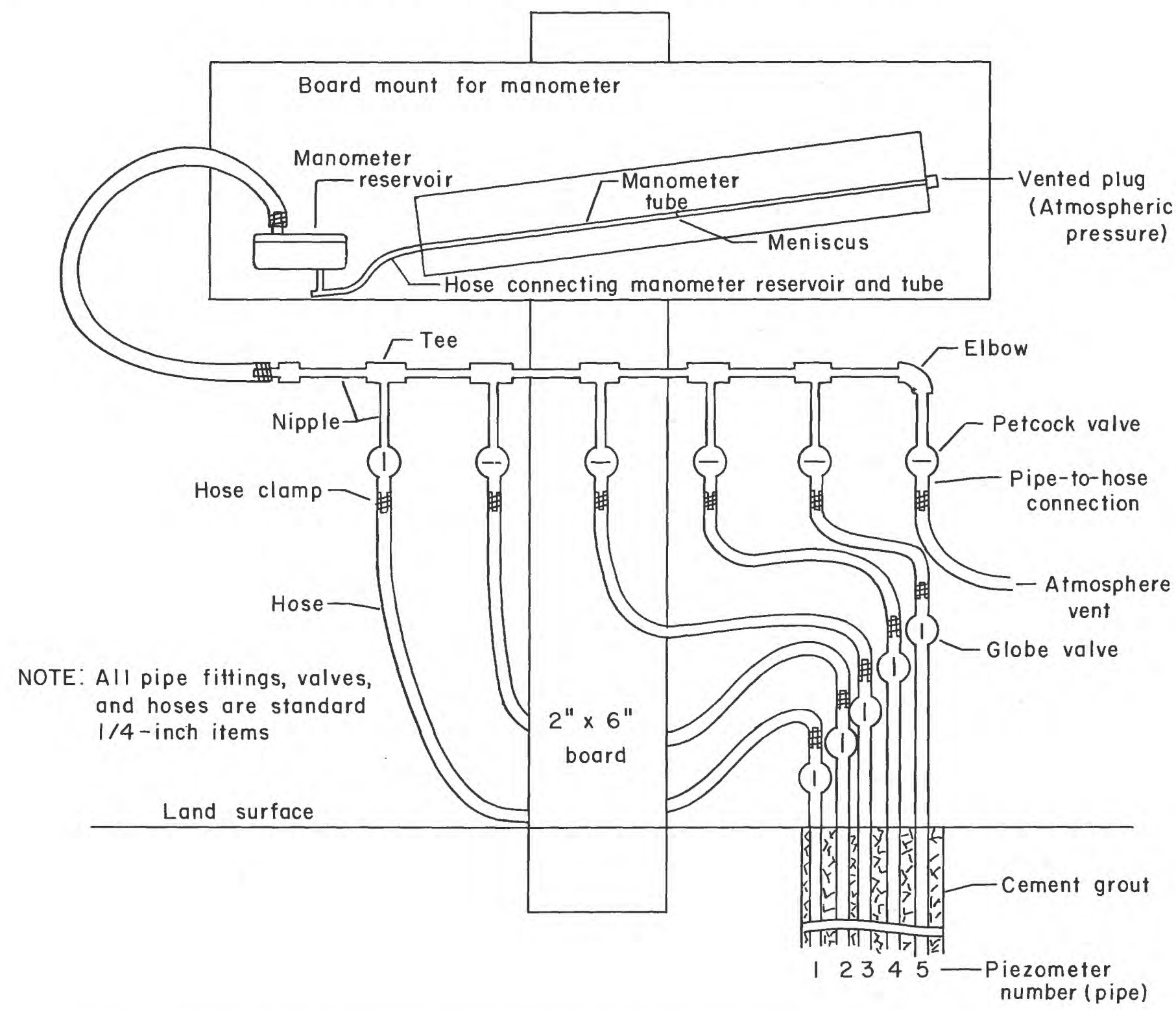

FIGURE 3. - Schematic diagram of a manifold, showing its construction and details of its connection to the piezometers and manifold. The connection shown is that used when the downhole pressure is greater than that at land surface, and the valve settings are those for reading piezometer 1 .

that may be used for the electric-analog analysis. Alternatively, for the digital computer analysis, the microbarograph data at selected times are punched on one set of cards. The differential manometer readings and their elapsed times are punched on a second set of cards, and both sets are read as data in the program. These data are converted by interpolation and algebraic manipulation within the program into a table of pneumatic head values, one for each screen and for land surface, for each short uniform time step used in the analysis. Details concerning data input to the program are described in the section on the AIRK program.
Pneumatic head differences occurring during the normal afternoon diurnal barometric change were found to be large enough to be read and analyzed at sites where the unsaturated zone was more than about 20 meters thick and there was at least one layer with a permeability of no more than 2 or 3 darcies. At other sites, where the unsaturated zone was thinner and the layers more permeable, head differences during such a diurnal change were too small to measure accurately using the described instrumentation. Moreover, short-term atmospheric pressure changes that could be characterized as noise tended to mask the differences. This noise would interfere with the pressure 


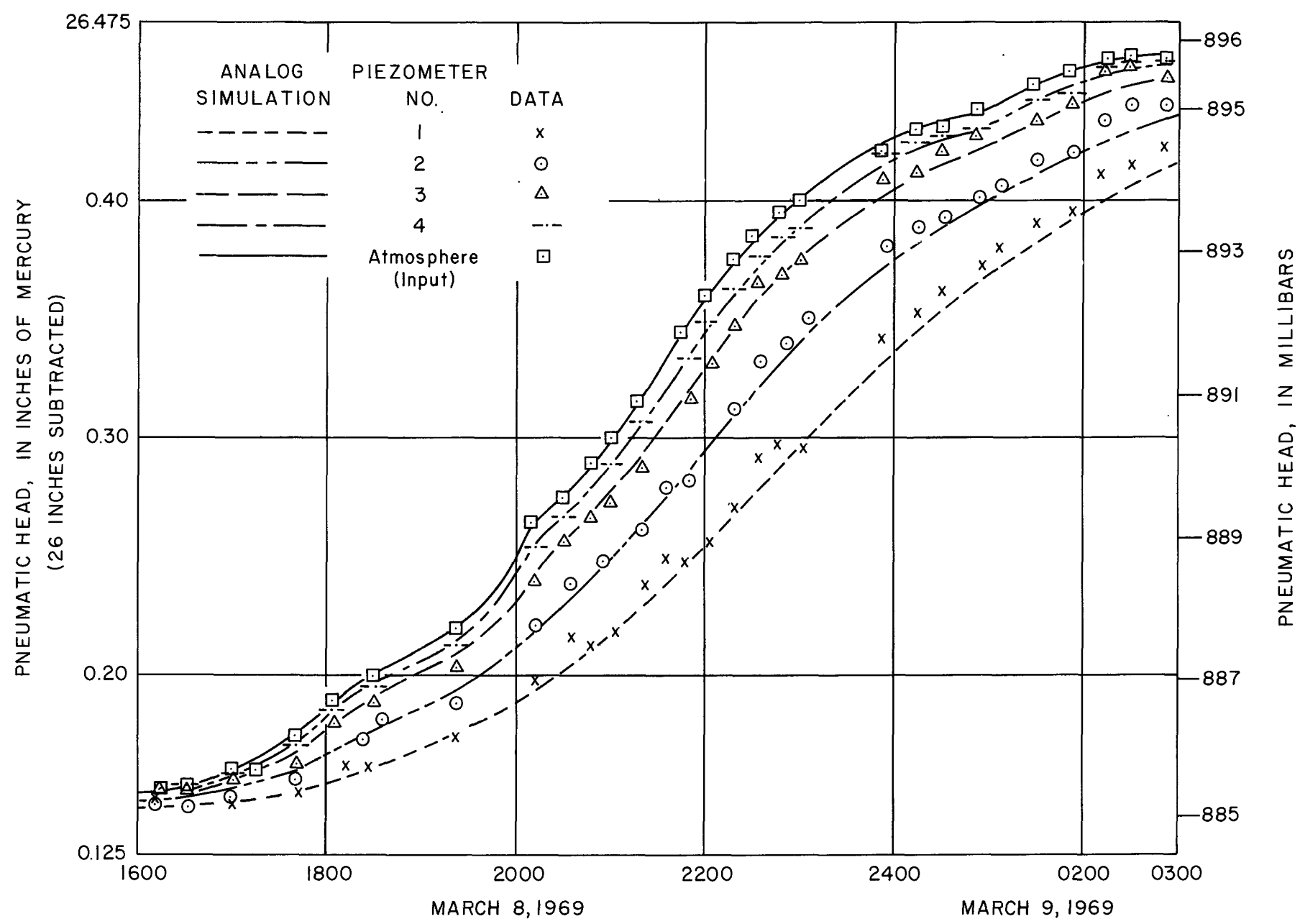

FIGURE 4. - Pneumatic heads measured March 8-9, 1969, at four depths at Lubbock, Tex., airport site A, and best-fitting analog simulation.

difference readings even if more sensitive instrumentation were used. However, usable readings can sometimes be obtained for a relatively thin, highly permeable section during the passage of a "front" in which the atmospheric pressure changes a few millibars in a few minutes to an hour. Such events are so rare and unpredictable, however, that the author was only able to make use of them twice during several attempts. These experiences in "chasing fronts" suggest that general use of such events is impractical.

\section{DATA ANALYSIS}

Data obtained during this investigation were initially analyzed by use of an electric analog model, based on the analogy between the flow of a compressible fluid and the flow of electricity (Karplus, 1958, p. 356-360). Required equipment for the analog analysis includes a device for electrically exciting or stressing the system, analogous to the atmospheric pressure change at land surface; a system of variable resistor-capacitor (R-C) networks or grids to simulate the layered unsaturated materials; and a device for recording voltage changes at selected points within the R-C grid due to the electrical excitation. The recorded voltage changes are analogous to the pneumatic head changes measured at depth. For this study, an electronic line follower fitted to an $x-y$ recorder (Rogers and Connolly, 1960, p. 37-38) was used to vary voltage, through high-gain direct-current amplifiers, in the R-C network. Voltage at selected junctions within the R-C network was read out through a large-value resistor and high-gain amplifiers to a second $x-y$ recorder. The time scale for both $x-y$ recorders was controlled by an external time-base device.

The electric-analog analyses, as performed, were made using a series of R-C grids, each grid consisting of 15 variable resistors individually connected to ground through fixed capacitors. The capacitors in each grid were of the same size.

Details of the electric-analog analysis are not given, because the system has been replaced by a digital computer program. However, the basic analytical procedure is similar to that described for the section on the AIRK program. As for the computer program, the layered system is analyzed by first treating the bottom layer as a complete system, and when that layer is adequately simulated, adding an R-C grid 
to the system to represent the overlying layer. Air permeability of the most recently added layer is determined from the analog analysis by trial-and-error manipulation of the resistors in that grid until the model results, in terms of the voltage variation with time within or at the bottom of that grid, match the measured pneumatic head at the appropriate screen. Once a match is obtained, air permeability for that layer may be computed from the relationship among air permeability, air-filled porosity, thickness of unsaturated material represented by each resistor (equal to $1 / 15$ th the layer thickness), the resistance and capacitance of each resistor and capacitor in the grid, and the ratio of analog to prototype time.

Because the electric analog system used for the initial analyses would not be available to most investigators, a digital computer program was formulated to analyze the pneumatic head data numerically while this report was in review. Comparison of the numerical and analog results indicated that the electric-analog analyses were incorrect. In retrospect, it was recognized that the capacitors in each grid representing a given layer should have been varied proportionally to the air-filled porosity of that layer, rather than being fixed at the same value for all the grids. Actually, the effect of variation in air-filled porosity in layers above the bottom one was rather minor compared to effects of variations in air permeability, and the analog system as used would have provided reasonably good results if air-filled porosity had been assumed constant for all the layers in the prototype system. Instead, the analyses were made by computing an effective pneumatic diffusivity for each layer based on the resistances and capacitances for the grid representing the layer. An air permeability was computed by multiplying this diffusivity by the appropriate air-filled porosity term for the layer. This procedure had no effect on determination of air permeability of the bottom layer, but for overlying layers with larger or smaller air-filled porosities, the computed air permeability was almost proportionately too large or too small.

Because of these problems with the electric-analog analysis, all of the described analyses were redone using the digital-computer program described and listed in the section on the AIRK program. The program, which is written in FORTRAN IV, uses data provided on the site, including screen depths and depth to the water table, estimates of air-filled porosity, preliminary estimates of $P D e^{\text {-based }}$ hydraulic conductivity, and periodic microbarograph and differential manometer readings to compute final estimates of air-permeability based hydraulic conductivity.

The basic procedure used in the AIRK program to arrive at these final hydraulic conductivity estimates is that of numerically solving the finite-difference form of equation 3 for systematically varied estimates of the air permeability of a given layer until the difference between measured and computed heads within or at the base of the layer is minimized. Details of the methods by which the supplied data are prepared for use in the finite-difference form of equation 3 , on the sequential analysis of data for each layer, on the numerical solution of equation 3 , and on the automatic search procedure to select the final hydraulic conductivity estimates are all described in the section on the AIRK program.

As mentioned above, air permeability at the prevailing moisture content, rather than hydraulic conductivity, is measured by the method. However, hydraulic conductivity is frequently the parameter of interest to hydrologists. Consequently, the computer program is set up to convert initial user-supplied estimates of hydraulic conductivity to air permeability, to search for the best-fitting air-permeability value, and to reconvert that value to hydraulic conductivity before printing data out. Because English units are used in the program, the conversion described in the section on the AIRK program is confusing to follow. In metric units, however, the conversion is straightforward. If the medium were air-dry, the conversion would be made by the equation:

$$
K=\frac{k g}{v_{w}}
$$

where $\quad K=$ hydraulic conductivity, $\mathrm{m} / \mathrm{sec}$;

$k=$ intrinsic permeability to air of the air-dry medium, $\mathrm{m}^{2}$;

$g$ =acceleration due to gravity, $9.81 \mathrm{~m} / \mathrm{sec}^{2}$;

and $\quad v_{w}=$ kinematic viscosity of water, $\mathrm{m}^{2} / \mathrm{sec}$, at the prevailing temperature.

Because the materials in the unsaturated zone are not air-dry, the air permeability values determined by the above analyses are equal only to a fraction of the value at air-dryness, expressed by the formula

$$
K_{r a k}
$$

where $\quad K_{r a}=$ ratio of air permeability of the porous medium at the prevailing moisture content to that of the air-dry medium.

Hence, the hydraulic conductivity determined by the analysis of pneumatic head data is approximate, and is given by the equation

$$
K_{e}=\frac{K_{r a k g}}{v_{w}}
$$

where $\quad K_{\ell}=$ field air-permeability based hydraulic conductivity; in $\mathrm{m} / \mathrm{sec}$.

As noted above, $K_{r a}$ generally ranges from 0.6 to 0.8 for materials drained to field moisture capacity.

The determined value of $K_{e}$ is dependent on the prevailing soil temperature during the test, because the dynamic viscosity of air, which is temperature-dependent, occurs in the pneumatic diffusivity term. Moreover, $K_{e}$ must be determined for some specified water temperature, 
because $v_{w}$ is also temperature-dependent. For the program, both $\nu_{w}$ and $\mu_{a}$ are read in, unless specified otherwise, for a temperature of $15.6^{\circ} \mathrm{C}$. The value for $\nu_{w}$ was chosen because the U.S. Geological Survey has historically used $15.6^{\circ} \mathrm{C}\left(60^{\circ} \mathrm{F}\right)$ as the reference temperature for hydraulic conductivity measurements (Wenzel, 1942, p. 7). The value for $\mu_{a}$ was chosen because the mean annual air temperature at Lubbock, Tex., where much of the work was done, is about $16^{\circ} \mathrm{C}$. Moreover, the viscosity of air varies only gradually with temperature, so the value generally should be adequate even in more northerly climes. The investigator does have the option of supplying values for viscosity at other temperatures if conditions warrant, however.

\section{RESULTS}

Field tests of the method were made at five sites in the Southern High Plains of Texas and at one site each at the Birch Creek Playa, located at the Idaho National Engineering Laboratory near Idaho Falls, Idaho; at the Central Great Plains Experiment Station near Akron, Colo.; in Scott County, Kans.; and at Nassau County Recharge Basin 306 on Long Island, N.Y. Tests were described in detail below for the sites in Idaho and New York and a site in the Southern High Plains near Lubbock, Tex. A wide range of hydrogeologic conditions exists at these sites. Moreover, other data are available from these sites for comparison with the air permeability data.

\section{BIRCH CREEK PLAYA, IDAHO}

The method was applied at this site to determine the air permeability of the playa sediments, basalt flows, and a sedimentary layer between basalt flows, termed an interflow bed. These data were needed to support tests of the feasibility of emplacing radioactive waste gases in unsaturated basalt underlying the sediments (Schmalz, 1969, p. 1; Robertson, 1969). Because air permeability, rather than hydraulic conductivity, is the parameter of interest for this test, complications arising from residual moisture content and structural changes of the medium due to wetting is not of concern. Thus the test represents a quite straightforward application of the air-permeability method.

The general stratigraphic sequence at Birch Creek playa, as described by Schmalz (1969), includes playa sediments overlying a thick sequence of basalt flows of the Snake River Group separated by one interflow sedimentary bed (fig. 5). The playa sediments range from 2 to $17 \mathrm{~m}$ thick, and consist of clay and silt with a small amount of sand. The basalts consist of interlayered individual flows ranging from several to $15 \mathrm{~m}$ thick. Permeability in the basalt is due to joints, fractures, and voids, and is very unevenly distributed. The sediments in the interflow bed consist of sand, silt, and clay, and probably are alluvial in origin. The top of the interflow bed lies from 23 to $37.5 \mathrm{~m}$ below land surface and ranges from 1.5 to $4.6 \mathrm{~m}$ thick.

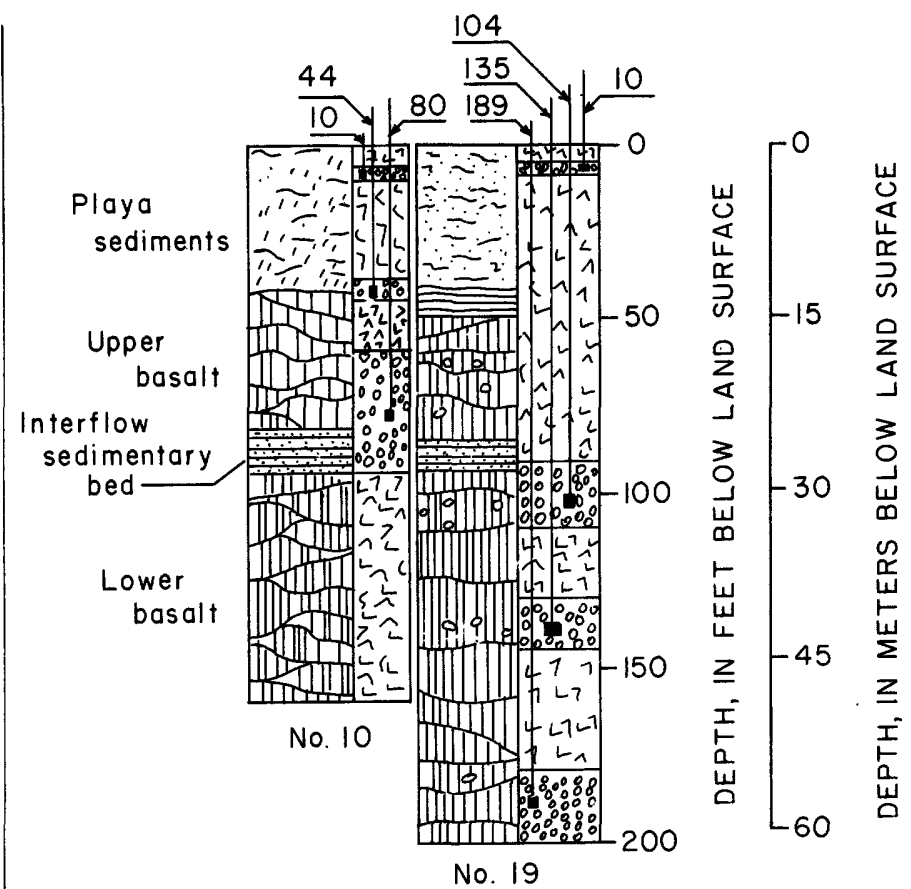

EXPLANATION

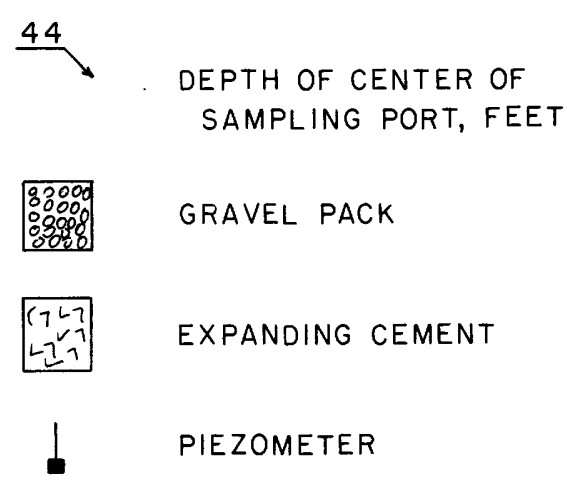

FIGURE 5. - Sample logs and construction of wells tested at Idaho National Engineering Laboratory (modified from Schmalz, ed.. 1969, fig. 9).

All permeability results for this site refer to intrinsic permeability in darcies ${ }^{2}$, because the hydraulic conductivity of the materials is not of concern, and other published permeability values for the site are also in darcies.

Data of pneumatic head versus time were obtained from two piezometer nests (wells 10 and 19, Schmalz, 1969, p. 47) located about $200 \mathrm{~m}$ apart during a normal afternoon barometric decline of about 4 millibars in a 5-hour period on October 24, 1969. Screens for piezometers in each nest consist of specially designed cages that were originally

${ }^{2} \mathrm{~A}$ one-centimeter cube of a porous medium has a permeability of one darcy if water at $68^{\circ} \mathrm{F}\left(20^{\circ} \mathrm{C}\right)$ (viscosity=l centipoise) will flow through at a rate of one $\mathrm{cm}^{3} / \mathrm{sec}$ under a pressure drop of one atmosphere. At $60^{\circ} \mathrm{F}\left(15.6^{\circ} \mathrm{C}\right)$, a porous medium with a permeability of one darcy would have a hydraulic conductivity of $0.74 \mathrm{~m} /$ day. 
installed to provide ports for sampling injected radioactive gas (Schmalz, 1969, fig. 10). These screens were gravel-packed and grouted with expanding cement as shown in figure 5 . Piezometers in well 19 tapped materials below the interflow sedimentary zone, and piezometers in well 10 tapped materials above the zone. Consequently, data from the two nests were combined to make a single analysis for the air permeability of layers in the profile.

Analysis of the pneumatic-head data from the Birch Creek playa site was complicated by three factors. First, during the test, it was observed that pneumatic head differences were greater in well 19 at the 32-meter depth than at the 41 -meter depth, indicating that the basalt surrounding the deeper cage is better connected to the surface by fissures, joints, and voids than that surrounding the shallower one. Such conditions differ from those assumed for the one-dimensional analysis, and consequently accurate simulation of flow in the lower basalt is not possible with the available data. Second, the gravel pack surrounding the screen at the 24-meter depth (fig. 5) extends from 19 to $30 \mathrm{~m}$, possibly allowing air circulation along the well bore. Third, the well screens at the 24- and 32-meter depths are not exactly at the upper and lower boundaries of the interflow zone.

Despite these complications, it was necessary to establish the effects of the underlying materials on the pneumatic heads at the base of the playa sediments before their permeability could be determined. Consequently, it was assumed that the lower basalt could be analyzed as a unit extending from 32 to $62 \mathrm{~m}$, based on matching computed and measured pneumatic heads at the 58-meter depth. It was further assumed that the pneumatic head in the 24-meter piezometer was representative of that in the formation at that level. Finally, it was assumed that the material from 24 to $32 \mathrm{~m}$, which includes the interflow bed, could be analyzed as a single layer. The basalt layers were assumed to have an air-filled porosity of 0.05 , based on data given by Robertson $(1969$, p. 13). The layer from 24 to $32 \mathrm{~m}$ was assumed to have an air-filled porosity of 0.15 , which is the approximate thickness-weighted average of 0.05 for basalt and 0.2 (assumed) for the interflow sedimentary zone.

Results of the analyses are shown in table 1. Although the results for the basalt and interflow sedimentary zones are

TABLE 1.-Summary of vertical air permeability values computed from pneumatic head data obtained from installations at the Birch Creek playa, Idaho

\begin{tabular}{|c|c|c|c|}
\hline $\begin{array}{c}\text { Nature of } \\
\text { materials in } \\
\text { layer }\end{array}$ & $\begin{array}{l}\text { Depth } \\
\text { interval } \\
\text { (meters) }\end{array}$ & $\begin{array}{l}\text { Air-filled } \\
\text { porosity }\end{array}$ & $\begin{array}{l}\text { Air permeabillty } \\
\text { (darcies) }\end{array}$ \\
\hline $\begin{array}{l}\text { Near-surface playa } \\
\text { sediments. }\end{array}$ & $0-3.0$ & 0.25 & 6 \\
\hline Playa sediments ................... & $3.0-13.4$ & .25 & 2 \\
\hline Upper basalt .................... & 13.4-24.4 & .05 & 5 \\
\hline $\begin{array}{l}\text { Interflow sedimentary } \\
\text { zone. }\end{array}$ & $24.4-31.7$ & .15 & 2 \\
\hline Lower basalt ......................... & $31.7-60.7$ & .05 & 10 \\
\hline
\end{tabular}

plausible, the complications mentioned above suggest that they be used with caution. Nonetheless, the analyses of data for piezometers at the base of and within the playa sediments described below result in a reasonably good match of measured and computed values (fig. 6). Consequently, it is assumed that the simulation of the basalt layer and interflow layers provided a good approximation of the boundary conditions prevailing at the base of the playa sediments, and that the results for the playa sediments are approximately correct.

Data from the 13-meter piezometer, at the base of the playa sediments, and from the 3-meter piezometer were analyzed to determine the air permeability of both a lower and an upper layer of playa sediments. The determined air permeabilities were 2 and 6 darcies (table 1) for the two layers, based on a laboratory-determined average air-filled porosity of the playa sediments of 0.25 for 16 samples. The higher permeability of the uppermost section of playa lake sediments probably results from the greater prevalence of desiccation cracks, root holes, and animal burrows at the shallow depth.

The field-determined air-permeability values compare favorably with laboratory measurements of air permeability at the prevailing moisture content on 11 drive cores, which ranged from 0.1 to 8.0 darcies. The geometric mean of permeability values, rather than the arithmetic or harmonic mean, has been suggested by Bouwer (1969) as providing a more valid estimate of the permeability of laterally and vertically heterogeneous materials, such as those comprising the Birch Creek playa. The geometric mean of the eleven sample permeability values is 0.96 darcies. Thus, the field value for the 3-13-meter layer of 2 darcies is about twice the geometric mean of the laboratory results, possibly because of compaction of the drive-cores, or because of the lack of secondary permeability features in the cores.

King (1968) also made estimates of air permeability of the playa sediments, based on injection pressure measurements during air injection at a constant rate into three auger holes. Of these three auger holes, two were open from a depth of 1.5 to $3 \mathrm{~m}$ and one from a depth of 1.5 to $4.6 \mathrm{~m}$. King's (1968, p. 39-40) values for several test replications in each of the three holes ranged from 5 to 18 darcies, and averaged 9 darcies. These values are slightly larger than that of 6 darcies determined for the 0-3-meter depth during this study. As King (1968, p. 33) noted, his values may be erroneously large because the effective radius of his wells may have been larger than assumed, which may account for the fact that the results of this method are lower than King's.

In conclusion, this method has yielded values for the vertical permeability of the Birch Creek playa sediments that are larger than those determined by laboratory analysis, but less than those determined by injection tests. These variations can be reasonably explained, and it is likely that the values determined by the present method are the most accurate of those determined for the vertical permeability of 


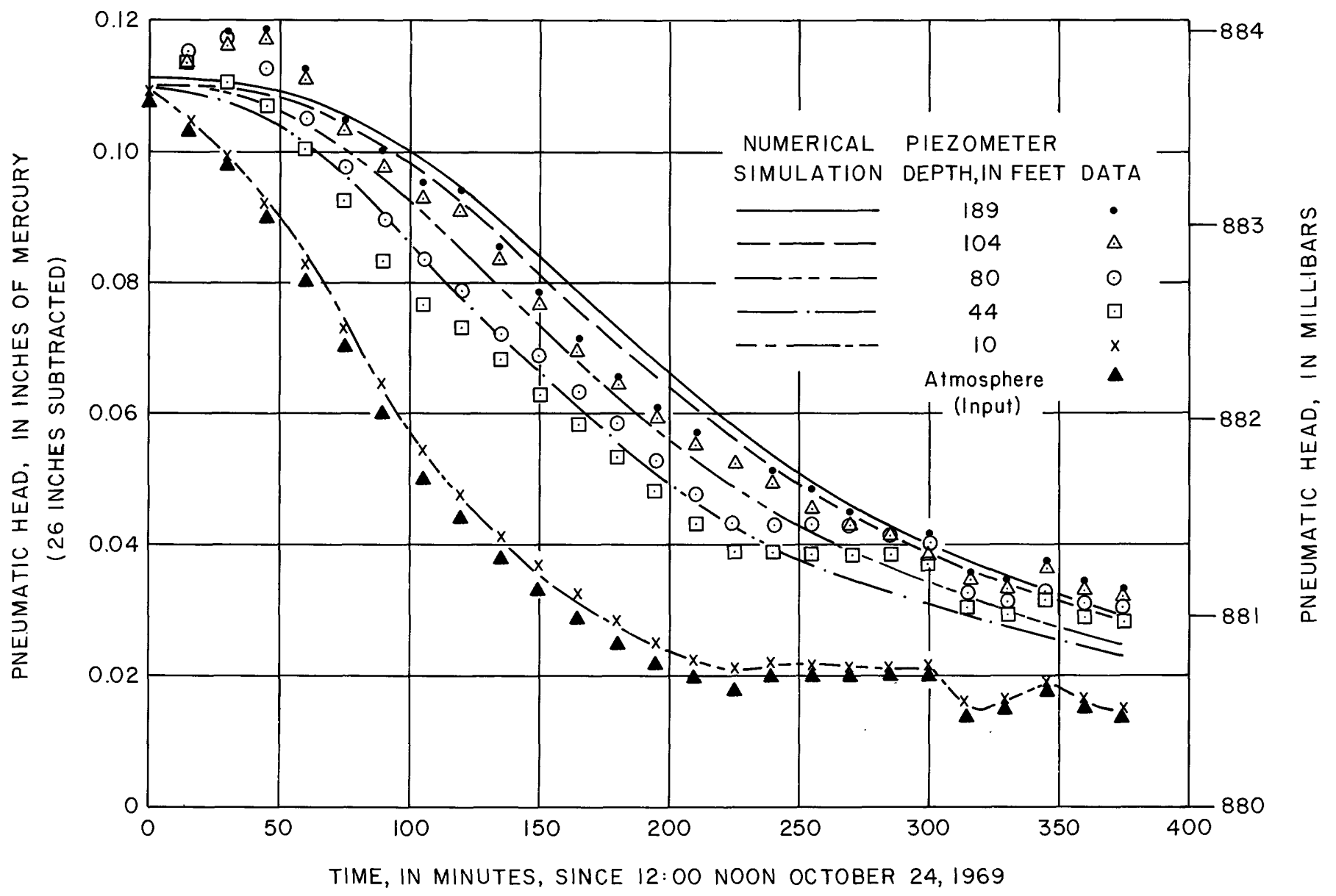

Figure 6. - Comparison of pneumatic heads measured on October 24, 1969 , at five depths in the unsaturated zone at the Birch Creek playa, Idaho, site to the best-fitting numerical simulation.

the playa sediments. The described method should be highly useful for evaluating the feasibility of temporary storage of gas in the unsaturated zone at other sites where the materials are well-drained.

\section{LUBBOCK, TEXAS, AIRPORT SITE}

A site adjacent to the Lubbock, Tex., Regional Airport was selected to test the utility of estimates of hydraulic conductivity determined by the described method to predict infiltration rates and the effects of perching layers during water-spreading operations. The Lubbock site is in a semiarid area, and problems arising from high residual moisture content were not anticipated, nor did they occur. However, the geologic section within the unsaturated zone at this site does contain significant quantities of clay minerals that were expected to swell or disperse upon wetting.

A great many field and laboratory data were obtained on the pneumatic and hydraulic properties and of correlative geophysical and lithologic properties of the unsaturated zone at this site. Air permeability values and equivalent hydraulic conductivities were determined from data obtained at three installations. In addition, laboratory deter- minations of volumetric moisture content, porosity, hydraulic conductivity, air permeability (both at the prevailing moisture content and at oven-dryness), grain-size distribution, pore-size distribution, carbonate content, and clay mineralogy were obtained on numerous drive cores from two wells, and on wireline cores from three wells. Extensive suites of geophysical logs were also obtained from several observation wells. Details of the laboratory tests and of geophysical logging at this site are described by Keys and Brown (1971). Finally, two recharge-basin experiments were conducted, and numerous data on infiltration rates, piezometric head, and neutron-log-based moisture content were obtained. Locations of instrumentation relative to the recharge ponds are shown in figure 7.

The site is underlain by near-surface deposits of Pleistocene and Holocene age and by the Ogallala Formation, which extends to about $55 \mathrm{~m}$ in depth. Before spreading operations were begun, the section was unsaturated to a depth of about $38 \mathrm{~m}$ below land surface. A lithologic log based on examination of drive cores obtained at one site (modified from Keys and Brown, 1971) is shown in figure 8. 

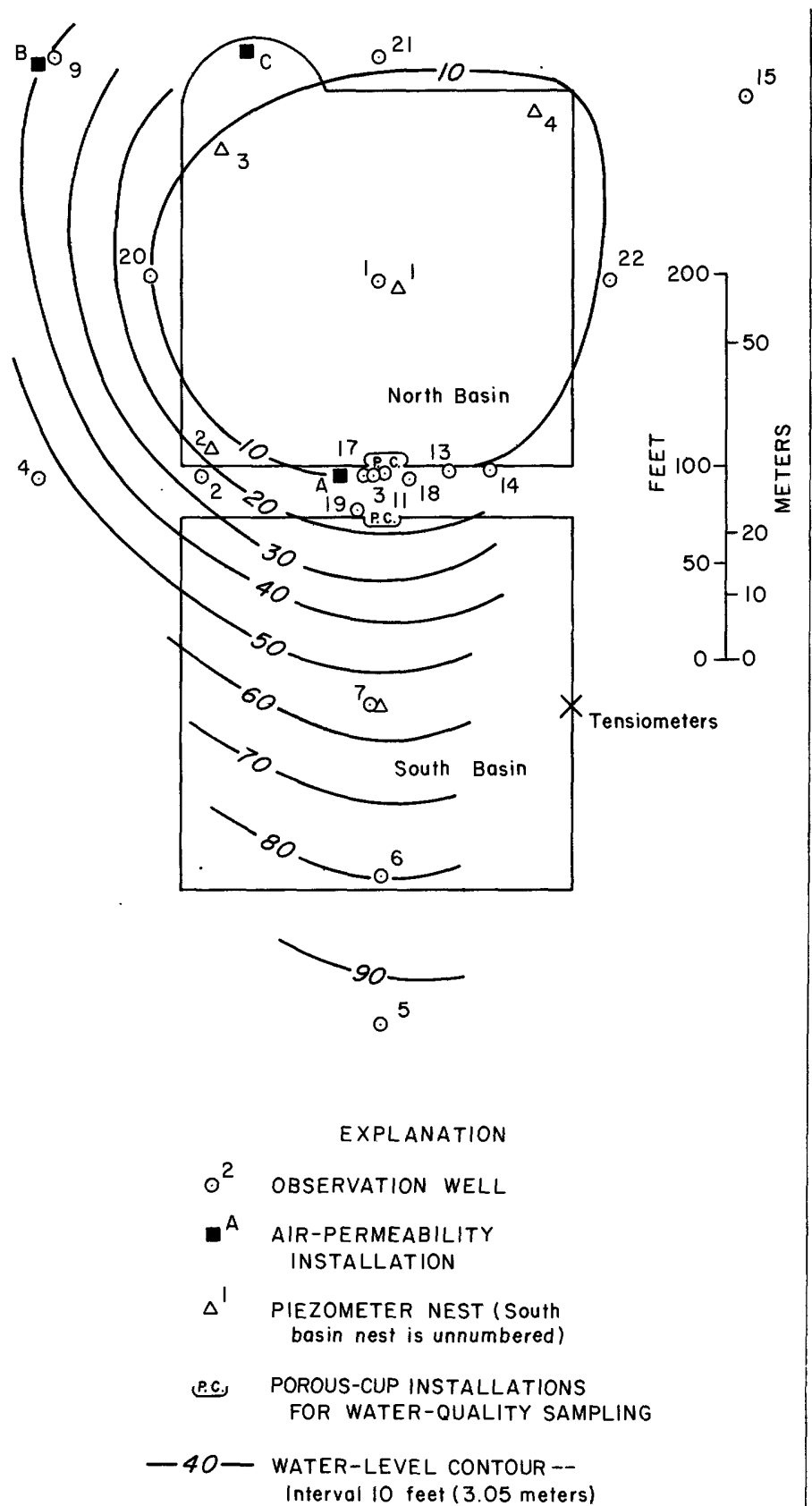

FIGURE 7. - Locations of air-permeability installations, observation wells, water-level piezometer nests, and spreading basins used in recharge experiments near the Lubbock, Tex., Regional Airport. Also shown are contours, as of July 1975, of the depth, in feet, from land surface to the top of the perched ground-water mound created by infiltration from the north basin.

Also shown is the occurrence of caliche based on the classification of Gile and others (1966).

Three installations for determining effective pneumatic diffusivity, herein labeled sites A, B, and C, (fig. 7) were each completed somewhat differently. Site A, the first installed, consisted of five piezometers (installed at depths listed in table 2) in three holes about $2.5 \mathrm{~m}$ apart on a line. These holes

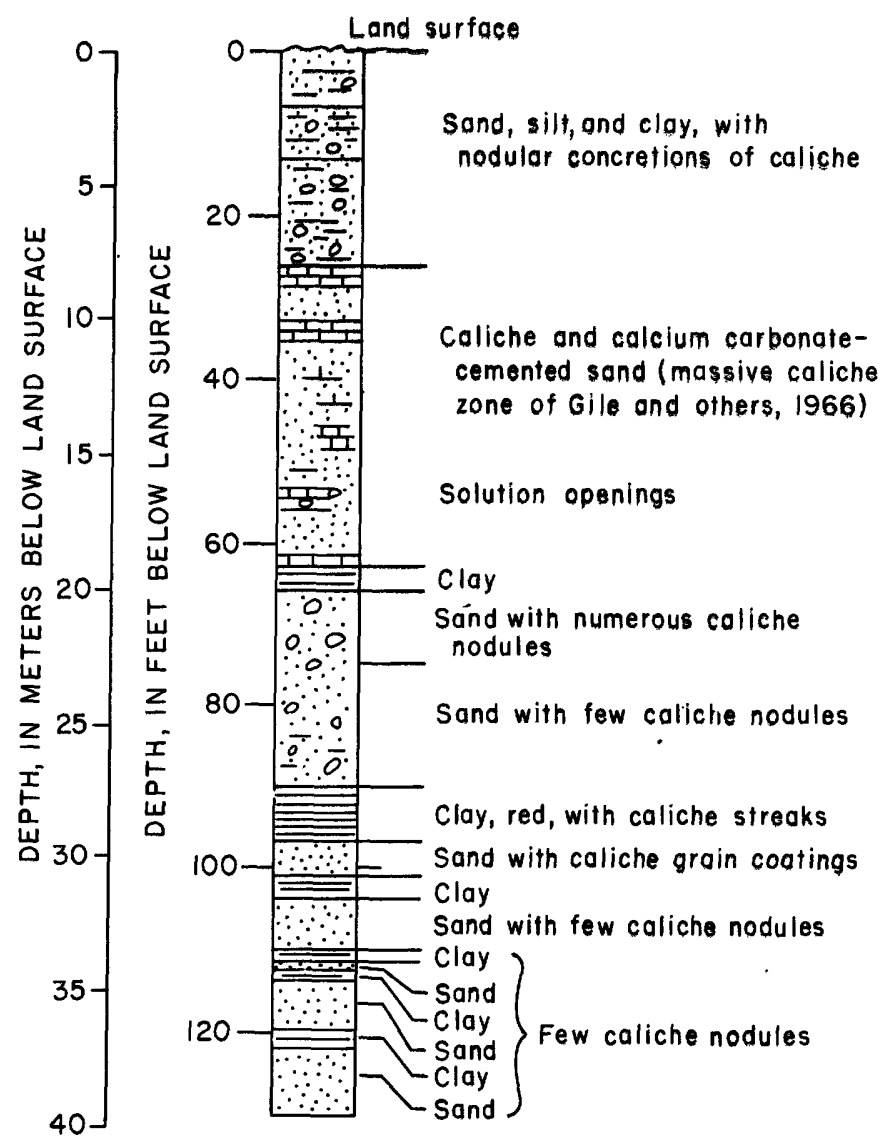

FIGURE 8. - Sample log of test well at Lubbock, Tex., airport spreading site, showing lithology and nature of caliche occurrence (modified from Keys and Brown, 1971).

were grouted with chemical grout. Readings of pressure versus time were first obtained at site A on March 7-8, 1969, during passage of a cold front that raised atmospheric pressure by about 17 millibars in a 12-hour period. Data for the period 16:00 March 7 to 03:00 March 8, 1969, were initially analyzed by use of the electric analog network to give the curve match shown in figure 3 .

Hydraulic conductivity estimates based on this analysis seemed unreasonably high, based on known values of hydraulic conductivity for the types of materials present. It

TABLE 2.-Depths of piezometers in three installations used to determine vertical air permeability at the Lubbock, Tex. airport spreading site

\begin{tabular}{cccc}
\hline & \multicolumn{3}{c}{ Depth of center of screen below land surface (meters) } \\
\cline { 2 - 4 } Piezometer No. & Site A & Site B & Site C \\
\hline 1 & 32 & 35 & 35 \\
2 & 25 & 31 & 30 \\
3 & 16 & 26 & 26 \\
4 & 10 & 22 & 22 \\
5 & 5 & 16 & 15 \\
6 & $\ldots$ & 10 & 9 \\
\hline
\end{tabular}


was originally hypothesized that the high results were obtained because a gap in the backfill in an observation well $6 \mathrm{~m}$ east of the easternmost piezometers, detected from geophysical logs (Keys and Brown, 1971, fig. 7), allowed rapid circulation of air between levels. However, results of subsequent numerical analysis of the data, listed in table 3, indicate that the problem instead resulted from the fact that the lowermost layer had been assumed to have a much lower air-filled porosity than the overlying layers. Because of the problems associated with the electric analog analysis described above, the air permeability and equivalent hydraulic conductivity values for the overlying layers were computed to be much too high. In fact, the data for this installation are in reasonable agreement with those from the other installations.

TABLE 3.-Summary of hydraulic conductivity values computed using pneumatic head data obtained from installations at the Lubbock, Tex., airport spreading site, 1969-72

\begin{tabular}{|c|c|c|c|c|c|c|}
\hline \multirow{2}{*}{$\begin{array}{l}\text { Depth' } \\
\text { interval } \\
\text { (meters) }\end{array}$} & \multirow[b]{2}{*}{${ }^{2} n_{d}$} & \multirow{2}{*}{$\begin{array}{c}\frac{\text { Site A }}{\text { March 7-8 }} \\
1969 \\
\text { (m/day) }\end{array}$} & \multicolumn{2}{|c|}{ Site B } & \multicolumn{2}{|c|}{ Site C } \\
\hline & & & $\begin{array}{c}\text { January } 14, \\
\text { 1970 } \\
\text { (m/day) }\end{array}$ & $\begin{array}{c}\text { May 17, } \\
1972 \\
(\mathrm{~m} / \text { day })\end{array}$ & $\begin{array}{c}\text { January } 15 \\
1970 \\
\text { (m/day) }\end{array}$ & $\begin{array}{c}\text { May 17, } \\
1972 \\
(\mathrm{~m} / \text { day })\end{array}$ \\
\hline $\begin{array}{r}0-10 \\
10-16 \\
16-22\end{array}$ & $\begin{array}{r}0.20 \\
.20 \\
.15\end{array}$ & $\begin{array}{r}12 \\
3\end{array}$ & $\begin{array}{l}7 \\
5 \\
3\end{array}$ & $\begin{array}{l}7 \\
3 \\
3\end{array}$ & $\begin{array}{l}6 \\
7 \\
4\end{array}$ & $\begin{array}{l}6 \\
5 \\
4\end{array}$ \\
\hline $\begin{array}{l}22-26 \\
26-30\end{array}$ & $\begin{array}{l}.21 \\
.03\end{array}$ & 2 & ${ }^{3} .2$ & 1.1 & 3 & 2 \\
\hline $30-38$ & .22 & & .2 & .1 & .2 & .1 \\
\hline
\end{tabular}

'The depth intervals are approximate, because screens were placed at somewhat different depths at each site. Exact depth intervals are shown in table 2 .

${ }^{2} n_{d}$ =air-filled porosity, dimensionless, as determined from core data and neutron logs.

'At Site $\mathrm{C}$, the screen immediately beneath the clay layer at the 30 -meter depth was plugged, so the material in the depth interval from $26-38 \mathrm{~m}$ was analyzed as a single uniform layer.

Because the data for site A were originally considered to be in error, site B was installed about $76 \mathrm{~m}$ northwest of site A (fig. 7). For this installation, six piezometers were installed in a single hole to depths shown in table 2 and the intervals between screens were grouted with chemical grout. Before pressure-time observations were obtained at site $B$, it was found that expanding cement was more effective in providing a seal in the well bore than chemical grout. Consequently, site $C$ was installed about $30 \mathrm{~m}$ east of site $B$, with six piezometers (depths listed in table 2 ) installed in a single hole and grouted with expanding cement.

Observations of pressure versus time were obtained during normal afternoon diurnal barometric declines at site B on January 14, 1970, and May 17, 1972, and at site C on January 15, 1970, and May 17, 1972. Results of the determinations are shown in table 3 . In addition, a comparison of measured versus computed pneumatic heads for the data obtained May 17, 1972, at site C is shown in figure 9. This comparison is typical of those for the airport spreading site data, and shows that the computed data match the measurements well.
The results of the analyses show that the upper layer is quite permeable to air, possibly because of root holes and desiccation cracks. However, the layer from 9 to $15 \mathrm{~m}$, which includes a massive caliche zone, is nearly as permeable. In fact, the air-permeability-determined hydraulic conductivity results for the massive caliche zone at all six sites where the Miocene Ogallala Formation was tested are similarly high. These results suggest that the commonly held belief that the massive caliche layer, or "caprock," is so nearly impermeable as to impede recharge (Cronin, 1964, p. 38-39, for example) is incorrect. Permeability of the massive caliche zone is almost undoubtedly the result of cracks, joints, and solution openings, as core examination indicates that the primary or intergranular permeability of the caliche is indeed low.

Air-permeability-based hydraulic conductivities of the materials in the two layers from 15 to 21 and 21 to $26 \mathrm{~m}$ are somewhat lower than are those of the caliche bed, but are reasonable for the materials tested.

The air-permeability-based hydraulic conductivity values for the intervals from 26 to $30 \mathrm{~m}$ and from 30 to $38 \mathrm{~m}$ are considerably higher than was anticipated. Low values were expected for these intervals because the upper interval contains a 2.4-meter-thick clay bed and the lower interval contains interbedded sand and clay beds. Cores show the clay beds to have very low hydraulic conductivities and geophysical logs indicate that the 2.4-meter-thick clay bed and some of the thinner underlying clay beds are continuous over the spreading basin area. Initially, it was assumed that the values determined by the air-permeability technique reflected a permeability to air that would be substantially reduced when the clay minerals in the clay beds swelled or disaggregated upon becoming water saturated. However, the results of subsequent recharge experiments indicate that the higher values may instead reflect the effects of cracks or fractures in the clay beds on their permeability.

\section{COMPARISON OF RESULTS FOR DIFFERENT SITES AND DATES}

Field air-permeability based hydraulic conductivities (table 3 ) are in reasonable agreement for all three sites. This agreement exists despite the desiccation and cracking of the chemical grout at sites $\mathrm{A}$ and $\mathrm{B}$, as discovered by backhoe excavation. Nonetheless, although the deterioration of the chemical grout apparently did not significantly affect the results of the tests, expanding cement would be preferred for this application as it provides greater ensurance that air circulation is not occurring through the bore hole.

Analysis of data for sites B and C obtained in January 1970 resulted in generally higher computed values of hydraulic conductivity than did the data obtained in May 1972. These differences may result from changes in moisture content in the profile, from air circulation in a nearby temporarily open test hole, or from experimental error. Although repeated neutron logs showed no measurable changes in moisture content in the immediate vicinity of sites 


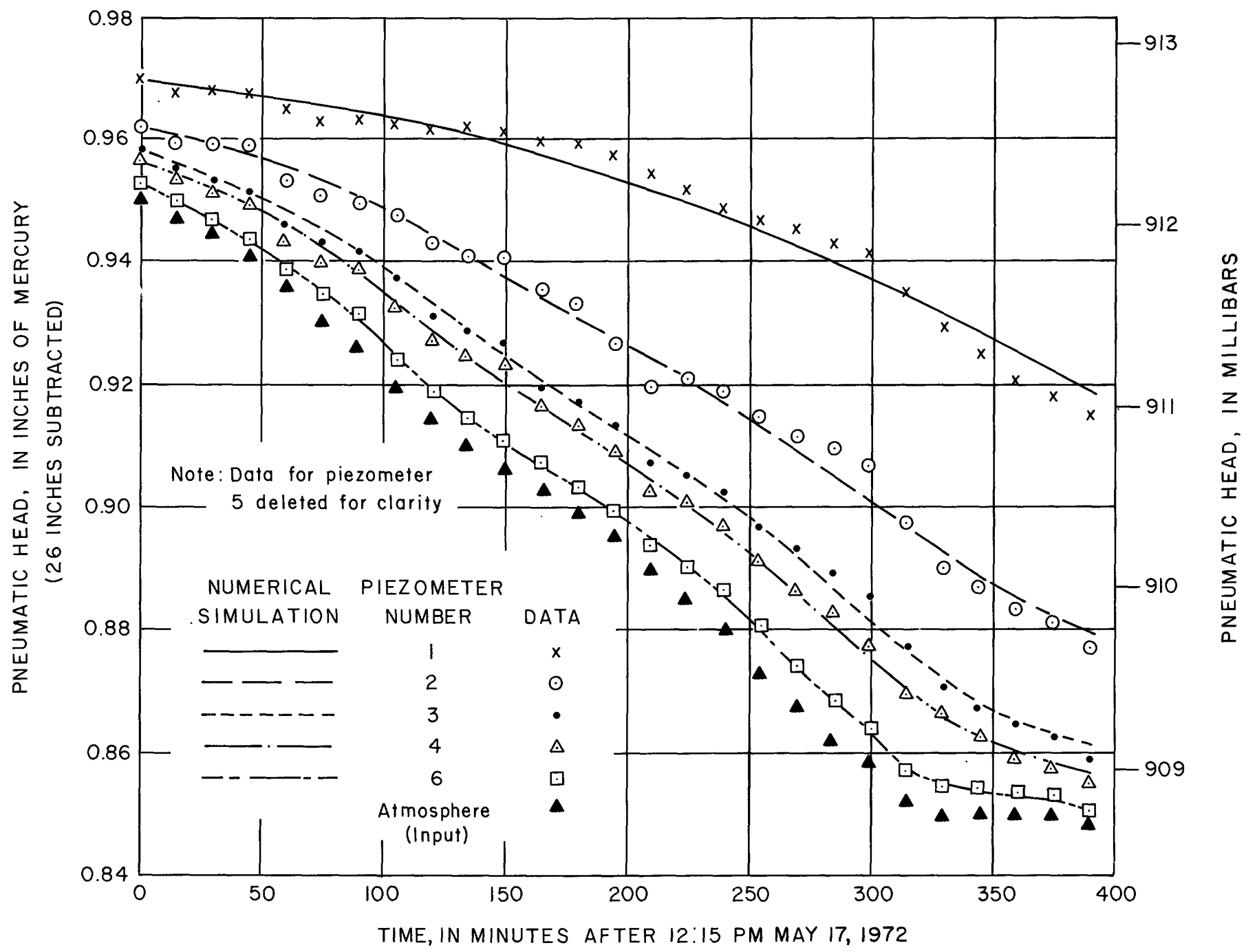

FIGURE 9. - Comparison of pneumatic heads measured May 17, 1972, at five depths at Lubbock, Tex., airport site B to best-fitting numerical simulation.

$\mathrm{B}$ and $\mathrm{C}$, a recharge test was in progress on the south basin during the time readings were obtained in 1972. Consequently, a possibility exists that the readings in May were affected by moisture changes in the general vicinity of the site. On the other hand, test drilling was in progress at the spreading basin site during January 1970 . Hence, a possibility exists that the higher values determined from the January 1970 data result from air circulation in an open test hole. Whether the differences are indeed due to moisture content changes, to circulation in an open bore hole, or to experimental error is not known, but possibly could be determined from a third set of data.

\section{COMPARISON OF RESULTS WITH RECHARGE DATA}

Two recharge experiments have been conducted at the Lubbock, Tex., site, the results of which were analyzed to evaluate the utility of the air-permeability data for predicting recharge basin performance. The first experiment was conducted from April 12, 1972, to June 11, 1973, on the 0.4 hectare pond located south of site A (fig. 7). The second experiment was conducted from April 28 to November 17, 1975 , on the 0.4 hectare pond north of site A. Both experiments were performed using water from Lake Meredith, a reservoir on the Canadian River near Amarillo, Tex. Hydraulic data collected during the experiments include inflow, pond stage, water table altitudes, and periodic neutron moisture logs at several locations, and piezometric readings of perched and semiperched ground-water mounds at six levels at each of five sites. Tensiometer data were obtained in the near-surface materials during the first test, but not the second.

The recharge-experiment data would best be analyzed by numerical simulation to include the effects of partial saturation on the movement of water from the spreading pond to the ground-water reservoir. Such an analysis, based on an approach modified from Green and others (1970), is planned. However, as these results are not yet available, saturated flow theory was used to provide estimates of the 
hydraulic conductivity of materials in various zones above the water table. Such an analysis is possible because the percolating recharge water perched almost to land surface during the test. Because piezometer data at six different levels within the perched mound were available at four sites for the second (North Basin) test, versus only one site for the first test, the analyses described below are for the North Basin test data.

Estimates of hydraulic conductivity were made for each zone bracketed by piezometers based on infiltration rate, neutron-log moisture content, and perched zone water level data collected at the end of July 1975. This period was selected because recharge had been in progress for about 90 days, allowing for much of the air that was initially entrapped in the unsaturated porous medium to be dissolved or dissipated. In addition, the infiltration rate was near its maximum at that time, and pressure heads within the perched mound were stable. Such stability is important, because storage changes within the mound are assumed negligible for the analysis.

Estimates of hydraulic conductivity from the recharge data were based on an application of Darcy's Law,

$$
K=\frac{Q}{I A}
$$

where $K$ =hydraulic conductivity, $\mathrm{m} /$ day;

$Q=$ average inflow rate to the spreading basin, $\mathrm{m}^{3} /$ day; $I=$ hydraulic gradient, $\mathrm{m} / \mathrm{m}$;

and $A=$ area of the perched mound at the top of the zone being analyzed, $\mathrm{m}^{2}$.

Because the hydraulic conductivity term includes the viscosity of water at the prevailing temperature in its formulation, the above equation is correct only for isothermal flow. To partially compensate for this, the infiltration rate was adjusted by the ratio of the dynamic viscosity at the prevailing temperature to that at $15.6^{\circ} \mathrm{C}$. With this correction, the infiltration rate at the end of July 1975 was approximately stable at about $0.9 \mathrm{~m} /$ day.

The hydraulic gradient for each zone bracketed by piezometers was computed by dividing the head difference between piezometers by the thickness of material separating them. The head gradients across a given zone showed substantial variation among the four sites, apparently because of areal heterogeneity of materials in each layer. For this analysis, the head gradient was assumed to be the average of that for the four sites.

The areal extent of the perched mound at the top of each layer was determined from neutron-log data obtained in July and early August. (The wells were not all logged at the same time). As shown in figure 7, the mound is not symmetrical about the center of the pond, and data are too sparse to accurately determine the area of mounding. However, rough estimates of the area of mounding were made by assuming radial symmetry from the center of the pond, and inter- polating mound heights along a line through wells 1 and 5 .

The results of the analyses of the piezometer and perched-mound area data are summarized and compared with the air-permeability data in table 4 . However, of the seven tabulated values, only the middle 5 were determined by the analyses described above. No formal analysis was made of the layer from 0 to $2 \mathrm{~m}$, because one of the piezometers open at the 2-meter level was dry. However, as the hydraulic gradient was near unity in the other three, it is reasonable to assume that the hydraulic conductivity of the layer is approximately equal to the infiltration rate of about 1 $\mathrm{m} /$ day. Also, no attempt was made to determine the hydraulic conductivity of the layer from 32 to $38 \mathrm{~m}$, because the perched mound at that level extended beyond the area for which neutron-log data were available. However, the hydraulic gradient across the zone was slightly steeper than that in the 26 to $32 \mathrm{~m}$ zone, indicating that hydraulic conductivity of the lower zone might be only slightly less than that in the 26 to $32 \mathrm{~m}$ zone.

TABLE 4.--Comparison of hydraulic conductivity values estimated from recharge data, from the air-permeability determinations, and from laboratory analyses of drive cores and wireline cores

\begin{tabular}{|c|c|c|c|c|c|}
\hline \multirow{4}{*}{$\begin{array}{c}\begin{array}{c}\text { Depth } \\
\text { interval } \\
(\mathrm{m})\end{array} \\
0-6\end{array}$} & \multicolumn{5}{|c|}{ Hydraulic conductivity ( $\mathrm{m} /$ day) } \\
\hline & \multirow{3}{*}{$\begin{array}{c}\begin{array}{c}\text { Recharge } \\
\text { experiment } \\
\text { data }\end{array} \\
\simeq 1\end{array}$} & \multicolumn{2}{|c|}{$\begin{array}{l}\text { Field air permeability data } \\
\text { (average for three sites) }\end{array}$} & \multirow{2}{*}{\multicolumn{2}{|c|}{$\begin{array}{l}\text { Laboratory data } \\
\text { (geometric mean) }\end{array}$}} \\
\hline & & Uncorrected & Corrected' & & \\
\hline & & \multirow[b]{2}{*}{6} & \multirow[b]{2}{*}{1.4} & 0.2 & $(4)^{2}$ \\
\hline 20 & 2 & & & 01 & (0) \\
\hline $8-17$ & 1 & 5 & .8 & .09 & (5) \\
\hline $17-21$ & 4 & 3 & .5 & .004 & (2) \\
\hline $21-26$ & 1 & 2 & .3 & .06 & (5) \\
\hline $26-32$ & .1 & .2 & .01 & .006 & (11) \\
\hline $32-38$ & $<.1$ & .2 & .02 & .02 & $(10)$ \\
\hline
\end{tabular}

I"Corrected" values have been computed using the scheme described in the text to account for the structural effects of wetting on the permeability of the materials.

${ }^{2}$ Numbers in parentheses refer to the number of sample values included in the mean

As a check of the above values, a different analysis was made of data obtained May 22-28, 1975 to determine the hydraulic conductivity of the 26-32-meter interval. This time period was chosen because saturated flow had been established through the depth interval, but the wetting front had not yet reached the water table, at least over most of the recharge area. Thus, saturated flow theory could be used to establish the hydraulic gradient, and changes in storage beneath the interval could be computed from neutron logs to provide an estimate of vertical flux.

For the analysis, the average hydraulic gradient across the 26-32-meter zone was determined for the one-week period at each of the four piezometer nests, as described above. As for the previous analysis, the gradient showed a wide range over the area (from 0.24 to $2.1 \mathrm{~m} / \mathrm{m}$ ). The arithmetic average hydraulic gradient of $1.3 \mathrm{~m} / \mathrm{m}$ was used for the analysis.

Flux through the 26-32-meter interval was estimated by determining the change in moisture content in the un- 
saturated zone from May 22 to May 28 using calibrated neutron logs for observation wells $13,20,21$, and 22 (fig. 7) and by dividing by the time interval between the logs. For the analysis, storage changes were computed in the depth interval from about $32 \mathrm{~m}$ (the approximate location of the wetting front on May 22) and the water table, which was at the 37-38-meter depth on the same date. These values of flux determined for the individual wells also showed considerable variation. They ranged from about 0.03 to $0.12 \mathrm{~m} /$ day and averaged $0.07 \mathrm{~m} /$ day.

Use of the average hydraulic gradient and average flux rate in Darcy's Law resulted in a computed hydraulic conductivity of $0.06 \mathrm{~m} /$ day. Assuming that air bubbles were trapped during the period in the pores or cracks that provide the permeability of the 26-32-meter layer it is not surprising that the estimate is somewhat lower than that for the August data.

The above recharge-experiment based values of hydraulic conductivity are very approximate, both because of assumptions made in the analyses, and because of the apparent wide areal variation in hydraulic conductivity of materials at the site. Nonetheless, the results are accurate enough to provide meaningful comparisons with the air-permeability data.

Comparison of the recharge-based and air-permeability-based hydraulic conductivities (table 4) is good for the four lower layers, but the air-permeability-based values for the 0-8- and 8-17-meter layers are about 3 to 4 times higher than those based on recharge data. The differences for the uppermost layer may be due to reduction in the intrinsic permeability of the material upon wetting. Moisture content in at least the upper part of this layer is reduced much below field capacity by evapotranspiration, providing an opportunity for desiccation cracks that would close upon wetting. In addition, root holes in the material in this zone might be open to air flow, but might be blocked to water flow by transported sediment or by swelling of clay minerals. Moreover, results from other air-permeability experiments conducted in the High Plains areas of Texas, Kansas, and Colorado all indicate $K_{e}$ values for the surface layer of the same general magnitude as those determined at the Lubbock site. However, other recharge experiments (Prill, 1976; Aronovici and others, 1972; Gillespie and Hargedine, written commun., 1976) all suggest that the surface layer hydraulic conductivity is about 1 to $3 \mathrm{~m} /$ day, in general agreement with the recharge experiment data described above. Hence, for the surface layer, hydraulic conductivities estimated by the air-permeability method appear to be consistently higher than those based on ponded infiltration tests.

The lack of agreement between the $K_{e}$ and recharge-experiment-based hydraulic conductivity values for the 8-17-meter depth is less readily explained. This zone is deep enough below land surface that soil moisture should be relatively unaffected by evapotranspiration. Moreover, the zone includes a massive caliche layer, and its permeability probably is due to secondary porosity. Such permeability is not likely to be affected by wetting of the medium. A possible explanation for the discrepancy between the air-permeability and recharge results exists in the extreme heterogeneity of the layer with respect to permeability.

\section{CORRECTION FOR STRUCTURAL ALTERATION OF} MATERIALS BY WETTING

The good agreement between the recharge experiment and air-permeability-based hydraulic conductivities for the bottom four layers was a surprise. It had been anticipated that the air-permeability-based hydraulic conductivity values would all be too high, because they did not include the effects on permeability of structural changes of the medium due to wetting. Because of these anticipated effects, a correction scheme, based on one used successfully by Reeve and Tamaddoni (1965) for an analogous problem, was tested. Basically, the scheme relies upon a laboratory investigation of the effects of wetting upon permeability. These laboratory data are used in the equation:

$$
K_{c}=K_{e} \times R K
$$

where $\quad K_{C}=$ corrected hydraulic conductivity; $K_{e}=$ hydraulic conductivity as computed from field-determined air permeability;

and $R K$ is the ratio of (1) hydraulic conductivity measured on a saturated laboratory sample to (2) the hydraulic conductivity of the sample computed from its air permeability as measured at the prevailing moisture content.

To test the correction method, both the air permeability at the prevailing moisture content and the saturated hydraulic conductivity were measured on 30 cores of the Ogallala Formation obtained at the Lubbock site and at other sites in the Southern High Plains of Texas. The results of these tests (table 5) show that the intrinsic permeability of these samples as measured with water collected from the underlying saturated part of the Ogallala Formation ranged from about $1 / 500$ th to slightly more than their intrinsic permeability as measured with air at the prevailing moisture content.

In an attempt to further generalize the correction factor, the ratio of water permeability to air permeability, $R K$, was correlated with the clay mineral content of the samples, as listed in table 5. Had the overall correction scheme been successful, the correlation equation would have provided a means to correct field-determined air permeability for the effects of wetting, based on x-ray mineralogical data from samples. The analysis resulted in the correlation equation:

$$
R K=0.3 \exp (-5.7 C M C)
$$

where $C M C$ is the quantity of expanding-lattice clay minerals of the montmorillonite group, expressed as a decimal fraction of the total mineral content. 
TABLE 5.-Laboratory data for 30 cores from the Ogallala Formation in the Southern High Plains of Texas, showing comparisons of measured hydraulic conductivity to those computed from air permeability

\begin{tabular}{|c|c|c|c|c|c|}
\hline Sample No.' & $\begin{array}{l}\text { Depth } \\
(\mathrm{m})^{2}\end{array}$ & $\begin{array}{l}\text { Air-permeability- } \\
\text { based hydraulic } \\
\text { conductivity } \\
(\mathrm{m} / \text { day })^{3}\end{array}$ & $\begin{array}{l}\text { Water-based } \\
\text { hydraulic } \\
\text { conductivity } \\
(\mathrm{m} / \text { day })^{4}\end{array}$ & $R K^{5}$ & $\begin{array}{l}\text { Clay minera } \\
\text { content }^{b}\end{array}$ \\
\hline $\begin{array}{r}70 \text { Tex } 48 \\
52 \mathrm{a} \\
52 \mathrm{~b} \\
58 \\
64\end{array}$ & $\begin{array}{l}25.5 \\
27.3 \\
27.3 \\
30.6 \\
33.7\end{array}$ & $\begin{array}{r}0.7 \\
.5 \\
.2 \\
1.4 \\
.4\end{array}$ & $\begin{array}{l}0.9 \\
.04 \\
.006 \\
.6 \\
.3\end{array}$ & $\begin{array}{l}1.3 \\
.08 \\
.03 \\
.4 \\
.8\end{array}$ & $\begin{array}{l}0.10 \\
.15 \\
.15 \\
.4 \\
.1\end{array}$ \\
\hline $\begin{array}{l}67 \mathrm{a} \\
67 \mathrm{~b} \\
71 \\
87 \mathrm{a}\end{array}$ & $\begin{array}{l}35.5 \\
35.5 \\
36.3 \\
30.0\end{array}$ & $\begin{array}{l}.01 \\
2.9 \\
7.9 \\
.6\end{array}$ & $\begin{array}{l}.00002 \\
1.2 \\
3.2 \\
.2\end{array}$ & $\begin{array}{l}.002 \\
.4 \\
.4 \\
.3\end{array}$ & $\begin{array}{l}.1 \\
.15 \\
.15 \\
.15\end{array}$ \\
\hline $87 b$ & 30.0 & 1.0 & .6 & .6 & .15 \\
\hline $\begin{array}{c}\text { Unnumbered }^{7} \\
\text { Unnumbered }^{7} \\
85 \\
88 \\
90 \mathrm{a}\end{array}$ & $\begin{array}{l}19.7 \\
31.7 \\
34.4\end{array}$ & $\begin{array}{l}.0026 \\
.0012 \\
.024 \\
.33 \\
.002\end{array}$ & $\begin{array}{l}.00026 \\
.00004 \\
.0007 \\
.03 \\
.00004\end{array}$ & $\begin{array}{l}.01 \\
.03 \\
.03 \\
.1 \\
.02\end{array}$ & $\begin{array}{l}.6 \\
.6 \\
.2 \\
.2 \\
.6\end{array}$ \\
\hline $\begin{array}{r}90 \mathrm{~b} \\
7 \mathrm{I} \mathrm{Tex} 98 \\
100 \\
102 \\
107 \\
155\end{array}$ & $\begin{array}{r}34.4 \\
1.7 \\
6.7 \\
9.1 \\
26.7 \\
19.2\end{array}$ & $\begin{array}{l}.03 \\
.034 \\
2.1 \\
.5 \\
7.6 \\
.07\end{array}$ & $\begin{array}{l}.0003 \\
.0001 \\
.02 \\
.016 \\
5.3 \\
.013\end{array}$ & $\begin{array}{l}.01 \\
.003 \\
.01 \\
.03 \\
.8 \\
.2\end{array}$ & $\begin{array}{l}.6 \\
.40 \\
.15 \\
.10 \\
.00 \\
.15\end{array}$ \\
\hline $\begin{array}{l}156 \\
157 \\
158 \\
159 \\
170\end{array}$ & $\begin{array}{l}22.7 \\
24.4 \\
30.0 \\
32.0 \\
20.0\end{array}$ & $\begin{array}{l}4.0 \\
1.7 \\
.002 \\
.02 \\
.1\end{array}$ & $\begin{array}{l}1.7 \\
.09 \\
.0002 \\
.015 \\
.0002\end{array}$ & $\begin{array}{l}.4 \\
.05 \\
.1 \\
.7 \\
.002\end{array}$ & $\begin{array}{l}.10 \\
.25 \\
.40 \\
.15 \\
.50\end{array}$ \\
\hline $\begin{array}{l}171 \\
172 \\
173 \\
174\end{array}$ & $\begin{array}{l}22.6 \\
24.2 \\
28.5 \\
29.9\end{array}$ & $\begin{array}{l}6.4 \\
2.4 \\
1.2 \\
.16\end{array}$ & $\begin{array}{l}1.3 \\
.2 \\
.04 \\
.0008\end{array}$ & $\begin{array}{l}.2 \\
.08 \\
.03 \\
.005\end{array}$ & $\begin{array}{l}.10 \\
.25 \\
.20 \\
.40\end{array}$ \\
\hline
\end{tabular}

'Sample numbers are those of the Hydrologic Laboratory, U.S. Geological Survey, Lakewood, Colo. Samples in the 70 Tex series were obtained at the Lubbock Airport Spreading Site, those numbered 71 Tex 98-107 are from a site near Caprock, Tex., and those numbered 71 Tex 155-174 are from a site near Stanton, Tex.

2Depth is to the top of the 0.15 -meter drive core from which the sample was taken for analysis. A lowercase a or $b$ after the sample number indicates that two samples were analyzed from that core.

${ }^{3}$ As measured at the prevailing moisture content.

AS measured at the prevailing moisture content.
${ }^{4}$ Samples from the Lubbock and Caprock sites were tested using water from a well tapping the Ogallala Formation at the Lubbock Airport site, and those from the Stanton site were tested using water from a well near that site.

water from a well near that site.
${ }^{R} R K$ is the ratio of hydraulic conductivity as determined by the air-permeability measurments to that meared using water, and is the same as the ratio of intrinsic permeability that would be determined by use of the two fluids.

determined by use of the two fluids. determined by Barbara Anderson of the Hydrologic Laboratory, U.S. Geological Survey, Lakewood Colo.

TThese samples are both from the clay bed at approximately $27 \mathrm{~m}$ in depth at the Lubbock Airport Spreading Site.

The correlation coefficient for this analysis is 0.54 , indicating that, although the correlation is significant at the 1 percent level (Crow and others, p. 240), only about 30 percent of the variation in the ratio $R K$ can be accounted for by variations in clay mineral content. This correlation is poorer than that determined by Reeve and others (1954, p. 132) for the correlation of the ratio of air- to distilled-water permeability with exchangeable sodium and cation-exchange capacity, probably in part because clay chemistry was not considered in this analysis, and in part because the clay-mineral contents are approximate.

Corrected values for hydraulic conductivity were computed for each of the six intervals for which air-permeability values were determined, based on a combination of equations 7 and 8 :

$$
K_{c}=K_{e} \times 0.3 \exp (-5.7 C M C)
$$

To apply equation 9 , the arithmetic average clay content was determined from data on all of the samples collected and tested from a given layer. This average value was used to represent $C M C$ in the equation. Use of the arithmetic average was arbitrary, and may not be completely appropriate because it assigns too little weight to the effects of wetting on the discrete clay layers within each interval. However, the worth of the correction for the effects of wetting would be questionable no matter what averaging scheme was used.

Results of applying equation 9 to compute corrected hydraulic conductivities are listed in table 4 . The results appear reasonable for the top two layers, but not for the bottom four layers. Moreover, the apparent agreement between the corrected air-permeability results and the recharge-based hydraulic conductivity for the surface layer may be fortuitous. The surface layer probably is indeed more sensitive to the effects of wetting than the deeper layers, as described above. However, the laboratory-based correction factor was determined on samples mainly collected at depth, and thus is not necessarily relevant for the surface layer data. Agreement of the corrected air-permeability-based hydraulic conductivity with the recharge-based value for the 8-15-meter layer also seems fortuitous, as the massive caliche in this zone should not be structurally affected by wetting.

Failure of the correction scheme to improve the air-permeability-based hydraulic conductivity estimates for the bottom four layers may result from flow occurring through secondary porosity features, such as cracks and joints, rather than through the intergranular porosity. Thus the laboratory results, which include effects of wetting on permeability related to intergranular porosity only, might not be relevant.

Additional experience with the air-permeability technique will be needed to reconcile whether, or under what conditions, a correction for the effects of wetting is warranted for layers at depth. On the other hand, sufficient experience has been gained to indicate that $K_{e}$ values of the near-surface materials generally would need to be corrected for the effects of wetting. Such a correction could be practically developed if the ratio of air-permeability-based to recharge-based hydraulic conductivity could be correlated with some readily measurable property of the near-surface materials.

\section{COMPARISON OF RESULTS WITH LABORATORY DATA}

As described above, a number of sequential laboratory analyses of air permeability at the prevailing moisture 
content and of hydraulic conductivity were made to assess the effects of wetting on permeability, as tabulated in table 5. In addition, hydraulic conductivity only was measured on many more cores obtained from the Lubbock Airport site to provide an independent assessment of the recharge potential at the site. The results of these laboratory analyses are compared with the field air-permeability and recharge-experiment results in table 4 .

In general, the field-determined $K_{e}$ values are somewhat larger than the laboratory values of hydraulic conductivity based on their air permeability at the prevailing moisture content. For example, in the 21-26-meter layer, the field-determined air-permeability-based hydraulic conductivity for the May 1972 data is about 4 times higher than the geometric mean of the laboratory values determined from drive-core samples of this unit. Comparison of hydraulic conductivity values for the 30-38-meter layer indicates that the geometric mean of the laboratory data is about the same as the air-permeability based hydraulic conductivity. However, this layer is much more strongly stratified than the 21-26-meter layer, and consists of alternating thin beds of relatively clean sand and of clay. Under these conditions, the harmonic mean of the laboratory values may represent the hydraulic conductivity of the layer as a whole more adequately than the geometric or arithmetic means (Terzaghi, 1943, p. 243-244). The harmonic mean of the sample hydraulic conductivities, assuming that each sample represents a bed of equal thickness, is about one-fifth to one-tenth the air-permeability-based hydraulic conductivity. Laboratory air-permeability data are available for too few samples to compute averages for the other layers for which field data are available. However, the laboratory values for samples within these layers are somewhat less than the field values.

These comparisons indicate that the air permeability values determined in the field are several times higher than those determined in the laboratory. These differences are not surprising, because of the inevitable compaction of drive-core samples during coring operations; and because of the small sample size of the core, which may miss secondary permeability features. In fact, if such features had appeared in a core, they probably would have been attributed to disturbance by coring, and the core would not have been analyzed.

The geometric mean of laboratory hydraulic conductivity values from drive cores obtained in each zone are also shown in table 4 to provide a comparison between the air permeability method and laboratory methods for estimating hydraulic conductivity. The laboratory values were obtained on drive cores from wells 3 and 11 by the U.S. Geological Survey Hydrologic Laboratory, Lakewood, Colo. Part of the analyses were made with Lakewood tap water, and part with Canadian River Aqueduct water. However, subsequent experiments by the author indicate that the hydraulic conductivity values should be the same using water from either source.

The laboratory-based values are all substantially smaller than those based on either the air-permeability-data or the recharge-data values, probably in part because of compaction of the samples during coring, and in part because effects of secondary permeability are not represented in the laboratory samples. The laboratory values are so much lower than those determined from the recharge experiment that their use in predicting recharge pond performance would be seriously misleading.

\section{DISCUSSION OF RESULTS}

The comparisons made among the various data obtained at the Lubbock Airport site indicate that the results of the air-permeability method are repeatable, and that the method can provide useful data for predicting the performance of recharge basins. The comparisons also indicate that the permeability of materials at depth is not affected by wetting nearly to the extent anticipated. Although the lack of permeability sensitivity may not be general, the results of these tests are encouraging that the method can be a useful tool for assessing the hydraulic conductivity in the unsaturated zone, particularly if the method is used in conjuction with other methods to evaluate the hydraulic conductivity of near-surface materials.

\section{LONG ISLAND, NEW YORK}

A test of the method was made on Long Island, N.Y., to evaluate its applicability to determine hydraulic conductivities in a humid region, where residual moisture content in the unsaturated zone might be high. The test, which included two installations, was made at a spreading basin (Nassau County Recharge Basin 306) for which much information on lithology, infiltration, and deep percolation was available (Prill and Aaronson, 1973). Materials in the unsaturated zone at this site (fig. 10) are glacial in origin, and include two

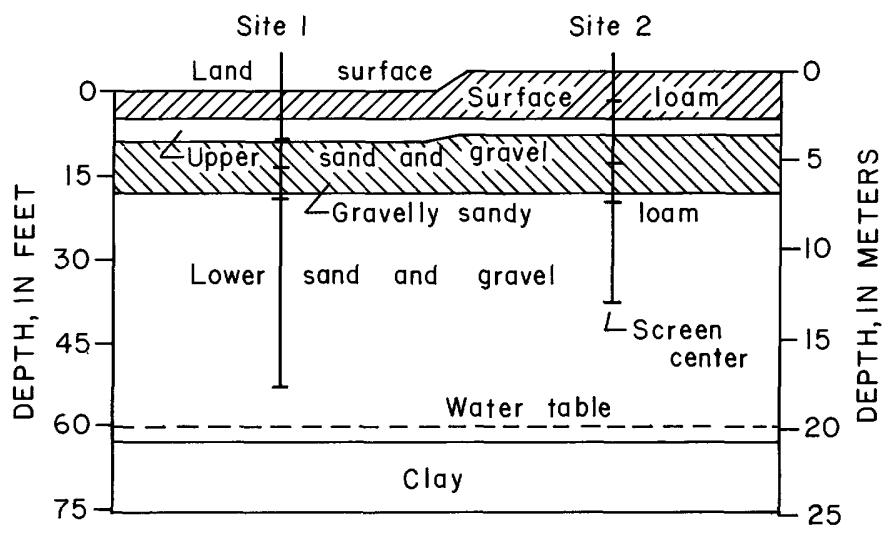

FIGURE 10. Cross-section showing assumed uniform layers of unsaturated materials at Nassau County, Long Island Recharge Basin 306 (modified from Prill and Aaronson, 1973, fig. 2). Not to horizontal scale. 
layers of sand and gravel that are separated by a gravelly sandy loam and are overlain by a surface loam.

The first installation (site 1) for determining air permeability, which consisted of four piezometers, was made in the basin in June 1971. Readings were obtained on July 1, 1971 , during an afternoon diurnal pressure change of about 3 millibars. These observations were made at a time when moisture content of the unsaturated materials was relatively low, as there had been only $50 \mathrm{~mm}$ of rain in June and no storm runoff had collected in the basin during that month. Moreover, very little storm runoff had collected in the basin during the previous April and May.

Data from the installation were initially analyzed by electric analog to determine air permeability and the equivalent hydraulic conductivity for four layers, including the lower sand and gravel, two layers differentiated on the basis of moisture content in the gravelly sandy loam, and a layer consisting of the surface loam and upper sand and gravel combined. The results of this initial analysis were greatly in error. In addition to the erroneous handling of the effects of variations in air-filled porosity between layers, as noted previously, initial conditions were inadequately represented for these data. Substantial differences in pneumatic head between depths occurred at the start of this test, but the analog system was designed only to handle initial conditions of constant pneumatic head with depth. An attempt was made to overcome this problem by manipulation of the input head readings, but the subsequent digital similation indicates that the attempt was not successful. Because of these problems, it was concluded that data from the site had given values for hydraulic conductivity that were much too low, and that only a poor match had been obtained.

Subsequent numerical analysis of this set of data resulted in hydraulic conductivity values (table 6) that are quite plausible, and the match of computed to measured pneumatic head data (fig. 11) is quite good. Moreover, the $K_{e}$ value for the lower part of the sandy gravelly loam agrees favorably with the hydraulic conductivity value of 0.03 $\mathrm{m} /$ day determined for this layer by Prill and Aaronson $(1973$, p. 741$)$ from infiltration data. However, the $K_{e}$ value of $0.06 \mathrm{~m} /$ day for the $0-1.2-$ meter layer is about five times smaller than their infiltration-based value of $0.3 \mathrm{~m} /$ day for this layer.

Because it had been assumed that erroneously low results had been obtained for the installation inside the pit, the second installation was made outside and about $3 \mathrm{~m}$ from the edge of the pit. It was assumed that the materials underlying the area outside the pit would be much better drained than those beneath the pit, because they would not receive deep percolation from ponded infiltration.

Data were obtained at this site (site 2 in table 6 ) on June 29,1972 , during an afternoon diurnal barometric change of 1.8 millibars. The data for this test are poor, because only very small pneumatic head differences with depth occurred,
TABLE 6.-Summary of analyses of pneumatic head data obtained from installations at the Nassau County, Long Island Recharge Basin 306

[ $K_{e}$, air permeability based hydraulic conductivity, $m /$ day: $n_{d}$, effective air-filled porosity, dimensionless]

\begin{tabular}{cccccccc}
\hline \multirow{2}{*}{$\begin{array}{c}\text { Nature of } \\
\text { materials in } \\
\text { layer }\end{array}$} & \multicolumn{3}{c}{ Site 1 } & \multicolumn{4}{c}{ Site 2 } \\
\cline { 2 - 8 } & $\begin{array}{c}\text { Depth interval } \\
(\mathrm{m})\end{array}$ & $\kappa_{e}$ & $n_{d}$ & $\begin{array}{c}\text { Depth interval } \\
(\mathrm{m})\end{array}$ & $K_{e}$ & $n_{d}$ \\
\hline $\begin{array}{c}\text { Surface loam .... } \\
\text { Upper gravelly }\end{array}$ & $10-1.4$ & 0.1 & 0.15 & $0-1.7$ & 11 & 0.2 \\
$\quad$ sandy loam. & $1.4-7$ & .9 & .1 & $21.7-4.7$ & 8 & .1 \\
$\begin{array}{c}\text { Lower gavelly } \\
\text { sandy loam. }\end{array}$ & $3.7-5.2$ & .03 & .05 & $4.7-6.4$ & 1.2 & .05 \\
$\begin{array}{c}\text { Lower sand and } \\
\text { gravel. }\end{array}$ & $5.2-17.7$ & 14 & .2 & $6.4-20.7$ & 62 & .2 \\
\hline
\end{tabular}

This layer includes $1.2 \mathrm{~m}$ of surface loam overlying $1.2 \mathrm{~m}$ of sand and gravel.

${ }_{2}^{2}$ This layer includes a layer of sand and gravel extending from 1.7 to $3.0 \mathrm{~m}$.

and these differences were of the same magnitude as wind-induced "noise" in the manometer readings. Nonetheless, results of analysis of these data probably are of the correct magnitude. Hydraulic conductivity values determined from the air-permeability data (table 6) range from about 6 to about 200 times larger than those determined inside the pit. Moreover, the values for the two less permeable layers do not agree at all well with the infiltration-based values of Prill and Aaronson (1973, p. 740-741).

In addition to the field air permeability values determined for the two sites, air-permeability values were also determined in the laboratory on five drive-core samples obtained from the 3.7-5.2-meter depth at site 1 . These samples, which were all from the lower gravelly sandy loam layer, had an average air permeability at their prevailing moisture content of about 0.3 darcies, equivalent to a hydraulic conductivity at $15.6^{\circ} \mathrm{C}$ of $0.24 \mathrm{~m} / \mathrm{day}$. This value is about five times greater than that determined from the field data for site 1 , and about five times less than that for site 2. However, Prill (oral communication, 1971) found that laboratory hydraulic conductivities obtained on samples from the pit were much greater than the values suggested by the infiltration data. $\mathrm{He}$ hypothesized that many of the samples were disturbed during the drive-coring operation. If this were the case for the samples analyzed here, the results would tend to verify the field air-permeability values for site 1 .

The differences in the air-permeability-based hydraulic conductivities for the two installations might be explained in several different ways. For example, it could be hypothesized that high residual moisture content of materials within the pit resulted in their having a low air permeability, whereas those outside the pit reflect the air permeability at field moisture capacity. For this explanation to be plausible, it must also be hypothesized that the surface loam and lower gravelly sandy loam are sensitive to the effects of wetting, with the permeability of these materials to air at field moisture capacity being 30 to 40 times greater than their 


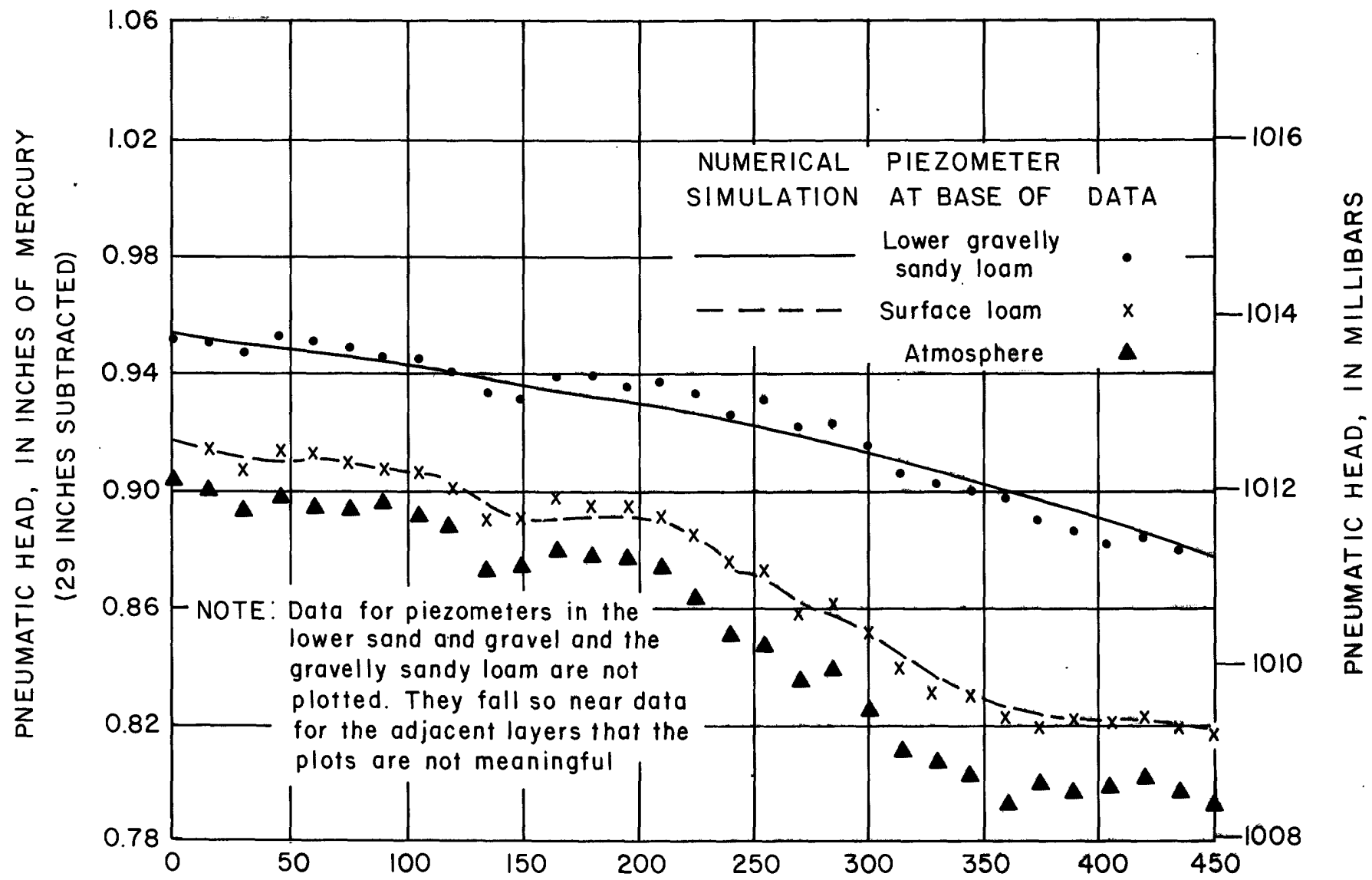

TIME, IN MINUTES, SINCE 10:00 AM JULY I, 1971

Figure 11. - Comparison of pneumatic heads measured July 1, 1971, at two depths at an installation inside Recharge Basin 306, Nassau County, Long Island, N. Y., to the best-fitting numerical simulation.

intrinsic permeability as determined from analysis of infiltration of storm runoff water. Based on these hypotheses, the apparent agreement between air-permeability-based and infiltration-based intrinsic permeabilities for site 1 is fortuitous. Alternatively, it could be hypothesized that the different results for the two sites are due to areal heterogeneity of the materials with respect to air permeability. Still another explanation might be that the hydraulic conductivity of the materials in the basin has been reduced by suspended sediment and suspended or dissolved organic matter in the infiltrating storm runoff. In conclusion, however, it is not known which, if any, of these explanations is true, and the results of the Long Island test remain ambiguous. Additional tests are needed to evaluate the worth of the air-permeability method in humid regions, where high residual moisture content is difficult to avoid.

\section{SUMMARY AND CONCLUSIONS}

A method has been described for determining the vertical permeability to air (referred to as "air permeability") of layers of material in the unsaturated zone, based on observations of the rate of change in pneumatic head at depth following a change in barometric pressure at land surface. These pneumatic head changes arise as the soil air compresses or expands in response to the surface pressure change, and the compression or expansion is slowed by the resistance to flow imposed by the medium.

Data collection and analysis for the method are relatively straightforward. Pneumatic head data may be obtained from nested piezometers in a single hole, and may be read fairly simply with an inclined manometer connected to the piezometers during a normal afternoon diurnal barometric change. Because the mathematical description of flow in layered media is complicated, data analysis is best accomplished by analog or by numerical simulation using the included digital computer program.

Hydraulic conductivity, rather than air permeability, is generally the parameter of interest to hydrologists. Air permeability values determined by the described method may be used to estimate the hydraulic conductivity of materials in the unsaturated zone under certain conditions. For example, if all the materials in the unsaturated zone are 
at or below field moisture capacity, are permeable enough that the Klinkenberg effect is small, and are structurally unaffected by wetting, the method should provide reliable estimates of vertical hydraulic conductivity.

The method was tested at several field sites, including three that are described in detail in this report. The complexity of the field sites relative to the information desired varied among the three sites, and this complexity affected the relative success of the method.

For the first test described, the method was used to determine the vertical permeability to air of playa sediments overlying basalt in Idaho. This information was needed to determine the feasibility of temporarily storing radioactive gas generated in a planned "loss of fluids" test of a nuclear reactor. The values determined are a few times larger than laboratory values and a few times lower than values determined by analysis of data obtained by injecting air into auger holes. The results of this method probably are more accurate than those of the other two because of compaction of the samples during the coring process and because horizontal as well as vertical flow occurred during the air injection tests. The results of the test indicate that the method is a straightforward one for determining vertical air permeability, and generally could be used with confidence to determine that parameter.

For the second test described, the method was used to estimate the hydraulic conductivity of materials at an experimental artificial recharge site near Lubbock, Texas. This site is in a semiarid area, and soil moisture is at or below field capacity to a depth just above the water table. However, the formation includes several clay beds that contain significant quantities of expandable-lattice (swelling) clay minerals. Hence, parts of the formation might be sensitive to the effects of wetting on its intrinsic permeability.

Data from different installations and from the same installation on different dates are in general agreement, indicating repeatability of the tests. In addition, hydraulic conductivity values determined from the air-permeability data are in good agreement with values based on recharge-experiment data for the lower four of six levels tested, despite the presence of swelling clay minerals. In fact, a scheme to correct for the effects of wetting failed to improve the values for this site. Air-based values for the top two layers were both a few times larger than the hydraulic conductivity values based on recharge data for the same depth intervals. The results for the top layer, but not the second layer, appear to be general for the tests run in areas where the residual soil moisture content is low, and may be due to the effects of wetting on the structure of the near-surface materials.

The third test described was made to estimate the vertical hydraulic conductivity of materials at an experimental recharge facility on Long Island, N.Y., which has a humid climate. The potential exists at this site both for problems due to the effects of high residual moisture content in the soil and to the effects on permeability of swelling clay contained in the materials in the unsaturated zone. Tests at two installations at this site, one within the spreading basin, and one outside but near the basin rim, showed substantially different results. Hydraulic conductivity estimates obtained from the installation inside the basin showed good agreement with hydraulic conductivity values determined from recharge data. However, analysis of data from the installation outside the basin resulted in hydraulic conductivity estimates from 6 to 200 times higher than those obtained inside the basin. The good agreement between air-based hydraulic conductivity values for the basin installation and recharge-based values coupled with the lack of agreement between air-permeability installations make the results of the test inconclusive. Additional tests will be necessary to assess the worth of the method to determine hydraulic conductivity in regions of high residual moisture content.

An added perspective on the worth of the air-permeability method may be obtained by considering the techniques currently available for determining hydraulic conductivity in the unsaturated zone. For most prediction problems, an average vertical hydraulic conductivity value is needed over some significant area, such as the areal extent of a recharge mound, or the area beneath a feedlot or sanitary landfill. However, current techniques, such as laboratory core analysis, infiltrometer techniques (Bouwer, 1961), or the dry auger hole method of Boersma (1965), all measure the hydraulic conductivity of relatively small samples of material. Consequently, a great many samples or tests would be necessary to approximate the average hydraulic conductivity of a heterogeneous layer or of a layer in which secondary permeability is predominant. Moreover, the hazard of compacting or disturbing the tested materials by current techniques is high, resulting in the possibility that the hydraulic conductivity determinations will be biased. Consequently, the air-permeability method offers promise in providing useful hydraulic conductivity data at relatively low cost, despite potential problems of high residual moisture content and of structural alteration of the medium upon wetting.

A final note of caution is needed in regard to determining the air permeability of relatively thin, highly permeable materials. Where the depth to water is not more than a few meters, and the materials in the unsaturated zone have a permeability of a few darcies or more, pressure differences would generally be too small to be measured by equipment described here. Although more sensitive measuring equipment could be used, short-term erratic atmospheric pressure variations that could be characterized as "noise" would be of similar magnitude, and the "signal," or desired pressure difference, would be difficult to determine.

In conclusion, a relatively simple and reliable field method to determine the vertical air permeability of layered materials in the unsaturated zone has been developed and tested. The method may also be used to estimate the 
hydraulic conductivity of well-drained materials at depth in the unsaturated zone under certain conditions. Thus, the method is potentially useful for a number of hydrologic applications, such as evaluation of spreading sites for artificial recharge, of ground-water pollution hazards from feedlots or sanitary landfills, or of sites for temporary storage of gas in the unsaturated zone. However, applicability of the method to estimate hydraulic conductivity of materials at depth that may not be well drained must be determined through additional testing.

\section{AIRK - A FORTRAN IV PROGRAM FOR COMPUTING HYDRAULIC CONDUCTIVITY FROM PNEUMATIC HEAD READINGS}

As described above, the AIRK program takes data acquired at the site, including screen depths and depth to the water table, estimates of air-filled porosity and preliminary estimates of $P D_{e}$-based hydraulic conductivity, and periodic microbarograph and differential manometer readings and computes final estimates of air-permeability based hydraulic conductivity for each layer into which the unsaturated zone has been divided. These hydraulic conductivity values are determined by converting the preliminary estimates of hydraulic conductivity to air permeability, computing pneumatic heads by numerical solution of the equation for one-dimensional flow of gas through a porous medium (equation 3), and comparing the computed heads to those measured at the appropriate screen. Based on this comparison, a new trial value for air permeability is determined and new pneumatic head values computed. This process is repeated until the computed and measured heads are suitably close.

An important procedure in making the trial-and-error selections of air permeability is to perform the computations by adding one layer at a time, starting with the layer at greatest depth. By using this procedure, the only unknown to be solved for in a given series of simulations is the air permeability of the last layer added. This overall stepwise procedure represents the basic function of the AIRK program. This procedure is discussed below, followed by a detailed discussion of some of the program elements that support its basic function. The following discussion is somewhat inexact in regard to the actual program sequence, but instead emphasizes the logic used in the program.

The stepwise procedure of numerically solving equation 3 to provide hydraulic conductivity values for a three-layer system is illustrated in figure 12. At the start of the simulation, the unsaturated zone is divided into JMAX-1 equal increments or nodes, and the faces of these nodes are numbered from 1 to JMAX, starting at land surface. The nodal position of each screen, assumed to represent the location of the layer boundary, is noted and stored as
JSD(NL) in statement 96 . NL represents the screen number, as counted from the bottom, and land surface is designated as JSD (number of screens plus 1).

In the first sequence of simulations, a uniform trial air permeability, based on a user-supplied hydraulic conductivity estimate, a uniform air-filled porosity value, and an interpolated initial head value are assigned to each node from JSD(2)+1 to JMAX in statements 138-163 (see program listing). These nodes are used to simulate layer 1 , as shown by nodal configuration $A$ in figure 12. Pneumatic head values for each time step, as interpolated from those measured at screen 2, are assigned to node $\operatorname{JSD}(2)$. Based on these head values, the trial air permeability value, and the air-filled porosity, pneumatic head is computed for each time step at each underlying node. The head values computed for node $\operatorname{JSD}(1)$ are compared to those interpolated from the measurements for screen 1. Based on this comparison, a new larger or smaller trial air permeability value, as appropriate, is assigned to each node. The logic used in the program to select the new trial permeability value is described in the section on the automatic search procedure.

Once a new trial permeability value is selected, initial head conditions are reestablished, and head values at each node are again computed. Computed head at node $\operatorname{JSD}(1)$ is again compared to the measured head at screen 1 , and a new trial air permeability selected. This process is repeated until the sum, for all the time increments, of the differences between computed and measured pneumatic head values has been minimized. The air permeability value that produces this minimum difference then remains assigned to each of the nodes from JSD(1)+1 to JMAX for the remainder of the ànalysis.

Once a satisfactory simulation of air movement in the bottom layer has been made, the user-supplied trial air permeability value for layer 2 is assigned to each node from JSD(3)+1 to JSD(2) (nodal configuration B in fig. 12) along with the air-filled porosity for that layer. Initial head values are assigned to each node from JSD(3)+1 to JMAX, and pneumatic head values interpolated from measurements for screen 3 for each time step are assigned to node $\operatorname{JSD}(3)$. Pneumatic heads are computed at each node for each time step, based on the trial air permeability value for layer 2 and the established air permeability for layer 1 . Computed heads at node $\operatorname{JSD}(2)$ are compared to head values interpolated from those measured in screen 2 , and a new trial air permeability value for layer 2 is determined from this comparison. The new trial air permeability is assigned to nodes $\operatorname{JSD}(3)+1$ to $\operatorname{JSD}(2)$, and initial head values are reestablished for the entire system below node $\operatorname{JSD}(3)$. Heads are again computed, and those for node $\operatorname{JSD}(2)$ are compared to those for screen 2 to arrive at a new adjusted air permeability value. This whole process is repeated until an air permeability value is selected for layer 2 through the search procedure. At that point, the selected air permeability 


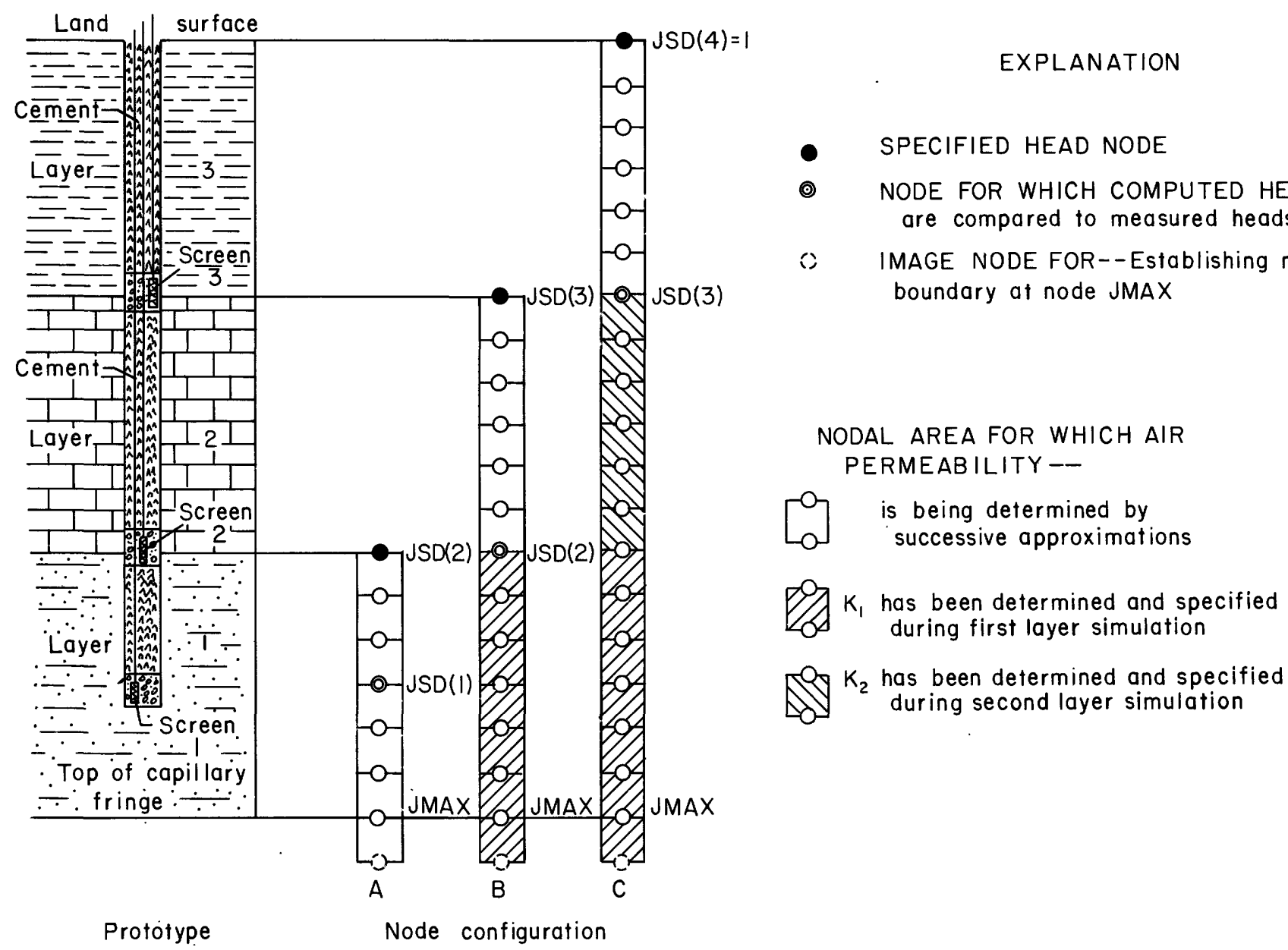

FIGURE 12. - Sketch showing the relationship between a hypothetical air-permeability installation at a site including three layers in the unsaturated zone and the nodal configurations used to solve for the air permeability of each layer. Nodal configurations A, B, and C represent those used to determine the permeability of layers 1,2 , and 3, respectively.

value remains assigned to each node from $\operatorname{JSD}(3)+1$ to $\mathrm{JSD}(2)$ for the remainder of the analysis.

Once an air permeability value for the second layer is selected and assigned to the appropriate nodes, a new layer is added for analysis, as shown by nodal configuration $\mathrm{C}$ in figure 12. For the example shown, this is the uppermost layer. The user-supplied trial air permeability value for layer 3 is assigned to nodes 2 to $\operatorname{JSD}(3)$, initial head values interpolated for the entire column are assigned to each node, and pneumatic head values interpolated from the microbarograph or altimeter record for each time step are assigned to node 1 . Pneumatic heads are computed for each node, and those computed for node $\operatorname{JSD}(3)$ are compared to the measured values for screen 3 . This comparison is, as above, used to repeatedly adjust the trial air permeability value until a satisfactory value is obtained.

At this point in the computer program, a complete simulation is made using the selected air permeability values for each layer, and pneumatic heads computed for each screen position during the simulation are printed out.
Comparison of the data for the final simulation to the measured pneumatic heads provides a means of assessing the overall adequacy of the analysis.

The final step of the program is to tabulate the hydraulic conductivity values computed from the selected air permeability values for each layer, along with appropriate information on the conditions of the test. (See "Sample output data.")

The above discussion describes the overall function and operation of the program. However, three of the procedures used in accomplishing this function are described in more detail below. These include the methods used to (1) synthesize head data from the supplied barometer and manometer readings, (2) numerically solve equation 3 for given values of air permeability and air-filled porosity, and (3) to select the most appropriate hydraulic conductivity value for each layer through the search procedure. Input data requirements are described in detail in a following section, as is the program output. Mnemonics used in the 
program are tabulated, the program is listed, and sample output data are presented.

\section{COMPUTATION OF PNEUMATIC HEAD VALUES}

For the method as described, pneumatic head values are read sequentially at somewhat irregular time intervals at a few points in the unsaturated zone profile. However, the computer program requires pneumatic head values at simultaneous short equal time intervals, and also requires, for initial conditions, that the pneumatic head be described at each node at the start of the test. Consequently, the barometric and differential manometer readings must be interpolated in time to produce simultaneous values of pneumatic head, and the initial readings must be interpolated in space. The first step in establishing a table defining pneumatic head versus time at each screen is that of interpolating pneumatic head at land surface from the microbarograph or altimeter records. This table is formulated by statements $60-72$ by linear interpolation of supplied values of microbarograph readings versus time, as read in card series 9 . If altimeter readings were obtained, rather than microbarograph records, they must be converted by the user to equivalent microbarograph readings before they are read into the program.

Pneumatic head values for each screen are determined in program steps 73-94 by converting the differential manometer readings, read in inches of manometer fluid in card series 10, to inches of mercury; and linearly interpolating between the converted readings to obtain values coincident with the end of each time step. These interpolated manometer readings are added algebraically to the interpolated barometric reading to give values for pneumatic head at the end of each time increment for each screen.

Orice the differential-manometer readings have been converted to pneumatic head, initial head values for each space node (required as an initial condition for the numerical solution of equation 3) are established by program statements 95-116. For each layer except the bottom one, these values are determined by linear interpolation of the heads at time zero for the screens that bracket the layer. However, with regard to the bottom layer, linear extrapolation of the head gradient between screens 1 and 2 (fig. 1) would result in an implied violation of the no-flow boundary condition at the top of the capillary fringe. Hence, within the bottom layer, head values are computed from a sine curve fit through the pneumatic head values for screens 1 and 2 . In addition to meeting the boundary condition at the water table, additional theoretical justification exists for assuming that the data for this layer should approximate a sine curve. Carslaw and Jaeger (1959, p. 99) show that, for four different sets of initial conditions for one-dimensional heat flow in a slab, the temperature distribution in the slab converges toward a sine-curve configuration with time. Based on the analogy between heat and fluid flow and the fact that the observed initial pneumatic head differences generally result from atmospheric pressure changes that either occurred or began some time before readings were begun, the sine-curve assumption seems well justified.

\section{NUMERICAL SOLUTION OF EQUATION 3}

For the computer analysis, flow of air in the unsaturated zone, as described by equation 3 , is analyzed by a numerical finite-difference technique. Use of the technique requires that the space and time derivatives of pneumatic head be approximated by values of the difference quotients of head at separate discrete points both in space and in time. The discrete points in space are generally termed nodes, and for this application it was convenient to express the head-difference quotients for equally spaced nodes solved at equal time increments. These head-difference quotients may be expressed in one of several ways, as described in textbooks on numerical analysis. For the AIRK program, the head-difference quotients are formulated in statements $127-167$ as a set of backward difference equations (von Rosenberg, 1969, p. 20-22), one for each node at a given time increment. These formulations, with the inclusion of the appropriate boundary and initial conditions, result in a set of equations whose nonzero coefficients form a tridiagonal matrix that is efficiently solved by use of the Thomas algorithm (von Rosenberg, 1969, p. 113). The Thomas algorithm is programed as the TRIMAT subroutine in the AIRK program.

Assignment of air permeability and air-filled porosity values, used in computing coefficients in the finite-difference equations, is straightforward except for the nodes representing the layer boundaries. Because a face-centered node configuration is used in this analysis, the interblock air-filled porosity at each layer boundary is computed as the arithmetic average of the values for the two adjoining layers. No need arises to compute interblock air permeability for this node configuration, however.

\section{THE AUTOMATIC SEARCH PROCEDURE}

The automatic search procedure is based on adjusting air permeability for a given layer to minimize the sum, for all the time increments, of the difference between measured and computed pneumatic heads in either the bottom screen, for the first layer simulation; or in the screen at the bottom of the uppermost layer, in subsequent simulations. As an example, if barometric pressure declined during the test, pneumatic heads would increase with depth. Moreover, if the trial air permeability is larger than the true value, the computed head differences across the layer will be less, and the average computed pneumatic heads smaller, than those measured. Hence, the sum for all of the time steps of the difference between computed and measured heads, symbolized HDIF in the program, would be negative. Conversely, if barometric pressure were rising, the head at depth would be less than that nearer the surface. Under these conditions, HDIF would be positive if the permeability estimate was too low. 
Hence, for tests involving rising barometric pressure, HDIF is multiplied by an IBSN value of -1 to make its sign consistent with that for falling barometric pressure.

As indicated by the above discussion, the need for increasing or decreasing the trial air permeability estimate may be determined by the sign of HDIF. In the program, equation 3 is solved for the user-supplied trial value of air permeability by the TRIMAT subroutine, HDIF is computed in statements 176-181, and its sign determined by statement 186. If HDIF is negative, the factor representing air permeability is doubled, and if positive, halved, based on statements 190 or 195 . In succeeding computations, the sign of HDIF is determined for the new air permeability value. If the sign of HDIF is the same as that determined in the previous step, the air permeability is again halved or doubled as before and the process repeated.

A change in the sign of HDIF indicates that the true air permeability should lie between the current and previous trial values. Hence, once a change in sign of HDIF occurs, an air permeability value is interpolated from the current and previous HDIF and air permeability values, based on statements 200 or 204. Following the interpolation of the head difference data, the various hydraulic conductivities equivalent to the trial air permeabilities are listed, and the computed heads for the node representing the screen for which comparisons were made are tabulated for selected time increments in a column beneath the respective hydraulic conductivity values.

At this point in the program, the interpolated air permeability value is used to again compute pneumatic heads, and HDIF and its sign are again determined. This time, however, the air permeability estimate is adjusted by a factor of only 10 percent. Computations are repeated until HDIF changes sign from that determined using the interpolated air permeability value. At this time, a second interpolation is made to determine hydraulic conductivity, and head values for the appropriate screen are computed a final time. Each of the hydraulic conductivity values used for the second set of computations and the resulting pneumatic heads are then tabulated.

Some situations may occur for which the search procedure will fail to find an air permeability value that minimizes HDIF. For example, head differences across a given layer might be so slight that, due to short term random variability in the readings, the measured heads in the lower screen may show less head difference than do those measured for the overlying screen. If, for this or some other reason, HDIF for a given layer fails to change sign after 10 trial values of air permeability have been used to solve equation 3 , the program notes its failure to find a solution. The program then lists the 10 values of hydraulic conductivity, tabulates the computed head values at the node representing the screen at the base of the layer for each permeability estimate, and terminates.

\section{PROGRAM VERIFICATION}

The AIRK program was verified by computing pneumatic heads for selected depths and assumed values of permeability and air-filled porosity based on two different analytical equations. These computed heads were entered as data into the program, along with wrong "estimates" of the equivalent hydraulic conductivity and correct values for the air-filled porosity. The program was run to compute values of hydraulic conductivity, and these values compared to those used in the analytical equations for the pneumatic head calculations.

For the first verification procedure, head values were computed at four levels in a uniform layer of unsaturated material, based on an analogous heat-flow equation presented by Carslaw and Jaeger (1959, p. 104, eq. 4). This equation is based on the assumptions that pneumatic head at land surface increases linearly as a function of time, that no flow occurs at the water table, and that pneumatic head is initially constant throughout the profile. These computed heads were inserted into the program, along with different wrong values for the hydraulic conductivity of each of the four assumed layers. Computed equivalent hydraulic conductivity values for each layer, computed through the automatic search procedure, ranged from $2.99 \mathrm{~m} / \mathrm{d}$ to 3.20 $\mathrm{m} / \mathrm{d}$, compared to the value of $3.05 \mathrm{~m} / \mathrm{d}$ used to compute the head values. A second run using other wrong estimates indicate that the search procedure converged to the same estimates whether the initial estimates were too high or too low.

A second verification run was made by computing heads at four levels in a two-layer unsaturated zone, also based on an analytical equation given by Carslaw and Jaeger (1959, p. 323-324). For this equation, pneumatic head at the land surface boundary is assumed to undergo an instantaneous change at time $t=0$, and to maintain that new value thereafter. The other boundary, corresponding to the water table, is assumed to be maintained at the initial pneumatic head. Although this boundary condition is different than that existing in the field or in the program, boundary conditions specified in the program were modified during that run to match those assumed for the analytical equation. Head values computed from the equation were used in conjunction with wrong values of air permeability in the AIRK program to estimate the true air permeability of four layers, including one that coincided with the lower layer in the analytical solution, and three that divide the upper layer. Computed values for the equivalent hydraulic conductivity are compared to those used in the analytical equation in the table below.

\begin{tabular}{ccccc}
\hline \multirow{2}{*}{$\begin{array}{c}\text { Depth } \\
\text { interval, } \\
\text { meters }\end{array}$} & $\begin{array}{c}\text { Initial } \\
\text { "estimate" }\end{array}$ & $\begin{array}{c}\text { Final } \\
\text { computed value }\end{array}$ & $\begin{array}{c}\text { True } \\
\text { value }\end{array}$ & $\begin{array}{c}\text { Air-filled } \\
\text { porosity }\end{array}$ \\
\hline $0-15$ & 50. & 7.76 & 8. & 0.2 \\
$15-35$ & 3. & 8.12 & 8. & .2 \\
$35-50$ & 1. & 8.55 & 8. & .2 \\
$50-100$ & 10. & .970 & 1. & .1 \\
\hline
\end{tabular}


As may be seen from the table, the computed values range from -3 percent to +7 percent of those used in the analytical equation.

Results of the two comparisons show that the program yields reasonably good approximations of the true hydraulic conductivity. Errors arise in part because of truncation and roundoff errors in computing heads from the finite-difference approximation of the differential equation, so that they do not agree exactly with those computed analytically. The significance of these errors is magnified in the permeability or hydraulic conductivity estimates, because that parameter must be changed by a few percent in order to alter computed head by a few tenths of a percent. This lack of sensitivity of head to small changes in permeability or hydraulic conductivity contributes to the general uncertainty of any problem concerned with the identification of aquifer properties. (See, for example, Hefez and others, 1975.) Moreover, as noted above, many other sources of error exist in estimating hydraulic conductivity from the air permeability at the prevailing moisture content. Hence, it was concluded from the above comparisons that the program is adequate for its intended purpose, although additional work is desirable to improve the comparison with the analytical equations.

\section{INPUT DATA REQUIREMENTS}

Required data to execute the program include ten cards or card series described in sequence and detail below.

Card 1.-Contains in the first 32 columns, under the label SINAM, the name of the site at which data were collected.

Card 2.-Contains in columns 1-4 and 7-10, the beginning and ending 24-hour clock times, labeled CLCKB and CLCKE, for the data being analyzed. In columns 13-24, the date the data were collected is given under the label RDATE. Example:

\section{5bb1615bbMARb15,b1972}

Card 3.-Contains, right-justified in columns 1-2, a number labeled IBSN that is used in the computations to account for the main direction of the barometer change. Because of limitations of the search procedure, the pneumatic head data must follow either a generally upward or a generally downward trend, although minor deviations are permissible. The period of record to be analyzed should be selected accordingly. If the barometer fell during most of the test, $b 1$ or +1 should be entered; if it rose during most of the test, -1 should be entered.

On the same card, an option code to weight the data, labeled IWTO, may be entered in column 4. If it is felt that the later data are more reliable than the early data, and hence worthy of greater weight, a " 1 " should be entered in column 4. If, on the other hand, the early data are to be weighted, a " 2 " should be entered in column 4 . If column 4 is left blank, all data are weighted equally.
Card 4.- This card contains five numbers. Rightjustified in columns 1-2 is an integer labeled NLYS that designates the number of layers used to represent the unsaturated zone. This number must be equal to the number of screens for which data are to be read in. As dimensioned, this number would be limited to 9 .

In columns 3-9, a floating-point number labeled UZD is entered to designate the thickness of the unsaturated zone, in feet. In general, it is convenient to round this number to the nearest foot.

In columns 10-13, a right justified integer labeled JMAX is entered to designate the total number of nodes to be used to simulate the unsaturated zone. It has been convenient for this study to divide the unsaturated zone into 1 -foot increments. Thus, JMAX generally is set equal to 1 plus the depth to the water table in feet. As dimensioned, this number has a maximum value of 200 .

In columns 14-20, a floating-point number labeled TINC is entered to designate the length, in minutes, of each time step to be used in the computations. For a typical afternoon diurnal record, this number would be set equal to 5 .

In columns $21-24$, a right-justified integer labeled NTS is entered to designate the total number of time steps to be used in the analysis. This number is equal to one plus the period of record in minutes divided by the time increment, which also is in minutes. As dimensioned, this number would be limited to 150 .

Card 5.-This card contains, right-justified in columns 1-2, an integer labeled NSTEP designating the number of time increments after which head data should be printed out. This number allows head data to be printed out less frequently than the computations are made, providing more succinct tables of head versus time for examination or plotting. For the usual observations of afternoon diurnal fluctuations made during this study, head values were computed at 5-minute intervals and printed out at 15-minute intervals. NSTEP would be set equal to 3 under these conditions.

Card 6.-This card contains two floating-point numbers. The first number, labeled SGMF, is punched in columns 1-7 and designates the specific gravity of the manometer fluid. The second number, labeled PBAR, is entered in columns 8-14 to designate the mean station barometric pressure, in inches of mercury, during the period of record being analyzed. It should be kept in mind that the station pressure is the actual atmospheric pressure at the site, rather than the pressure corrected to sea level generally quoted by the U.S. Weather Service. If such data are not available, the value may be estimated by correcting the average sea-level pressure of 29.92 inches of mercury for the altitude of the site, using, for example, the equation:

$$
\bar{P}=29.9 \exp \text { (-altitude in feet } / 27,000 \text {.), }
$$

where

$\bar{P}$ is in inches of mercury. 
Alternatively, the station pressure could be determined from handbook values of atmospheric pressure versus altitude. It is adequate to enter this value to the nearest 0.1 inch.

Card 7.- Card 7 is the first of NLYS cards containing data on screen depths and assumed or estimated physical properties of each layer used to represent the unsaturated zone. It contains, in the first 5 columns, a floating-point value, labeled SD, representing the depth to the bottom screen, from land surface, in feet. An initial estimate of the hydraulic conductivity, HYDC, of the lowermost layer, in feet per day, is entered as a floating-point number in columns 6-13. The following table may be used to make such estimates for each layer, assuming the record was obtained during a normal afternoon barometric pressure decline.

\begin{tabular}{c}
$\Delta h^{1}$ \\
\hline$>.5$ \\
$.2-.5$ \\
$.05-.2$ \\
$.01-.05$ \\
$<.01$
\end{tabular}

$\begin{gathered}\text { Hydraulic conductivity, } \\ \text { feet per day }\end{gathered}$
0.01
.1
1.
100.

' $\Delta \mathrm{h}$ is the approximate maximum pneumatic-head difference, in inches of water, measured between screens straddling the layer for which estimates are to be made.

The air-filled porosity estimate, labeled DPOR, based on neutron logs, core analyses, and any other available data for the lowermost layer is entered as a two-digit decimal fraction in floating-point format in columns 14-17. DPOR generally would be equivalent to specific yield.

If it is desired for any reason to retain the provided hyraulic conductivity estimate, a "1" (labeled KOP) should be entered in column 20 . As an example, a plot of computed and measured head data for a previous computer run may have indicated a less-than-ideal curve fit for a given layer. Under these conditions, the investigator may choose, from the plot, a somewhat different value for hydraulic conductivity than was selected by the programed search routine. The investigator should then insert his selected value in the appropriate space on the card, enter a 1 in column 20 of the card representing that layer, and rerun the program to obtain improved estimates of the hydraulic conductivity of the layers overlying that for which the hydraulic conductivity estimate was revised.

Each additional card of the NLYS cards in the Card 7 series must contain the screen depth, hydraulic conductivity, and air-filled porosity or specific yield for the overlying screens and layers. These cards must be in sequence, it being remembered that both the screens and layers are numbered upward from the water table, but that all depths are measured from land surface.

Card 8.-This card contains either a 1 in column 1 (labeled IVIS) or a blank in column 1 and two numbers in double-precision exponent format in columns 2-11 and 12-21 designating the dynamic viscosity of air, labeled ADV, at the prevailing temperature of the soil gas at the site and the kinematic viscosity of water, labeled WKV, at a temperature selected by the investigator. ADV must be in pound-seconds per square foot, and WKV in square feet per second. If 1 is entered in column $1, \mathrm{ADV}$ and $\mathrm{WKV}$ at $60^{\circ} \mathrm{F}$ are read in by default.

Card 9 (series).-This series contains data on barometric pressure changes during the period of record to be analyzed. For the first card, the barometric pressure, BAR1, as measured in inches of mercury, preferably precise to 0.001 inch, is entered in columns 1-6. In general, it is preferable to drop the digits to the left of the decimal point, adjusting the readings by 0.5 inch or so if necessary to avoid any change in dropped digits during the record. Dropping these digits reduces round-off error in the finite difference computations. The time after the start of the record in minutes is entered as a floating point numeral in columns $7-11$. The first such value, designated $\mathrm{T} 1$, would be 0 .

Each subsequent card in the Card 9 series should contain, in sequence, the barometer reading designated BAR2 and the time, designated $\mathrm{T} 2$, in minutes, after the start of the test in columns 1-6 and 7-11, respectively. The time readings need not be incremented equally. However, the last time value must equal the product TINC $\times($ NTS -1$)$.

A card containing 99999 . in columns 1-6 should be entered in the data deck to indicate the end of the barometer-time file.

Card 10(series).- This card series contains the differential manometer readings for each screen and time during the period of record. As many as six differential manometer readings and their corresponding times are entered on each card, with readings for the bottom screen in the leftmost columns. The entered differential manometer readings represent the net difference, in inches of manometer fluid, between the reading when the manometer is opened to a given screen and that obtained when both ports of the manometer are open to the atmosphere. Readings are considered positive when the downhole pneumatic head is greater than that at land surface. For each card, initial differential manometer readings, designated DMRl or DMR2, for screens $1,2,3, \ldots$, are entered as floating point numbers in columns $1-6,12-17,23-28, \ldots$, and the time value for each reading in minutes since the test began and designated TR1(NL) or TR2(NL), is entered in floating-point format in columns $7-11,18-22,29-33, \ldots$. For the first card, all time readings must be 0 ., and for the last card, all time readings must equal TINC $\times($ NTS -1$)$. For each of the other cards, the times for readings at each screen may differ from the others, and need not be incremented equally. Readings for any given screen must be in sequence, however, and each card must contain a reading for each screen. Consequently, if, during a sequence of measurements, a reading for a given screen is not available, a value should be interpolated for inclusion on the card.

The last card in the Card 10 series should be followed by a card containing 99999. in the first 6 columns to indicate the 
end of file. This card will complete the data deck for the program.

\section{LIST OF MNEMONICS AND CONSTANTS USED IN THE AIRK PROGRAM}

The following list describes the mnemonics and constants used in the AIRK program that are not described in the section on input data. Items are listed in the order that they appear in the program, and, where appropriate, units are provided.

$\mathrm{NL}$ is a counter designating screen or layer number. It is 1 for the bottom screen or layer and NLYS for the top screen or layer.

MPT designates whether the initial or final hydraulic conductivity estimates are to be printed, and determines whether the heading for table 1 or table 5 will be printed, as appropriate.

HYDS (NL)=final hydraulic conductivity selected through the search procedure for the NLth layer, saved for printing in table 5 .

NBS=total number of observation points, including that at land surface.

NT=counter for time steps.

M1, M2=counters for interpolating barometer and differential manometer readings at equal time steps.

$13.56=$ specific gravity of mercury at $60^{\circ} \mathrm{F}$.

HR (NBS, NT)=atmospheric pressure at land surface at the end of the NTth time step, in inches of mercury, as interpolated from input data.

NTL $(\mathrm{NL})=$ counter for keeping track of last previous interpolated head value for the NLth screen.

$D V=i n t e r p o l a t e d$ differential manometer reading, converted to inches of mercury.

HR (NL, NT)=pneumatic head reading at the NLth screen and NTth time step, in inches of mercury, as determined by interpolation of input data.

JSD is the node number for the NLth screen, or for land surface $(\mathrm{NL}=\mathrm{NBS})$, as measured from land surface. Land surface is at node 1 (i.e., $\operatorname{JSD}(\mathrm{NBS})=1$ ).

NNL (NL)=number of nodes in NLth layer.

NBOT=number of nodes between screen 1 and screen 2 .

ELB=floating-point designation of number of nodes representing bottom layer.

$\mathrm{XL}=$ ratio of number of nodes between screens 1 and 2 to number of nodes in layer 1 .

HMAX=pneumatic head at water table (node JMAX).

$\mathrm{J} l=$ counter to vary the upper boundary node designation within nested DO-loops as layers are added to the model.

HNS $(\mathrm{J})=$ initial pneumatic head, in inches of mercury, at any node $J$, used to specify initial conditions in the solution of equation 3.

$\mathrm{J} 2=$ counter to designate the bottom node of the layer for which trial values of permeability are being established. For this program each layer above the first is assumed to extend to the bottom of the node immediately above the subjacent screen.

DELH= difference in pneumatic head at the start of the test across any layer except the bottom one.

TIME=elapsed time from start of test, in minutes.

DELT $=$ time increment in days.

DZSQ=square of the depth increment represented by adjacent nodes, in square feet.

$P(N L)=a$ factor representing air permeability, in $\mathrm{ft}^{5}$ per inch-pound-day. These awkward units arise from expressing hydraulic conductivity in $\mathrm{ft}$ per day, pneumatic head in inches of mercury, dynamic viscosity in pound-seconds per $\mathrm{ft}^{2}$, kinematic viscosity in $\mathrm{ft}^{2}$ per second, and gas specific storage $(\mathrm{SS}(\mathrm{J}))$ in $\mathrm{ft}^{3}$ per inch-pound.

386.4= acceleration due to gravity, inches per second squared.

SS $(J)=$ specific storage term for soil gas for the material represented by the $\mathrm{J}$ th node, in $\mathrm{ft}^{3}$ per inch-pound.

846. =weight density of mercury at $60^{\circ} \mathrm{F}$, in pounds per $\mathrm{ft}^{3}$.

$R(J)=$ coefficient for computing time rate of change of storage within the material represented by the Jth node due to a change in head during the time period DELT.

$\mathrm{JJ} 2$, JM2, JP1=delimiters to control the head difference quotients at nodes not on either boundary of the system being analyzed.

ICT2=a counter to designate whether air permeability is to be halved or doubled, or to be increased or decreased by 10 percent.

JS=node designation of screen within or at the bottom of the layer being simulated, used in comparing measured and computed heads at that point.

ICT=counter to designate the number of trial air permeability values used for a given layer.

$A(J), B(J)$, and $C(J)=$ the finite-difference equation coefficients by which the unknown heads for the current time step at nodes $J-1, J$, and $J+1$ are multiplied in the backward-difference formulation of equation 3 .

$H(J)=$ head at node $J$ at time step $N T$, initialized to HNS $(J)$ for time step 1.

$D(J)=$ finite-difference equation coefficient times the head at the Jth node computed during the previous time step.

TRIMAT=subroutine for solving the set of implicit finite-difference equations for pneumatic head at the current time step by use of the Thomas algorithm.

HSCS (ICT, NT)=pneumatic head expressed in inches of mercury, computed for the ICT th trial hydraulic conductivity and NTth time step for the NLth screen. These head values are saved for printing in table 3.

HSCS (INL, NT)=computed head for the NLth screen at time NT, based on the final simulation. These head values are printed in table 4.

HDIF=the difference between computed and measured heads, summed for each time step, for the screen within or at the base of the NLth layer. 
ISIGN=counter to keep track of the sign of HDIF in repeated simulation trials.

PS=air permeability for the current time step saved for possible interpolation of an air permeability value following the next simulation trial.
HDS=HDIF for the current trial saved for possible interpolation of an air permeability value following the next trial.

ISIGN2=counter for sign of HDIF for the current trial air permeability, used for comparison with ISIGN, the sign of HDIF for the previous trial.

\section{AIRK PROGRAM LISTING}

$\begin{array}{lllll}\text { FORTRAN IV G LEVEL } 21 & \text { MAIN } & \text { DATE }=77318 & 18 / 44 / 45\end{array}$

0001

0003

0004

0005

0006

0007

0008

0009

0010

0011

0012

0013
C THIS PROGRAM COMPUTES THE PNEUMATIC DIFFUSIVITY OF N LAYERS OF UNSAT

C URATED MATERIAL, BASED ON READINGS OF PRESSURE VERSUS DEPTH AT EACH

C LAYER BCUNDARY, AS MEASURED DURING A CHANGE OF ATMOSPHERIC PRESSURE.

C REQUIRED DATA ARE BAROMETRIC READINGS VERSUS TIME, PRESSURE CHANGES

C VERSUS TIME FOR EACH DEPIH, THE NUMBER OF LAYERS, THE THICKNESS OF

C THE UNSATURATED ZONE, THE DEPTH OF EACH SCREEN, MEAN STATION PRESSURE

C DURING THE TEST, SPECIFIC GRAVITY OF THE MANOMETER FLUID, AND INITIAL

C ESTIMATES OF HYDRAULIC CONDUCTIVITY AND DRAINED POROSITY FOR EACH

C LAYER, STARTING FROM THE WATER TABLE.

IMPL ICIT REAL * $B(A-H, O-Z)$

COMMON ICOML/ H(200),A(200),B(200),C(200),D(200)

DIMENSION HR $(9,150), S S(200), R(200), \operatorname{SD}(9), H Y D S(9), \operatorname{DPOR}(9)$, NTL

1(9), NNL (9), DMR1(9), DMR2(9), TRL19), TR2(9), JSD(9), P(9), KOP(9

2). $X(2), H Y D C(9,10)$

DIMENSION HSCS $(10,200)$, HNS $(200)$

DIMENSION SINAM(8), RDATE(3), NLINT(9)

DATA $X / 1.0,0.1 /$

$X(I C T 2)=F A C T O R$ FOR VARYING PERMEABILITY BY 100 PER CENT FOR THE FIRST

SWEEP. AND BY 10 PER CENT FOR THE SECOND SWEEP. READ 82, ( $\operatorname{SINAM}(I), I=1,8$ )

C $* * * * * * * * * * * * * * * * * * * * * * * * * * * * * * * * * * * * * * * * * * * * * * * * * * * * * * * * * * * * * * * * * * * * *$

SINAME IS A $32-$ CHARACTER FIELD FOR THE SITE NAME AND LOCATION.

$* * * * * * * * * * * * * * * * * * * * * * * * * * * * * * * * * * * * * * * * * * * * * * * * * * * * * * * * * * * * * * * * * * * * *$
READ 78, CLCKB,CLCKE, (RDATE $(1), I=1,3)$

***********************************************************************

RDATE IS A 12-CHARACTER FIELD FOR THE DATE READINGS WERE OBTAINED.

CLCKB AND CLCKE ARE 4-CHARACTER FIELOS FOR BEGINNING AND ENU ING 24-

HOUR CLOCK TIMES.

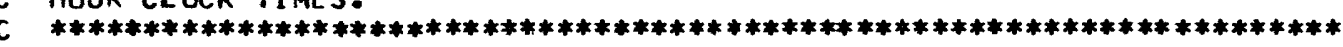
READ 69 , IBSN, IWTO

C $* * * * * * * * * * * * * * * * * * * * * * * * * * * * * * * * * * * * * * * * * * * * * * * * * * * * * * * * * * * * * * * * * * * * * *$

IBSN IS SIGN OF BAROMETER CHANGE, - 1 FOR RISING BAROMETER; + 1 FOR

A FALLING BAROMETER.

IWTO IS A CODE FOR HE IGHTING THE. DATA WITH RESPECT TO TIME, O FOR

EQUAL MEIGHTING, I FOR MORE HEAVILY WEIGHTING EARLY DATA, AND 2 FOR

MORE HEAVILY WE IGHTING LATER DATA.

***********************************************************************

READ 63, NLYS, UZD, JMAX, T INC, NTS

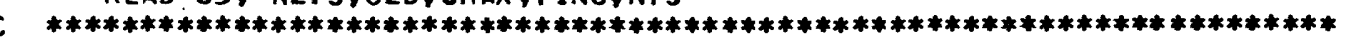
READ 69, NSTEP

$N=N S T E P+1$

NSTEP DESIGNATES THE INTERVAL AT WHICH HEAD READINGS ARE PRINTED.

**********************************************************************

NLYS = NUMBER OF LAYERS.

NTS=TOTAL NUMBER OF TIME STEPS.

JMAX = TOTAT NUMBER OF POSITION NODES.

TINC=T IME INCREMENT FOR PNEUMAT IC HEAD COMPUTATIONS, IN MINUTES.

UZO=UNSATURATED ZONE DEPTH, IN FEET.

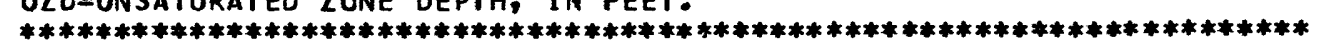
READ 64, SGMF, PBAR

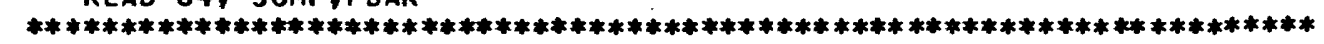

SGM=SPECIFIC GRAVITY OF MANOMETER FLUID.

PBAR = MEAN PRESSURE DURING TEST, IN INCHES OF MERCURY. 
0014 0015

0016

0017

0018

0019

0020

0021

0022

0023

0024

0025

0026

0027

0028

0029

0030

0031

0032

0033

0034

0035

0036

0037

0038

0039

0040

0041

0042

0043

0044

0045

0046

0047

0048

0049

0050

0051

0052

0053

0054

0055

0056

0057

0058

0059 DO $1 \mathrm{NL}=1, \mathrm{NL} Y \mathrm{~S}$

1 READ 65, SO(NL), HYDC (NL, 1$), D P O R(N L), K O P(N L)$

C **********************************************************************

SDINL)=DEPTH OF NLTH SCREEN, NUMBERED FROM THE BOTTOM AND MEASURED FROM LAND SURFACE.

DPOR (NL) = DRAINED POROSITY ESTIMATE FOR NLTH LAYER.

(HYDC INL, 1)=EST IMATED. HYDRAUL IC CONDUCT IVITY, IN FEET PER DAY, FOR

LAYER 1. THIS VALUE IS CONVERTED TO AIR PERMEABILITY, P(NL), WITHIN

THE PROGRAM.

KOP $=1$ WILL CAUSE PROGRAM TO RETAIN THE HYDC VALUE FOR A GIVEN LAYER,

RATHER THAN TO CONTINUE SEARCHING FOR A BEST-FIT SOLUTION.

C

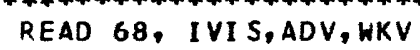

C WKV=KINEMATIC VISCOSITY OF WATER AT DESIRED TEMPERATURE, IN SQUARE

C FEET PER SECOND.

IF (IVIS.NE. 1$)$ GD TO 2

$A D V=3.74 D-07$

WKV $=1.210-05$

2 CONT INUE

C $\quad * * * * * * * * * * * * * * * * * * * * * * * * * * * * * * * * * * * * * * * * * * * * * * * * * * * * * * * * * * * * * * * * * * * * *$

C THE FOLLOWING STATEMENTS PRINT OUT INPUT DATA ANC INFORMATION

C REGARDING THE TEST.

$$
M P T=0
$$

3 PRINT 76, (SINAMI I ), I $=1,8$ )

PRINT 72, UZD

PRINT 73, NLYS, JMAX

PRINT 77, CLCKB,CLCKE, (RDATE(I), I=1,3)

PRINT 74, NTS,TINC

PRINT 97, PBAR

PRINT 98, SGMF

IF IIBSN.EQ. I) GO TO 4

PRINT 95

GO TO 5

4 PR INT 96

5 CONT INUE

IF (IWTO-1) 6,7,8

6 PRINT 92

GO TO 9

7 PRINT 93

GO TO 9

8 PRINT 94

9 CONT INUE

PRINT 101, ADV, WKV

IF (IVIS.EQ.1) PRINT 102

PRINT 84

IF (MPT.EQ.1) GO TC 10

PRINT 79

GOTO 12

10 PRINT 83

DO $11 \mathrm{NL}=1$, NLYS

$11 \mathrm{HYOC}(\mathrm{NL}, 1)=\mathrm{HYDS}(\mathrm{NL})$

12 PRINT 80

NBS $=N L Y S+1$

$S D(N B S)=0$.

$\mathrm{NL}=1$

PRINT 75, NL, SO (2),UZD, HYDC (NL, 1), OPOR (NL)

IF (NLYS.EQ. 1) GO TO 14

DO $13 \mathrm{NL}=2$, NLYS

13 PRINT 75, NL, SD(NL+1), SD (NL), HYOC (NL, 1$)$, DPOR (NL)

14 IF (MPT.EQ.1) GO TO 62

PRINT 99, SD(1)

C THE FOLLOWING STATEMENTS COMPUTE ATMOSPHERIC PRESSURE AT LAND SUR-

C FACE FOR EQUAL TIME INCREMENTS BY INTERPOLATION FROM USER-SUPPLIED
A 59

A 60

A 61

A 62

A 63

A 64

A 65

A 66

A 67

A 68

A 69

A 70

A 71

A 72

A 73

A 74

A 75

A 76

A 77

A 78

A 79

A 80

A 81

A 82

A 83

A 84

A 85

A 86

A 87

A 88

A 89

A 90

A 91

A 92

A 93

A 94

A 95

A 96

A 97

A 98

A 99

A 100

A 101

A 102

A 103

A 104

A 105

A 106

A 107

A 108

A 109

A 110

A 111

A 112

A 113

A 114

A 115

A 116

A 117

A 118

A 119

A 120

A 121

A 122

A 123

A 124

A 125

A 126

A 127

A 128

A 129

A 130 
C BARI, TI=RAH MICROBARCGRAPH READINGS AT TIME TI,.WITH BARI IN AN 133

C INCHES OF MERCURY, ANO TI IN MINUTES SINCE START OF TEST. $H R(N B S, 1)=B A R 1$

0061

0062

0063

0064

0065

0066

0067

0068

0069

0070

0071

0072

0073

0074

0075

0076

0077

0078

0079

0080

0081

0082

0083

0084

0085

0086

0087

0088

0089

0090

0091

0092

0093

0094

0095

0096

0097

0098

0099

0100

0101

0102

0103

0104

0105

0106

0107

0108

0109
$M 2=0$

15 READ $66, B A R 2, T 2$

IF (BAR2.GT.99.90) GO TO 17

$M 1=M 2+1$

$M 2=(T 2 / T I N C)+1$

DO $16 N T=M 1, M 2$

$16 \operatorname{HR}(N B S, N T)=B A R 1+(B A R 2-B A R 1) *((N T-1) * T I N C-T 1) /(T 2-T 1)$

$T 1=T 2$

$B A R 1=B A R 2$

GO TO 15

17 CONT INUE

C THE FOLLOWING STATEMENTS RELATE TO CGMPUT ING PNEUMATIC HEAD AT EACH

C SCREEN FOR THE END OF EACH TIME INCREMENT. THESE COMPUTATIONS

C ARE ACCOMPL ISHED BY CCNVERTING THE MANOMETER READING FOR A GIVEN

C SCREEN AND TIME TO INCHES OF MERCURY, INTERPOLATING TO OBTAIN A

C A VALUE FOR THE READING AT THE END OF THE TIME STEP, AND ALUE-

C BRAICALLY ADDING THE READING TO THE CCNCURRENT BAROMETER READING. NT $=1$

READ 67, (DMRI (NL), TRI (NL), NL=1,NLYS)

C DMR(NL)=DIFFERENTIAL MANOMETER READING AT NLTH SCREEN AT START OF

TEST .

DMR 2 (NL)=DIFFERENTIAL MANOMETER READING AT NLTH SCREEN AT TIME TL2,

IN MINUTES AFTER START OF TEST.

DO $18 \mathrm{NL}=1$, NLYS

$N T L(N L)=1$

DMR $1(N L)=D M R 1(N L) * S G M F / 13.56$

$18 H R(N L, N T)=H R(N B S, 1)+D M R I(N L)$

19 READ 67, (DMR2 (NL), TR2 (NL), NL=1, NLYS)

C DIFFERENTIAL MANOMETER READINGS ARE CONSIDERED POSITIVE WHEN THE

$C$ DCHNHOLE PNEUMATIC HEAD IS GREATER THAN THAT AT LAND SURFACE. IF (DMR2(1).GT.99.90) GO TC 22

DO $21 \mathrm{NL}=1$, NLYS

$M L=N T L(N L)$

DMR2 $(N L)=D M R 2(N L) * S G M F / 13.56$

$M 2=(T R 2(N L) / T I N C)+1$

DO $20 \mathrm{NT}=M 1, M 2$

$D V=D M R 1(N L)+(D M R 2(N L)-D M R 1(N L)) *((N T-1) * T I N C-T R I(N L)) /(T K 2(N L)-T R 1$

1 (NL))

$H R(N L, N T)=H R(N B S, N T)+D V$

20 CONTINUE

DMR 1 (NL) = DMR 2 (NL)

$\operatorname{TRL}(N L)=T R 2(N L)$

$N T L(N L)=M 2+1$

21 CONT INUE

GO TO 19

22 CONT INUE

C THE FOLLOWING STATEMENTS RELATE TO COMPUTING HEAD AT EACH SPACE NODE

C AT THE START OF THE TEST. THESE COMPUTATIONS ARE BASED ON FITTING

C A SINE CURVE THROUGH THE DATA FOR THE BOTTOM LAYER, AND BY LINEAR

C INTERPOLATION FOR THE OVERLYING LAYERS. DO $23 \mathrm{NL}=1$, NBS

23 JSD $(N L)=(S D(N L) / U Z D) * D F L O A T(J M A X-1)+1$

C JSD (NL) =NODAL POSITION OF NLTH SCREEN. NNL $(1)=J M A X-J S D(2)$

C NNL (NL) = NUMBER OF NODES INCLUDED IN NLTH LAYER. NBOT $=J S O(1)-J S D(2)$

$J 1=J S D(2)$

$P I=3.1415926$

ELB=DFLOAT (NNL $(2))$

$X L=N B O T / E L B$

HMAX $=(H R(1,1)-H R(2,1)) / D S I N(P I * X L / 2$.

NL $=1$

DO $24 \mathrm{~J}=\mathrm{J} 1, \mathrm{~J}$ MAX

$24 \operatorname{HNS}(J)=H R(N L+1,1)+\operatorname{HMAX} * \operatorname{DS} I N(P I *(J-J 1) /(2 \cdot * E L B))$

IF (NLYS.EQ. 1 ) GO TO 28

DO $25 \mathrm{NL}=2$, NLYS

$25 \mathrm{NNL}(\mathrm{NL})=J \operatorname{JS}(\mathrm{NL})-J S D(N L+1)$
A 135

A 136

A 137

A 138

A 139

A 140

A 141

A 142

A 143

A 144

A 145

A 146

A 147

A 148

A 149

A 150

A 151

A 152

A 153

A 154

A 155

A 156

A 157

A 158

A 159

A 160

A 161

A 162

A 163

A 164

A 165

A 166

A 167

A 168

A 169

A 170

A 171

A 172

A 173

A 174

A 175

A 176

A 177

A 178

A 179

A 180

A 181

A 182

A 183

A 184

A 185

A 186

A 187

A 18.8

A 189

A 190

A 191

A 192

A 193

A 194

A 195

A 196

A 197

A 198

A 199

A 200

A 201

A 202 
0110
0111
0112
0113
0114
0115
0116
01117
0118
0119
0120
0121
0122
0123
0124

0125

0126

0127

0128

0129

0130

0131

0132

0133

0134

0135

0136

0137

0138

0139

0140

0141

0142

0143

0144

0145

0146

0.147

0148

0149

0150

0151

0152

0153

0154

0155

0156

0157

0158

0159

0160

0161

0162

0163

0164

0165

0166

0167

0168
$\mathrm{J} 2=\mathrm{J} 1-1$

DO $27 \mathrm{NL}=2$, NLYS

$J I=J S D(N L+1)$

$D E L H=H R(N L, 1)-H R(N L+1,1)$

DO $26 \mathrm{~J}=\mathrm{Jl}, \mathrm{J} 2$

$H N S(J)=H R(N L+1,1)+D E L H *(J-J 1) / N N L(N L)$

26 CONT INUE

$\mathrm{J} 2=\mathrm{J} 1-1$

27 CONT INUE

28 PRINT 81

PRINT 100

PRINT 89

DO 29 NT $=1, N T S, N S T E P$

TIME $=(N T-1,1) *$ TINC

29 PRINT 71, NT, TIME, (HR (NL,NT),NL =1, NBS)

C THE FOLLOWING STATEMENTS SET UP INITIAL VALUES FOR PERMEABILITY,

C SPECIFIC STORAGE, AND THE STORAGE-TIME TERM FOR THE DIFFERENCE

C EQUATIONS.

$D E L T=T I N C / 1440$.

$D Z S Q=(U Z D /(J \operatorname{MAX}-1,1) * * 2$.

$\mathrm{J} 2=\mathrm{J}$ MAX

DO $31 \mathrm{NL}=1, N L Y S$

$P(N L)=H Y D C(N L, 1) * W K V /(386.4 * A D V)$

$J 1=J S D(N L+1)$

DO $30 \mathrm{~J}=\mathrm{J} 1, \mathrm{~J} 2$

$30 S S(J)=D P O R(N L) /(P B A R * 846$. $)$

$J 2=J 1-1$

31 CONT INUE

$R(1)=S S(1) * D 2 S Q / D E L T$

DO $32 \mathrm{~J}=2$, JMAX

$32 R(J)=(S S(J)+S S(J-1)) * D Z S O / / D E L T * 2$.

C THE FILLNWING STATEMENTS ESTABLISH THE COEFFICIENTS FOR THE UN-

C KNOWN.HEAD TERMS IN THE FINITE-CIFFERENCE EQUAT ION. THEY ARE RE-

C COMPUTED FOR EACH TRIAL PERMEABILITY VALUE.

$\mathrm{J} J 2=J M A X$

DO $60 \mathrm{NL}=1$, NLYS

JM $2=J J 2-1$

PRINT 85, NL, NL

ICT $2=1$

$J 1=J S D(N L+1)+1$

$J P 1=J 1+1$

$J S=J S D(N L)$

33 CONT INUE

DO 58 ICT $=1,10$

34 HDIF $=0$.

DO $35 \mathrm{~J}=\mathrm{J1}, \mathrm{JM} 2$

$A(J)=P(N L)$

$B(J)=-(2 . * P(N L)+R(J))$

$35 \mathrm{C}(\mathrm{J})=P(N L)$

IF (JJ2.NE.JMAX) GC TO 36

$A(J J 2)=2 * * P(N L)$

$B(J J 2)=-(2 . * P(N L)+R(J J 2))$

GO 1037

$36 \quad A(J J 2)=P(N L)$

$B(J J 2)=-(P(N L)+P(N L-1)+R(J J 2))$

$C(J J 2)=P(N L-1)$

37 CONT INUE

$H Y D C(N L, I C T)=P(N L) * 386.4 * A D V / W K V$

C THE FOLLOWING STATEMENTS REESTABLISH INITIAL HEAD CONOITIONS FOR

C EACH TRIAL PERMEABILITY VALUE. DO $38 \mathrm{~J}=\mathrm{JI}, \mathrm{JMAX}$

$38 \mathrm{H}(J)=H N S(J)$

C THE FOLLOWING STATEMENTS SOLVE THE DIFFERENCE ECUATIONS FOR A GIVEN

C TRIAL PERMEABILITY, ONE TIME STEP AT A TIME, AND DETERMINE THE SUM

C OF THE DIFFERENCE FROM MEASURED VALUES. DO 46 NT $=2$, NTS

$D(J 1)=-(P(N L) * H R(N L+1, N T)+R(J 1) * H(J 1))$

DO $39 \mathrm{~J}=J P 1$, JMAX

$39 D(J)=-(R(J) * H(J))$

CALL TRIMAT ( JI, JMAX)

C DETERMINES WHETHER TO SAVE HEAD MATRIX AT SCREEN FOR PRINTING AFTER.

C FINAL HYDRAUL IC CONDUCTIVITY VALUE FOR A GIVEN LAYER IS CHOSEN, OR
A 203

A 204

A 205

A 206

A 207

A 208

A 209

A 210

A 211

A 212

A 213

A 214

A 215

A 216

A 217

A 218

A 219

A 220

A 221

A 222

A 223

A 224

A 225

A 226

A 227

A 228

A 229

A 230

A 231

A 232

A 233

A 234

A 235

A 236

A 237

A 238

A 239

A 240

A 241

A 242

A 243

A 244

A 245

A 246

A 247

A 248

A 249

A 250

A 251

A 252

A 253

A 254

A 255

A 256

A 257

A 258

A 259

A 260

A 261

A 262

A 263

A 264

A 265

A 266

A 267

A 268

A 269

A 270

A 271

A 272

A 273

A 274 
0169

0170

0171

0172

0173

0174

0175

0176

0177

0178

0179

0180

0181

0182

0183

0184

0185

0186

0187

0188

0189

0190

0191

0192

0193

0194

0195

0196

0197

0198

0199

0200

0201

0202

0203

0204

0205

0206

0207

0208

0209

0210

0211

0212

0213

0214

0215

0216
C TO ESTABLISH table OF Final heAd VALUES FCR COMPLETE SIMULAT ION. IF (NL.EQ.NLYS.AND.KCP(NLYS).EQ.1) GO TO 40 $H S C S(I C T, N T)=H(J S)$

GO TO 42

40 CONT INIUE

DO 41 I NL=1, NLYS

$41 \mathrm{HSCS}(I N L, N T)=H(J S D(I N L)$

GO TO 46

C WEIGHTS DIFFERENCE BETWEEN CCMPUTED AND MEASURED HEADS WITH TIME,

C ACCORDING TO SPECIFIED IWTO VALUE.

42 IF (INTO-1) $45,44,43$

$43 H D I F=H D I F+((H(J S)-H R(N L, N T)) * I B S N * C F L D A T(N T / N T S))$ GO TO 46

$44 H D I F=H D I F+((H(J S)-H R(N L, N T)) * I B S N *(1,-N T / N T S))$

GO TO 46

$45 H D I F=H D I F+((H(J S)-r R(N L, N T)) * I B S N)$

46 CONT INUE

C TESTS FOR END OF COMPLETE SIMULATICN, AND ROUTES PROGRAM TO FINAL

C TABLE PREPARATION.

IF ( $A L, E Q . N L Y S$. ANC.KCP(NLYS),EQ. 1$)$ GO TO 60

C TESTS FOR END OF SIMULATION OF A GIVEN LAYER, AND ROUTES PROGRAY TO

C PRINT HEAD VS TIME TABLES FCR TRIAL SIMULATIONS. IF (KOP(NL),EQ.1) GC TC 53

C TESTS FOR FIRST TRIAL SIMULATION OF A GIVEN LAYER.

C TESTS WHETHER A PREVICUS SIMULATION CF THE HEAD CHANGE ACROSS THE

LAYER HAS BEEN MADE, AND IF SO, ROUTES THE PROGRAM TO COMPAKE THE

C SIGN OF THE CURRENT HEAL CIFFERENCE WITH THAT FGR THE PREVIOUS SIMULATION.

IF (ICT.GT.1) GO TC 49

IF (HDIF) $47,52,48$

C FOR AN INITIAL SIMULATICN. ASSIGNS A CODE FOR THE SIGN OF HJIF, SAVES

C THE OLD VALUES OF PERMEABILITY AND HOIF, AND INCREASES OR DECREASES

PERMEABILITY ACCORDINE TO THE SIGN OF HDIF.

47 I SIGN=1

$P S=P(N L)$

HDS $=$ HD IF

$P(N L)=P(N L) /(1,+X(I C T 2))$

GO TO 58

48 ISIGN=2

$P S=P(N L)$

HDS $=$ HDIF

$P(N L)=P(N L) *(1,+X(I C T 2))$

GO TO 58

EST ABLI ISHES CODE FOR SIGN

作

POLATES A PERMEABILITY VALUE FRCM THE PRESENT AND PREVIOUS VALUES FOR

PERMEABILITY AND HDIF. IF HOIF DOES NOT CHANGE SIGN, ROUTES PROGRAM

TO SAVE THE SIGN CODE, HDIF, AND PERMEABILITY FOR THE PRESENT SIMU-

LATION, AND TO INCREASE OR DECREASE THE TRIAL PERMEABILITY VALUE,

AS APPROPRIATE.

49 IF (HDIF) $50,52,51$

50 ISIGN2=1

IF ( (ISIGN-ISIGN2).EG.0) GC TO 47

$P(N L)=P S-((P S-P(N L) *(D A B S I H C S)) /(D A B S(H D S)+D A B S(H D I F))$

GO TO 52

51 ISIGN2=2

IF ( (ISIGN-ISIGN2).EQ.0) GO TO 48

$P(N L)=P S+((P(N L)-P S) *(D A B S(H C S)) /(D A B S(H D S)+C A B S(H D I F))$

52 CONT INUE

C PRINTS OUT TABLES FOR HEAD VERSUS TIME FOR THE TRIAL SIMULATIONS FOR

C A GIVEN LAYER, ONCE A CHANGE IN THE SIGN OF HDIF HAS BEEN OETECTED.

IF (ICT2.LT.2) GO TC 54 $K O P(N L)=1$

IF (NL.LT.NLYS) GO TO 58

53 PRINT 87

GO TO 55

54 PRINT 86

55 PRINT 88

PRINT 90, (HYDC (NL, IC), IC = 1, ICT)

PRINT 89

DO $56 N T=N, N T S, N S T E P$

$T$ I $M E=(N T-1) *$.$T INC$
A 275

A 276

A 277

A 278

A 279

A 280

A 281

A 282

A 283

A 284

A 285

A 286

A 287

A 288

A 289

A 290

A 291

A 292

A 293

A 294

A 295

A 296

A 297

A 298

A 299

A 300

A 301

A 302

A 303

A 304

A 305

A 306

A 307

A 308

A 309

A 310

A 311

A 312

A 313

A 314

A 315

A 316

A 317

A 318

A 319

A 320

A 321

A 322

A 323

A 324

A 325

A 326

A 327

A 328

A 329

A 330

A 331

A 332

A 333

A 334

A 335

A 336

A 337

A 338

A 339

A 340

A 341

A 342

A 343

A 344

A 345

A 346 
0217
0218
0219
0220
0221
0222
0223
0224
0225

0226
0227
0228
0229
0230
0231
0232

0233
0234
0235
0236
0237
0238

0239

0240

0241

0242

0243

0244

0245

0246

0247

0248

0249

0250

0251

0252

0253

0254

0255

0256

0257

0258

0259

0260

0261

0262

0263

0264

0265
56 PRINT 71, NT, TIME, (HSCSIIC,NT), IC $=1, I C T)$ IF (ICT2.EQ.2) GO TC 57 ICI $2=2$ GO TC 33

$57 \mathrm{HYOS}(\mathrm{NL})=P(N L) * 386.4 * A C V / W K V$ IF (NL.EQ.NLYS) GC TC 34 $J \mathrm{~J} 2=\mathrm{J} 1-1$ GO TO 60

58 CONT INUE

C PRINTS DUT CONVERgenCE faILURE MESSAGE AND RESULTS GF THE TEN TRIAL

C SIMULATIONS MADE WHEN NC CHANGE IN THE SIGN OF HDIF CCCURS. PRINT 70, NL, HYDCINL,ICT)

PRINT 90, (HYDC(NL, IC), IC $=1, I C T)$

DO $59 \mathrm{NT}=\mathrm{N}, \mathrm{NTS}, \mathrm{NST}$ EP

TIME $=(N T-1,1)$ T INC

59 PRINT 71, NT, TIME, (HSCSIIC,NT), IC $=1, I C T)$ GO TO 62

60 CONT INUE

C PRINTS GUT COMPUTED PNEUMATIC HEAD VALUES AT EACH SCREEN FOR THE

C FINAL SIMULATION.

PRINT 91

PRINT 100

PR INT 89

DO $61 \mathrm{NT}=\mathrm{N}, \mathrm{NTS}, \mathrm{NSTEP}$

$T I M E=(N T-1) * T I N$,

61 PRINT 71, NT, TIME, (HSCS(NL,NT), NL =1, NLYS), HR (NBS, NT)

C ESTABLISHES CODE FOR FINAL TABLE AND PDUTES PROGRAM TO PRINT TEST

C INPUT DATA AND A TABLE SHCWING THE FINAL HYDRAULIC CONDUCTIVITY CHOSE FOR EACH LAYER, FOLLOWED BY PRCGRAM TERMINATICN.

$M P T=1$

GO TO 3

62 CONT INUE

C STOP

63 FORMAT $(12, F 7.0,14, F 7.0,14)$

64 FORMAT $(2 \mathrm{~F} 7.2)$

65 FORMAT $(F 5.1, F 8.4, F 4.2,2 X, 11)$

G6 FORMAT (FG.3,F5.0)

E7 FORMAT $(6(F 6.3, F 5.0))$

68 FORMAT $(I), 2010.3)$

69 FORMAT $(212)$

70 FORMAT (' FAILeD TC CCCNVERge AT', 13,'LAYER. LAST HYOC WAS', E10.3,' 1 FEET/DAY.'।

71 FORMAT $(1 X, I 3, F 8,0,10 F 12,4)$

72 FORMAT $(1,39 \times$, 'THE UNSATURATED ZONE IS',F7.0," FEET THICK AT THIS ISITE.')

73 FORMAT $1 /, 32 \times$, ,FOR THE ANALYSIS, THIS ZONE WAS DIVIDEO INTG', I3," 1LAYERS AND', I5," NODES."I

74 FORMAT $(1,34 X$, 'FOR PURPOSES CF CONPUTATION, THIS INTERVAL WAS DIVI IDED', /,40X,' INTI', I5,' TIME STEPS OF',F5.0,' MINUTES EACH.')

75 FORMAT $(27 X, 12,8 X, F 4.0,0-1, F 4.0,11 X, 010.3,13 X, F 4.2)$

76 FORMAT $11 H 1,24 X$, 'ANALYSIS OF PNEUMATIC HEAD DATA AT THE', 8A4," SIT IE TO $, 1,35 \mathrm{X}, 1$ DETERMINE VERTICAL HYDRAULIC CCNDUCTIVITY OF THE UNS 2ATURATED ZONE.")

77 FORMAT $/ / / /, 30 \mathrm{X}$, ' DATA WERE CCLLECTEO FROM ', A4,' TO ', a4,' HOURS 1 ON $1,3 A 4,1 / 1 / 1$

73 FORMAT $(2(A 4,2 X), 3 A 4)$

79 FORMAT $125 X$, 'TABLE 1.--INPUT DATA ON LAYER BCUNDARIES, INITIAL EST 1 IMATES OF HYDRAULIC',1,41X, 'CONDUCTIVITY, AND AIR-FILLED POROSITY. $2 \cdot 1$

80 FORMAT (57X,' 'ESTIMATED', /,25X,'LAYER ',3X,'LAYER INTERVAL HYDRAUL IIC CONDUCTIVITY 2 (FEET PER DAY)

AIR-FILLED', $1,25 X, \cdot$ NUMBER POROSITY, , II

81 FORMAT $11 \mathrm{H1}$, TABLE 2.--MEASURED OR INTERPOLATED PNEUMATIC HEAD DA ITA, IN INCHES OF MERCURY, AT EACH SCREEN.'I

82 FORMAT (8A4)

83 FORMAT $(25 \mathrm{X}$, "TABLE 5--FINAL ESTIMATES OF HYDRAULIC CONDUCTIVITY, IBASED ON THE ASSUMED $, 1,40 \mathrm{X},{ }^{\prime}$ LISTED VALUES OF AIR-FILLED POROSITY 2.1

84 FORMAT $(/ / / / /)$

85 FORMAT IIH1, 10X,' ASSUMED VALUES FOR HYDRAUL IC CONDUCTIVITY FOR LA IYER', 14," AND THE RESULT ING COMPUTFD, /,30X, 'HEAR VALUES at SCREEN
A 347

A 348

A 349

A 350

A 351

A 352

A 353

A 354

A 355

A 356

A 357

A 350

A 359

A 360

A 361

A 362

A 363

A 364

A 365

A 366

A 367

A 368

A 369

A 370

A 371

A 372

A 373

A 374

A 375

A 376

A 377

A 378

A 379

A 382

A 383

A 384

A 385

A 386

A 387

A 388

A 389

A 390

A 391

A 392

A 393

A 394

A 395

A 396

A 397

A 398

A 399

A 400

A 401

A 402

A 403

A 404

A 405

A 406

A 407

A 408

A 409

A 410

A 411

A 412

A 413

A 414

A 415

A 416

A 417

A 418

A 419

A 420 
0266

0267

0268

0269

0270

0271

0272

0273

0274

0275

0276

0277

0278

0279

0280

0281

0282

0283
$2:$ I3,' ARE LISTED BELOW.'!

86 FORMAT $1 / /, 15 X$, VALUES FOR THE FIRST SET OF COMPUTATIONS (HYORAULI 1C CONDUCTIVITY HALVED OR DOUBLED EACH TIME. 1 '।

87 FORMAT $/ / / /, 15 X, 1$ VALUES FOR THE SECCND SET OF COMPUTATIONS (HYUR 1 AULIC CONDUCTIVITY CHANGED BY TEN PER CENT EACH TIME.)')

88 FORMAT $(/, 20 X, 1$ HYCRAULIC CONDUCTIVITY, FEET PER DAY')

89 FDRMAT 1 "TIME TIME,', ," STEP MIN',6X,'PNEUMATIC HEAu VAlues, 1 IN INCHES OF MERCURY',

90 FORMAT $(12 \mathrm{X}, 10(2 \mathrm{X}, \mathrm{C} 10.3)\}$

91 FORMAT IIHI, 16X,'TABLE 4-DNEUMATIC HEADS AT EACH SCREEN, BASED UN 1 ATMOSPHERIC PRESSURE CHANGES', /,20X, 'AND THE FINAL COMPUTER-SELEC 2TED HYDRAULIC CONDUCTIVITY VALUES LISTED IN TABLE 5 BELOW'I

92. FORMAT $130 X$, 'FOR THIS SET CF COMPLTATIONS, ALL READINGS ARE WEIGHT IED EQUALLY';

93 FORMAT (15X, 'FOR THIS SET OF COMPUTATIONS, READINGS OF PNEUMATIC H IEAD ARE WEIGHTED INVERSELY WITH TIME')

94 FORMAT $125 X$, IFGR THIS SET OF COMPUTAIIONS, READINGS OF PINEUMATIC H IFAD ARE WEIGHTED DIRECTLY WITH TIME')

95 FORMAT $130 X$, " THE BARDMETER WAS RISINE DURING MOST OF THE READING IPERI OD.')

96 FORMAT $130 \mathrm{X}$, THE BAROMETER DECLINED DURING MOST OF THE READING IPERIOD."1

97 FORMAT $22 \mathrm{X}$, MMEAN STATION PRESSURE DUR ING THESE CRSERVATIDNS WAS ' $1, F 5.2$, ' INCHES OF MERCURY.'1

98 FORMAT $125 \mathrm{X}$, THE MANCMETER FlUIC USED FOR THIS TEST HAS A SPECIFIC 1 GRAVITY OF ',F5.21

99 FORMAT $1 / / 225 \mathrm{X}$, 'THE BOTTCM SCREEN IS AT THE ',F5.0,' FOUT DEPTH BE ILOW LAND SURFACE')

100 FORMAT IIOX,'PNEUMATIC HEAC VALUES ARE LISTEC IN SEQUENCE FRGM SCK IEEN 1 ON THE LEFT IO LAND SURFACE ON THE RIGHT.')

101 FORMAT $120 \mathrm{X}$, 'THE DYNAMIC VISCOSITY VALUE FOR AIR USED IN THIS RUN IIS 'DI0.3,' LB*SEC/SQUARE FCOT,',1,19X,'AND THE VALUE Fur THE KIN 2EMAT IC VISCOSITY OF WATER IS 'D $10.3,1$ SQUARE FEET PER SECOND.")

102 FORMAT $(30 X, \cdot T H E S E$ VISCOSITY VALUES ARE FOR A TEMPERATURE DF 60 DE IGREES $F, 1,43 X, \cdot$ ANC WERE REAC IN BY THE DEFAULT OPTION.') END
A 421

A $42: 2$

A 423

A 424

A 425

A 426

A 427

A 428

A 429

A 430

A 431

A 432

A 433

A 434

A 435

A 436

A 437

A 438

A 439

A 440

A 441

A 442

A 443

A 444

A 445

A 446

A 447

A 448

A 449

A 450

A 451

A 452

A 453

A 454

A 455

A 456-

\section{TRIMAT SUBROUTINE LISTING}

1 CONT INUE

$H(J M A X)=G A M M A(J M A X)$

$J L I M=J M A X-J I$

DO $2 \mathrm{JJ}=1$, JLIM

$J=J M A X-J J$

$H(J)=G A M M A(J)-C(J) * H(J+I) / B E T A(J)$

2 CONT INUE

RETURN

END 


\section{SAMPLE COMPUTER OUTPUT}

Output from the AIRK program is in five tables. Table 1 lists the input data, with appropriate headings, from cards $1-4$ and 6-8. These data provide a means of checking the input data for accuracy.

Table 2 lists the pneumatic heads at each screen at the end of specified time steps used in the analysis, in inches of mercury. These data are computed within the program from the barometric data read in card series 9 , and from the differential manometer values read in card series 10 . Readings for a given time are listed from the bottom screen in the first column of head values sequentially up to the atmospheric pressure in the rightmost column.

The third table (unnumbered) is actually a series of NLYS tables, and lists the equivalent hydraulic conductivity values used in the programed search procedure for a given layer, and in a column immediately below each value, lists computed head values for the included or underlying screen based on that value. Pneumatic head values in this table may be compared to those in table 2 to judge the adequacy of the simulation. Moreover, these head values may be used to make a manual selection of the most appropriate hydraulic conductivity value if the fit chosen by the automatic search procedure is inadequate. The first page of twelve pages for this table is shown in the sample output below.

Table 4 lists pneumatic heads computed at each screen based on the final computer-selected air permeability values for each layer and on the observed barometric pressure changes at land surface. Values in table 4 may be compared to those in table 2 to judge the overall adequacy of the simulation.

Table 5 lists the selected hydraulic conductivities in the same format as in table 1 to provide a summary of the computer analysis.

\title{
SAMPLE OUTPUT DATA
}

\author{
ANALYSIS OF PNEUMATIC HEAD DATA AT THELUBBOCK AIRPORT SPREADING SITE $B$ SITE ID \\ DETERMINE VERTICAL FYDRAUL IC CONDUCTIVITY JF THE UNSATURATED ZONE. \\ the UNSATURATED zONE IS 125. FEET THICK AT THIS SITE. \\ FOR THE ANALYSIS, THIS ZONE waS DIVIDED INTD O LAYERS AND 126 NODES.
}

DATA WERE COLLECTED FRCM 1215 TO 1925 HOURS ON MAY 17,1972

FOR PURPOSES CF COMPUTATION, THIS INTERVAL WAS DIVIDED INTO 79 TIME STEPS OF 5. MINUTES EACH.

MEAN STATION PRESSURE CURING THESE OBSERVATIONS WAS 26.50 INCHES OF MERCURY.

THE MANOMETER FLUID USED FOR THIS TEST HAS A SPECIFIC GRAVITY OF 1.20

THE BAROMETER DECLINED DURING MOST OF THE REAUING PERIOD.

FOR THIS SET OF CCMPUTATICNS, ALL READINGS ARE WE IGHTED EQUALLY

THE DYNAMIC VI SCOSITY VALUE FOR AIR USEC IN THIS RUN IS $0.3740-06$ LB*SEC/SQUARE FOUT, AND THE VALUE FOR THE KINEMATIC VISCCSITY OF WATER IS 0.12iD-04 SQUARE FEFT PER SECOND. THESE VISCOSITY VALUES ARE FOR A TEMPERATURE OF 60 DEGREES $F$, AND WERE REAC IN BY THE DEFAULT OPT ION.

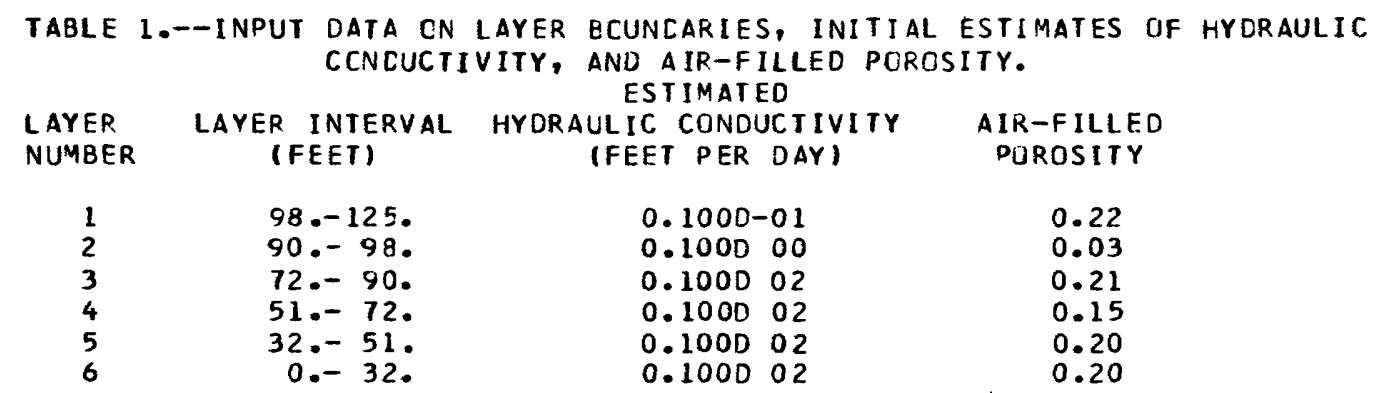


TABLE 2.- MEASURED CR INTERPOLATED PNEUMAT IC HEAC DATA, IN INCHES OF MERCURY, AT EACH SCREEN: PNEUMATIC HEAD VALUES ARE LISTEC IN SEQUENCE FROM SCREEN I ON THE LEFT TO LAND SURFACE ON THE RIGHT.

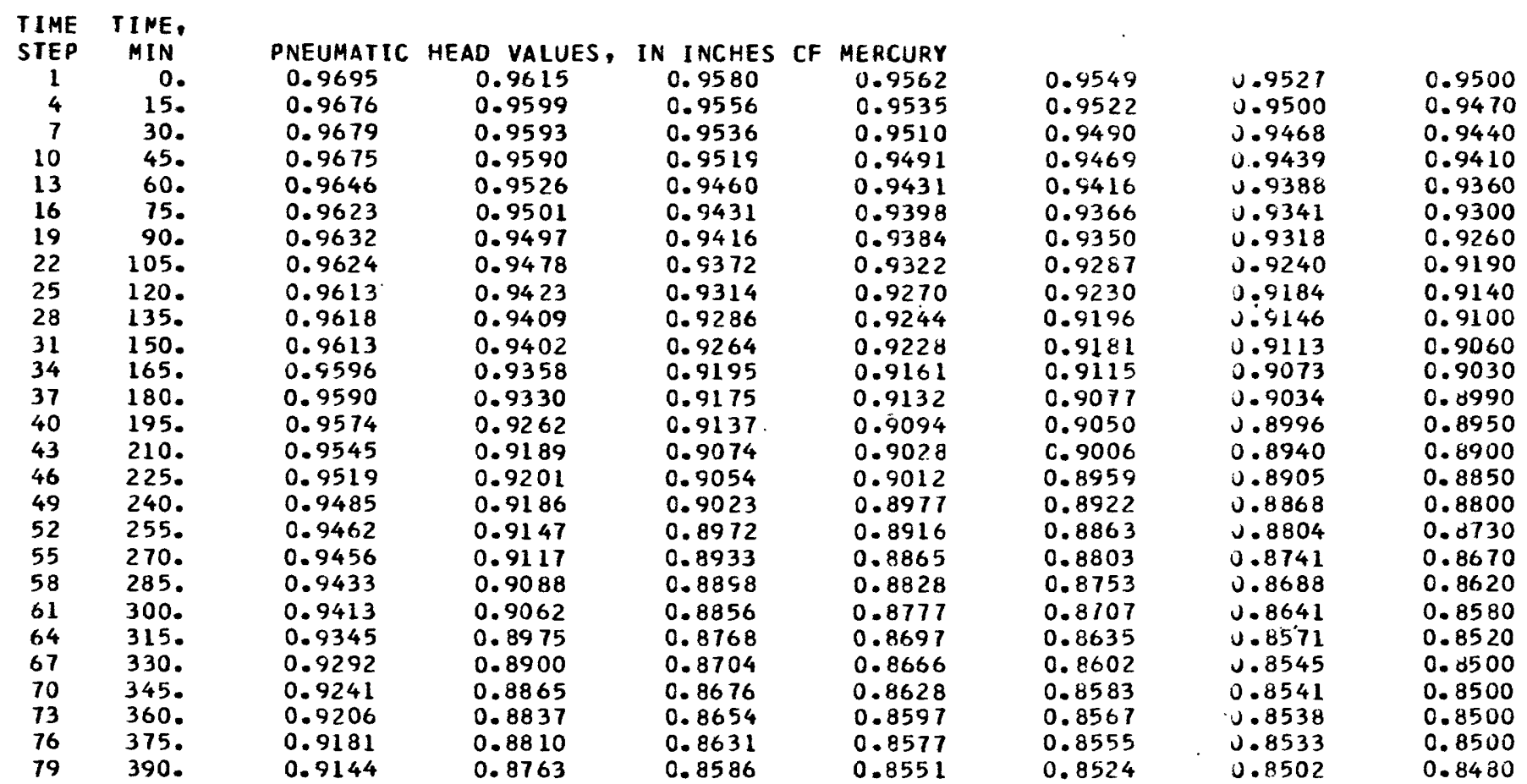

ASSUMED VALUES FOR HYORAULIC CONDUCTIVITY FOR LAYER 1 AND THE RESULTING COMPUTED HEAD VALUES AT SCREEN 1 ARE LISTED BELOH.

VALUES FOR THE FIRST SET CF CCMPUTATIONS

(HYORAULIC CONDUCTIVITY HALVED OR DOUBLED EACH TIME.)

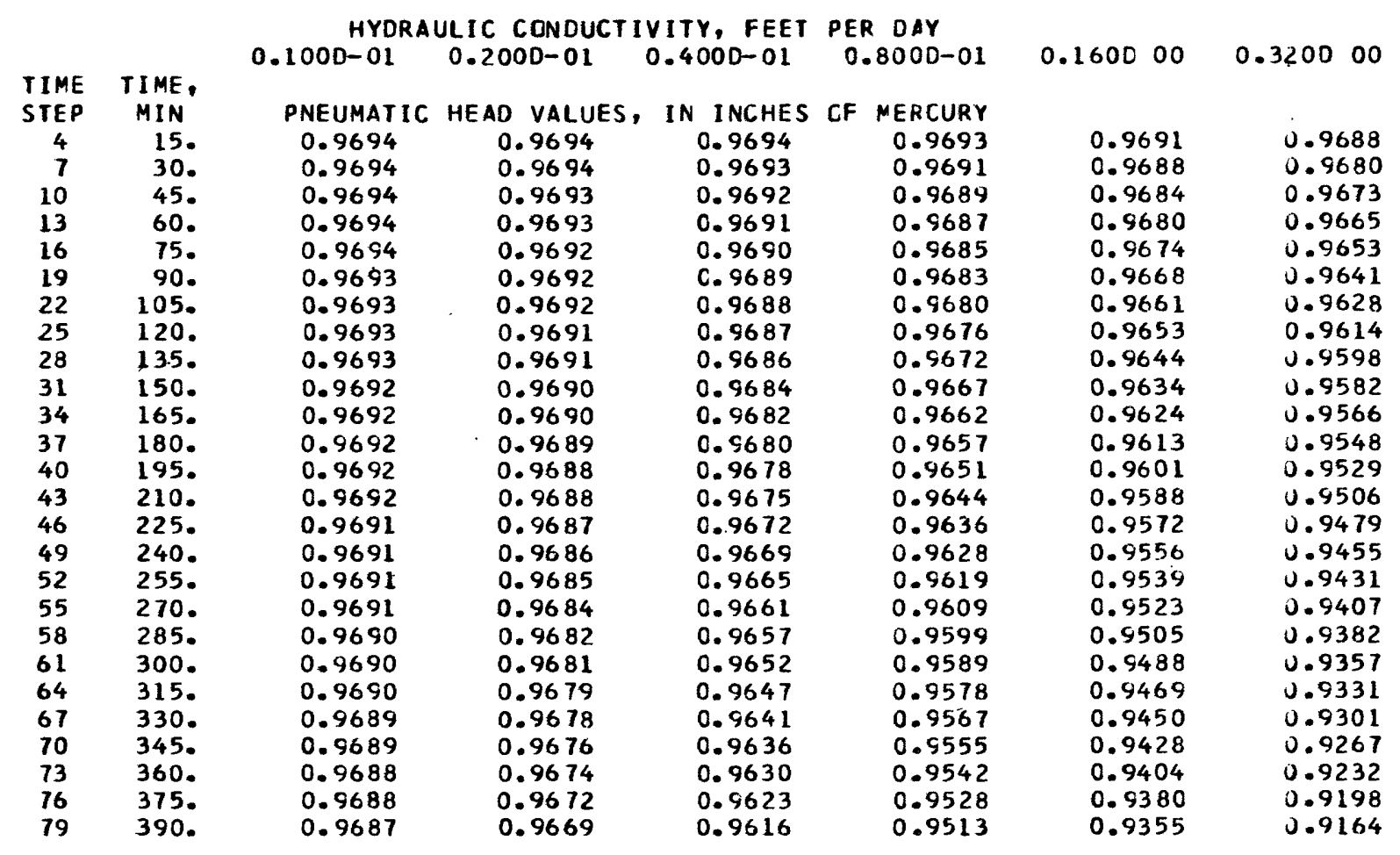


VALUES FOR THE SECOND SET CF COMPUTATIONS

(HYDRAULIC CONDUCTIVITY CHANGED BY TEN PER CENT EACH TIME.)

\begin{tabular}{cccccc}
\multicolumn{5}{c}{ HYDRAULIC CCNCUCTIVITY, FEET PER DAY } \\
TIME & TIME, & 0.296000 & 0.269000 & 0.291000 \\
STEP & MIN & PNEUMATIC & HEAD VALUES, IN INCHES CF MERCURY \\
4 & 15. & 0.9688 & 0.9689 & 0.9688 \\
7 & 30. & 0.9681 & 0.9683 & 0.9682 \\
10 & 45. & 0.9674 & 0.9676 & 0.9675 \\
13 & 60. & 0.9667 & 0.9669 & 0.9667 \\
16 & 75. & 0.9656 & 0.9660 & 0.9657 \\
19 & 90. & 0.9644 & 0.9649 & 0.9645 \\
22 & 105. & 0.9632 & 0.9637 & 0.9633 \\
25 & 120. & 0.9619 & 0.9625 & 0.9620 \\
28 & 135. & 0.9604 & 0.9611 & 0.9606 \\
31 & 150. & 0.9588 & 0.9596 & 0.9590 \\
34 & 165. & 0.9573 & 0.9582 & 0.9575 \\
37 & 180. & 0.9556 & 0.9566 & 0.9558 \\
40 & $195:$ & 0.9538 & 0.9549 & 0.9540 \\
43 & 210. & 0.9516 & 0.9528 & 0.9518 \\
46 & 225. & 0.9491 & 0.9505 & 0.9494 \\
49 & 240. & 0.9467 & 0.9482 & 0.9470
\end{tabular}

TABLE 4--PNEUMATIC HEADS AT EACH SCREEN, BASED ON ATMOSPHERIC PRESSURE CHANGES AND THE FINAL COMPUTER-SELECTEC HYDRAULIC CONOUCTIVITY VALUES LISTED IN TABLE 5 BELOW PNEUNATIC HEAD VALUES ARE LISTEC IN SECUENCE From SCREEN 1 ON THE LEFT TO LAND SURFACE DN THE RIGHT.

$\begin{array}{cr}\text { TIME } & \text { TIME } \\ \text { STEP } & \text { MIN } \\ 4 & 15 . \\ 7 & 30 . \\ 10 & 45 . \\ 13 & 60 . \\ 16 & 75 . \\ 19 & 90 . \\ 22 & 105 . \\ 25 & 120 \\ 28 & 135 \\ 31 & 150 . \\ 34 & 165 . \\ 37 & 180 . \\ 40 & 195 . \\ 43 & 210 . \\ 46 & 225 . \\ 49 & 240 . \\ 52 & 255 . \\ 55 & 270 . \\ 58 & 285 . \\ 61 & 300 . \\ 64 & 315 . \\ 67 & 330 . \\ 70 & 345 . \\ 73 & 360 . \\ 76 & 375 . \\ 79 & 390 . \\ & \end{array}$

$\begin{array}{cccc}\text { PNEUMATIC HEAD VALUES, IA INCHES } & \text { CF } & \text { MERCURY } \\ 0.9688 & 0.9603 & 0.9559 & 0.9541 \\ 0.9682 & 0.9589 & 0.9537 & 0.9517 \\ 0.9675 & 0.9572 & 0.9514 & 0.9491 \\ 0.9667 & 0.9554 & 0.9488 & 0.9462 \\ 0.9658 & 0.9531 & 0.9456 & 0.9425 \\ 0.9648 & 0.9505 & 0.9418 & 0.9384 \\ 0.9637 & 0.9476 & 0.9378 & 0.9339 \\ 0.9624 & 0.9443 & 0.9334 & 0.9291 \\ 0.9610 & 0.9408 & 0.9288 & 0.9244 \\ 0.9594 & 0.9373 & 0.9245 & 0.9200 \\ 0.9577 & 0.9339 & 0.9205 & 0.9160 \\ 0.9558 & 0.9306 & 0.9168 & 0.9123 \\ 0.9539 & 0.9273 & 0.9131 & 0.9085 \\ 0.9518 & 0.9241 & 0.9093 & 0.9045 \\ 0.9496 & 0.9206 & 0.9053 & 0.9002 \\ 0.9473 & 0.9171 & 0.9010 & 0.8958 \\ 0.9450 & 0.9133 & 0.8965 & 0.8909 \\ 0.9425 & 0.9093 & 0.8915 & 0.8855 \\ 0.9399 & 0.9050 & 0.8863 & 0.8802 \\ 0.9372 & 0.9007 & 0.8814 & 0.8752 \\ 0.9343 & 0.8964 & 0.8765 & 0.8703 \\ 0.9313 & 0.8922 & 0.8719 & 0.8657 \\ 0.9283 & 0.8882 & 0.8680 & 0.8622 \\ 0.9252 & 0.8849 & 0.8652 & 0.8600 \\ 0.9220 & 0.8821 & 0.8632 & 0.8584 \\ 0.9189 & 0.8797 & 0.8616 & 0.8570\end{array}$

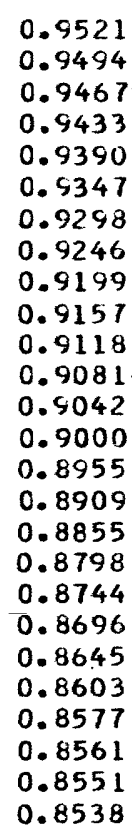

0.9470 0.9440 0.9410 0.9360 0.9300 0.9260 0.9190 0.9140 0.9100 0.9060 0.9030 0.8990 0.8950 0.8900 0.8850 0.8800 0.8730 0.8670 0.8620 0.8580 0.8520 0.8500 0.8500 0.8500 0.8500 0.8480

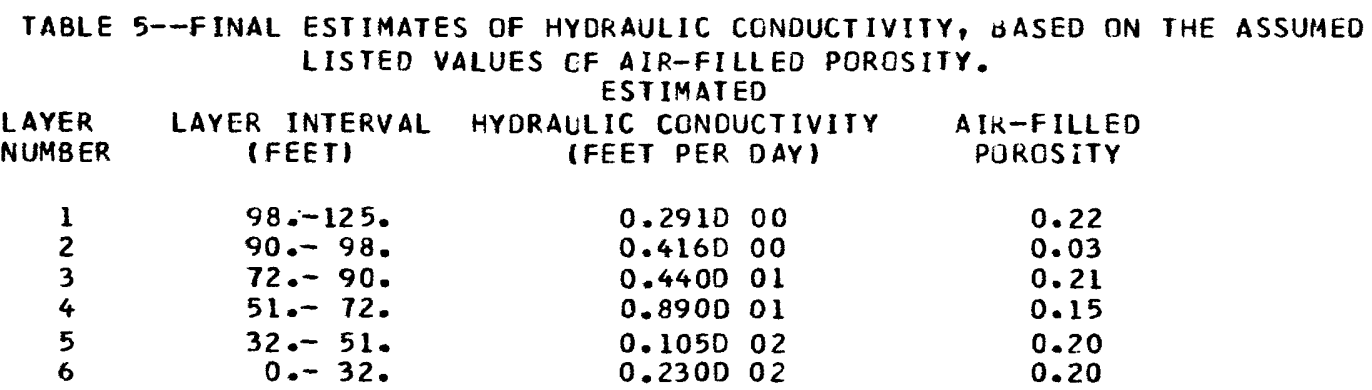




\section{REFERENCES CITED}

Aronovici, V. S., Schneider, A. D., and Jones, O. R., 1972, Basin recharge of the Ogallala aquifer: Am. Soc. Civil Engineers Proc., Jour. Irrigation and Drainage Div., v. 98, no. 1, p. 65-76.

Boardman, C. R., and Skrove, J. W., 1966, Distribution in fracture permeability of a granitic rock mass following a contained nuclear explosion: Jour. Petroleum Technology, v. 18, no. 5, p. 619-623.

Boersma, L., 1965, Field measurement of hydraulic conductivity above a water table: in C.A. Black, ed., Methods of soil analysis: Am. Soc. Agronomy, Agronomy Mon. 9, p. 242-248, Madison, Wis.

Botset, H. G., 1940, Flow of gas-liquid mixtures through consolidated sand: AlME Trans., v. 136, p. 91-96.

Bouwer, Herman, 1961, A double-tube method for measuring hydraulic conductivity of soil in sites above a water table: Soil Sci. Soc. America Proc., v. 25, p. 334-342.

1969, Planning and interpreting soil permeability measurements: Am. Soc. Civil Engineers Proc., Jour. Irrigation and Drainage Div., v. 95, no. IR3, p. 391-402.

Buckingham, Edgar, 1904, Contributions to our knowledge of the aeration of soils: U. S. Dept. Agriculture Soils Bur. Bull. 25, 52 p.

Carslaw, H. S., and Jaeger, J. C., 1959, Conduction of heat in solids: London, Oxford University Press, $510 \mathrm{p}$.

Childs, E. C., 1969, An introduction to the physical basis of soil water phenomena: New York, John Wiley and Sons, Inc., 493 p.

Cronin, J. G., 1964, A summary of the occurrence and development of ground water in the Southern High Plains of Texas: U.S. Geol. Survey Water-Supply Paper 1693, p. 38-39.

Crow, E. L., Davis, F. A., and Maxfield, M. W., 1960, Statistics manual: New York, Dover Publications, $288 \mathrm{p}$.

Evans, D. D., and Kirkham, Don, 1949, Measurement of air permeability of soil in situ: Soil Sci. Soc. America Proc., v. 14, p. 65-73.

Gile, L. H., Peterson, F. F., and Grossman, R. B., 1966, Morphological and genetic sequences of carbonate accumulation in desert soils: Soil Sci. v. 101 , p. $347-360$.

Green, D. W., Dabiri, H. E., Weinaug, C. F., and Prill, R. C., 1970, Numerical modeling of unsaturated ground water flow and comparison of the model to a field experiment: Water Resources Research, v. 6, no. 3, p. $862-874$.

Grover, B. L., 1955, Simplified air permeameters for soil in place: Soil Sci. Soc. America Proc., v. 19, p. 414-418.

Hefez, E., Shamir, U., and Bear, J., 1975, Identifying the parameters of an aquifer cell model: Water Resources Research, v. 11, no. 6, p. 993-1004.

Hubbert, M. K., 1940, The theory of ground-water motion: Jour. Geology, v. 48 , no. 8 , p. $785-944$.

Jacob, C. E., 1963, Determining the permeability of water-table aquifers: in Bentall, Ray, compiler, Methods of determining permeability, transmissibility, and drawdown: U. S. Geol. Survey Water-Supply Paper 1536-I, p. 245-271.

Johnston, Norris, and Beeson, Carrol, 1945, Water permeability of reservoir sands: Petroleum Tech., v. 8, no. 3, p. 43-55.

Karplus, W. J., 1958, Analog simulation: New York, McGraw-Hill, p. 356-360.

Katz, D. L., and others, 1959, Handbook of natural gas engineering: New York, McGraw-Hill, 802 p.

Keys, W. S., and Brown, R. F., 1971, The use of well logging in recharge studies of the Ogallala Formation in West Texas: U. S. Geol. Survey Prof. Paper 750-B, p. B270-B277.

King, L. O., 1968, Mathematical models for underground injection of gaseous wastes into the vadose zone: Batelle Northwest Laboratories Pub. BNWL-945, 55 p.

Kirkham, Don, 1946, Field methods for determination of air permeability of soil in its undisturbed state: Soil Sci. Soc. America Proc., v. 11, p. 93-99.

Klinkenberg, L. J., 1941, The permeability of porous media to liquids and gases: Am. Petroleum Inst. Drilling and Production Practice, p. 200.
Leverett, M. C., and Lewis, W. B., 1941, Steady flow of gas-oil-water mixtures through unconsolidated sands: AIME Trans., v. 142, p. 107.

Lohman, S. W., and others, 1972, Definitions of selected ground-water terms - revision and conceptual refinements: U. S. Geol. Survey Water-Supply Paper 1988, p. 9.

McNeal, B. L., and Coleman, N. T., 1966, Effect of solution composition on soil hydraulic conductivity: Soil Sci. Soc. America Proc., v. 30, p. 308-312.

McNeal, B. L., and others, 1968, Factors influencing hydraulic conductivity of soils in the presence of mixed-salt solutions: Soil Sci. Soc. America Proc., v. 32, p. 187-190.

Morris, G. A., and Snoeberger, D. F., 1971, Calculations of pressure change at depth in a nuclear chimney following atmospheric pressure change: Lawrence Livermore Lab. Report UCID-15963, 6 p.

Muskat, Morris, 1946, Flow through porous media: New York, McGraw-Hill, p. 72.

Osoba, J. S., and others, 1951, Laboratory determination of relative permeability: AIME Trans., v. 192, p. 47-51.

Peck, R. L., 1964, Chem-Comp-new shrinkage-compensating cement for crack-resistant concrete: Modern Concrete, v. 28, no. 6, p. 54-56.

Prill, R. C., 1976, Movement of moisture in the unsaturated zone in a loess-mantled area, southwestern Kansas: U. S. Geol. Survey Open-File Report 76-611, 73 p.

Prill, R. C., and Aaronson, D. B., 1973, Flow characteristics of a subsurface-controlled recharge basin on Long Island, New York: U. S. Geol. Survey Jour. Research, v. 1, no. 6, p. 735-744.

Quirk, J. P., and Schofield, R. K., 1955, The effect of electrolyte concentration on soil permeability: Jour. Soil Sci., v. 6, no. 2, p. 163-178.

Reeve, R. C., 1953, A method for determining the stability of soil structure based upon air and water permeability measurements: Soil Sci. Soc. America Proc., v. 17, p. 324-329.

Reeve, R. C., and Tamaddoni, G. H., 1965, Effect of electrolyte concentration on laboratory permeability and field intake rate of a sodic soil: Soil Sci., v. 99, no. 4, p. 261-266.

Reeve, R. C., and others, 1954, A comparison of the effects of exchangeable sodium and potassium upon the physical condition of soils: Soil Sci. Soc. America Proc., v. 18, p. 130-132.

Robertson, J. B., 1969, Behavior of xenon-133 gas after-injection underground: U. S. Geol. Survey open-file report, $37 \mathrm{p}$.

Rogers, A. E., and Connolly, T. W., 1960, Analog computation in engineering design: New York, McGraw-Hill, 443 p.

Rosza, R. B., Snoeberger, D. F., and Baker, J., 1975, Permeability of a nuclear chimney and surface alluvium, Area 2, ERDA NTS: Lawrence Livermore Lab. Report UCID-16722, 11 p.

Schmalz, B. L., (ed.), 1969, Injection of gas into the lithosphere at the National Reactor Testing Station: AEC Research and Development Report IDO-12069, $166 \mathrm{p}$

Snoeberger, D. F., Morris, C. J., and Baker, J., 1972, Chimney permeability by atmospheric pressure change-instruments and data handling: Lawrence Livermore Lab. Report UCID-16154, 14 p.

Stallman, R. W., 1967, Flow in the zone of aeration, in Ven Te Chow, ed., Advances in Hydroscience: New York, Academic Press, v. 4, p. 151-195.

Stallman, R. W., and Weeks, E. P., 1969, The use of atmospherically induced gas-pressure fluctuations for computing hydraulic conductivity of the unsaturated zone (abs.): Geol. Soc. America Abs. with Programs, pt. 7, p. 213.

Tanner, C. B., and Wengel, R. W., 1957, An air permeameter for field and laboratory use: Soil Sci. Soc. America Proc., v. 21, p. 663-664.

Terzhagi, Karl, 1943, Theoretical soil mechanics: New York, John Wiley and Sons, Inc., p. 243-244.

von Rosenberg, D. U., 1969, Methods for the numerical solution of partial differential equations: New York, American Elsevier, 125 p.

Wenzel, L. K., 1942, Methods for determining permeability of water-bearing materials: U. S. Geol. Survey Water-Supply Paper 887 , p. 7. 